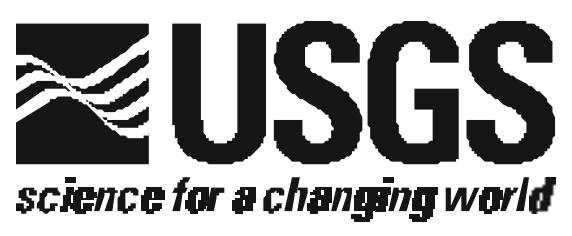

\title{
MAGNETOTELLURIC DATA ACROSS THE BATTLE MOUNTAIN-EUREKA TREND IN PUMPERNICKEL VALLEY AND KELLY CREEK BASIN, NEVADA
}

\author{
by \\ Jackie M. Williams \\ and \\ Brian D. Rodriguez 1
}

Open-File Report 01-316

on-line edition

2001

This report is preliminary and has not been reviewed for conformity with U.S. Geological Survey editorial standards and stratigraphic nomenclature. Any use of trade, product, or firm names is for descriptive purposes only and does not imply endorsement by the U.S.

Government.

U.S. DEPARTMENT OF THE INTERIOR

U.S. GEOLOGICAL SURVEY

1 Denver, Colorado 
TABLE OF CONTENTS

INTRODUCTION

MAGNETOTELLURIC METHOD 3

MAGNETOTELLURIC SURVEY

MAGNETOTELLURIC DATA

REFERENCES CITED 9

APPENDIX - MAGNETOTELLURIC DATA PLOTS 12 


\section{INTRODUCTION}

Many sediment-hosted gold deposits occur along linear trends in northern Nevada. The distribution and genesis of these deposits along the Battle Mountain-Eureka gold trend is not fully understood. In general, most models agree that regional structures played an important role in the spatial distribution of these deposits (e.g. Arehart and others, 1993; Ilchik and Barton, 1997; Radtke, 1985; Shawe, 1991; Sillitoe and Bonham, 1990; Tosdal, 1998). To investigate crustal structures that may be related to the genesis of gold deposits along this trend, a regional southwest-northeast profile of magnetotelluric (MT) soundings was acquired in 2000 (line MT9MT9', Figure 1). Resistivity modeling of the MT data can be used to infer the deep resistivity structure of the crust to investigate possible tectonic controls on the emplacement of mineral deposits along these linear trends that may be used to help improve critical gold endowment estimates in the Humboldt River Basin. The purpose of this report is to release the MT sounding data; no interpretation of the data is included.

\section{MAGNETOTELLURIC METHOD}

The magnetotelluric (MT) method is a passive surface geophysical technique, which uses the earth's natural electromagnetic fields to investigate the electrical resistivity structure of the subsurface. The resistivity of geologic units is largely dependent upon their fluid content, porosity, degree of fracturing, temperature, and conductive mineral content (Keller, 1989). Saline fluids within the pore spaces and fracture openings can reduce resistivities in a resistive rock matrix. Also, resistivity can be lowered by the presence of conductive clay minerals, carbon, and metallic mineralization. It is common for altered volcanic rocks to contain authigenic minerals that have resistivities ten times lower than those of the surrounding rocks (Nelson and Anderson, 1992). Increased temperatures cause higher ionic mobility and mineral activation energy, reducing rock resistivities significantly. Unaltered, unfractured igneous rocks are normally very resistive (typically 1,000 ohm-m or greater), whereas fault zones will show low resistivity (less than $100 \mathrm{ohm-m}$ ) when they are comprised of rocks fractured enough to have hosted fluid transport and consequent mineralogical alteration (Eberhart-Phillips and others, 1995). Carbonate rocks are moderately to highly resistive (hundreds to thousands of ohm-m) depending upon their fluid content, porosity, fracturing, and impurities. Marine shales, mudstones, and clay-rich alluvium are normally very conductive (a few ohm-m to tens of ohm-m). Unaltered, metamorphic rocks 
(non-graphitic) are moderately to highly resistive (hundreds to thousands of ohm-m). Tables of electrical resistivity for a variety of rocks, minerals and geological environments may be found in Keller (1987) and Palacky (1987).

The MT method can be used to probe the crust from depths of tens of meters to depths of tens of kilometers (Vozoff, 1991). Natural variations of the Earth's magnetic and electric field are measured and recorded at each MT station. The primary frequency bands used by the MT method are 10,000 $\mathrm{Hz}$ to $1 \mathrm{~Hz}$ from worldwide lightning activity and $1 \mathrm{~Hz}$ to $0.0001 \mathrm{~Hz}$ from geomagnetic micro-pulsations. Natural electric and magnetic fields propagate vertically in the earth because the very large resistivity contrast between the air and the earth causes a vertical refraction of both fields transmitted into the earth (Vozoff, 1972).

The natural electric and magnetic fields are recorded in two orthogonal, horizontal directions. The vertical magnetic field ("tipper") is also recorded. The resulting time-series signals are used to derive the tensor apparent resistivity and phase. First the signals are converted to complex crossspectra using FFT (fast-Fourier-transform) techniques. Then, least-squares, cross-spectral analysis (Bendat and Piersol, 1971) is used to solve for a transfer function that relates the observed electric fields to the magnetic fields under the assumption that the Earth consists of a two-input, two-output, linear system with the magnetic fields as input and the electric fields as output (Rodriguez and others, 1996). Prior to conversion to apparent resistivity and phase, the tensor is normally rotated into principal directions that correspond to the direction of maximum and minimum apparent resistivity. For a two-dimensional (2-D) Earth, the MT fields can be decoupled into transverse electric (TE) and transverse magnetic (TM) modes; 2-D modeling is generally done to fit both modes. When the geology satisfies the 2-D assumption, the MT data for the TE mode is for the electric field parallel to geologic strike, and the data for the TM mode is for the electric field across strike. The MT method is well suited for studying complicated geological environments because the electric and magnetic relations are sensitive to vertical and horizontal variations in resistivity. The method is capable of establishing whether the electromagnetic fields are responding to subsurface terranes of effectively 1-, 2-, or 3-dimensions. An introduction to the $\mathrm{MT}$ method and references for a more advanced understanding are contained in Dobrin and Savit (1988) and Vozoff (1991). 


\section{MAGNETOTELLURIC SURVEY}

Nine MT soundings were located along or near profile MT9MT9" (Figure 1) with spacing that varied from 6.1 to 16.8 kilometers. The profile is roughly perpendicular to the Battle Mountain-Eureka trend. All stations were collected with a portable EMI MT-1 system (EMI, 1996). Horizontal electric fields were sensed using an L-shaped, three-electrode array with dipole lengths of 30 meters. The orthogonal, horizontal magnetic fields in the direction of the electricfield measurement array were sensed using permalloy-cored induction coils (Stanley and Tinkler, 1983). The vertical magnetic field was recorded at all stations. Frequencies sampled ranged from 100 to $0.009 \mathrm{~Hz}$ using single station recordings of both orthogonal horizontal components of the electric and magnetic fields. Sampling this frequency range in previous areas of widely varying geology (Eberhart-Phillips and others, 1990; Stanley and others, 1991; Stanley and others, 1997; Rodriguez, 1998) has allowed us to probe the crust from depths of hundreds of meters to depths of tens of kilometers.

The recorded time-series data were transformed to the frequency domain and processed to determine a two-dimensional apparent resistivity and phase tensor at each site. Rotation of the impedance tensor to maximum and minimum directions allows for decoupling into the TE and TM modes. Local reference sensors to help reduce bias in the impedance determinations due to instrument or environmental noise (Gamble and others, 1979a; Clarke and others, 1983) were not used at any stations. Although true remote reference techniques were not used in our survey, we did sort crosspower files to select optimal signal-to-noise data sets (see Appendix).

The effects of near-surface resistivity anomalies cause "static shifts" (Sternberg and others, 1988) in the data. Static shifts of this data set ranged from 0.0 to 0.3 of a $\log$ decade.

\section{MAGNETOTELLURIC DATA}

The following table shows nine magnetotelluric (MT) station locations (from southwest to northeast). Coordinates are referenced to the 1866 Clarke spheroid and North American 1927 Western United States datum. Longitude and latitude format below is decimal degrees. Elevation is in meters. 


\begin{tabular}{clllll} 
Station & & Longitude & & Latitude & Elev $(\mathrm{m})$ \\
\cline { 1 - 1 } 90 & & -117.48972 & & 40.74573 & 1440 \\
91 & -117.41152 & 40.78297 & 1390 \\
92 & -117.38475 & 40.83747 & 1390 \\
93 & -117.31868 & 40.87867 & 1370 \\
94 & -117.27735 & 40.93117 & 1340 \\
49 & -117.16232 & 41.08410 & 1360 \\
95 & -117.04928 & 41.13012 & 1420 \\
96 & -116.95985 & 41.14575 & 1420 \\
97 & -117.17020 & 40.79370 & 1400
\end{tabular}

The figures in the Appendix represent the field-processed MT data for each station after the time series data were converted to the frequency domain and the tensor-transfer function was rotated into principal directions as described above in the "Magnetotelluric Method" section.

For each station, nine separate plots are given:

1. Apparent Resistivity for the rotated maximum ( $x$ symbol) and minimum (o symbol) modes

2. Impedance Phase for the rotated maximum ( $x$ symbol) and minimum (o symbol) modes

3. Rotation Angle for the impedance tensor (corresponds to the direction of maximum apparent resistivity)

4. Impedance skew for the impedance tensor

5. Multiple Coherency for the rotated maximum ( $x$ symbol) and minimum (o symbol) modes of the electric field

6. Impedance Polar Plots (at 12 selected frequencies)

7. Tipper Magnitude for the vertical magnetic field

8. Tipper strike for the vertical magnetic field, and

9. $\mathrm{HzHx}$ ( $\mathrm{x}$ symbol) and HzHy (o symbol) Coherency

Error bars on the Apparent Resistivity, Impedance Phase, Skew, Tipper Magnitude, and Tipper strike plots represent probable errors within one standard deviation of the sample variance (Gamble and others, 1979b).

Apparent resistivity is a measure of the magnitude of the electric field strength over the magnetic field strength for a given frequency. The impedance phase is proportional to the slope of the apparent resistivity curve on a log-log plot, but from a baseline at -45 degrees (Vozoff, 1991). A measure of the dimensionality for MT data is provided by the impedance skew of the impedance tensor (Vozoff, 1972). If the effective measured resistivity response to the geology beneath a MT station is truly $1-D$ or $2-D$, then the skew will be zero. Both 
instrument and environmental sources of noise contribute to non-zero skew values, but are typically small (about 0.1) for relatively low noise level recordings. Higher skews (above 0.2) are an indication of either the resistivity response to 3-D geology or higher levels of noise. Man-made electrical noise, such as power lines, power generators, moving vehicles and trains can have a negative effect on MT data quality. All these local disturbances produce an incoherent noise mainly affecting frequencies above $1 \mathrm{~Hz}$. Other man-made electrical noise, such as direct current electric trains and active cathodic protection of pipelines produce coherent electromagnetic signals mainly affecting frequencies below 1 $\mathrm{Hz}$.

In the survey area, noise from a number of small power lines and small moving vehicles was negligible at distances of $0.4 \mathrm{~km}$ and greater from the noise source. Power line levels were measured at each site and were typically less than $20 \%$ of the maximum recordable signals. Noise from larger power lines, power generators, pipelines, railroads, and steamdriven trains, mostly near mining operations, was negligible at least $5 \mathrm{~km}$ from them. Recordings were not made when noise from moving vehicles affected the magnetic signals. Local lightning, wind, and rainstorms can also degrade data quality, but these were avoided by not recording during active thunderstorm periods. Wind noise was minimized by burying the magnetic induction coils.

Predicted values of the electric field can be computed from the measured values of the magnetic field (Vozoff, 1991). The coherence of the predicted electric field with the measured electric field is a measure of the signal-to-noise ratio provided in the multiple coherency plot. Values are normalized between 0 and 1 , where values at 0.5 signify signal levels equal to noise levels. For this data set, coherencies were generally at an acceptable level, except at times in the "dead band" (0.1 to $1 \mathrm{~Hz})$ and at times in the lower frequencies $(0.009$ to 0.1$)$. The lower frequency ionospheric signals are related to sunspot activity whose levels typically follow an 11-year cycle. The sunspot activity was near the highest level of the cycle during the 2000 survey.

The figures in the Appendix represent the field-processed MT data at each station, which includes some data scatter and poor signal-to-noise ratios. Our only effort at removing noisy data points was to visually inspect and select the best signal-to-noise field data to combine into the final data plots. 
The impedance polar plots provide a measure of the MT data dimensionality (Reddy and others, 1977). For 1-D resistivity structures, the principal impedance polar diagram (dashed line) is a circle. For 2-D or 3-D resistivity structures, the principal impedance polar diagram (dashed line) elongates either parallel or perpendicular to strike direction. Over resistors, the principal impedance polar diagram elongates perpendicular to strike direction and over conductors, the principal impedance polar diagram elongates parallel to strike direction. Also, for 2-D resistivity structures, the additional impedance polar diagram (solid line) attains the shape of a symmetric clover leaf. For 3-D resistivity structures, the additional impedance polar diagram (solid line) elongates in one direction and its amplitude is comparable to that of the principal impedance polar diagram (dashed line). Sites whose polar plots indicated 3-D character in the lower frequencies were MT stations 91, 92, and 93 (Figure 1).

The tipper can be calculated when the vertical component of the magnetic field is measured. The tipper magnitude is a measure of the tipping of the magnetic field out of the horizontal plane (Vozoff, 1991). The magnitude is zero for the $1-D$ case and typically increases between 0.1 to 0.5 , and rarely as great as 1 , as it responds to vertical and subvertical structures. The tipper strike is typically used to help resolve the 90-degree ambiguity in the impedance rotation angle. The vertical component of the magnetic field was measured at all stations. The tipper magnitude of these stations was typically 0.1 to 0.4 over the lower frequencies indicating vertical structure at depth. The HzHx and HzHy coherency is a measure of the signal-to-noise ratio of the vertical magnetic field with respect to each of the orthogonal horizontal magnetic field directions. Values are normalized between 0 and 1 , where values at 0.5 signify signal levels equal to noise levels. These three-component magnetic field coherencies provide a check on the signal-to-noise ratio of the measured values in the tipper magnitude and tipper strike plots. 


\section{REFERENCES CITED}

Arehart, G.B., Foland, K.A., Naeser, C.W., and Kesler, S.E., 1993, 40Ar/39Ar, K/Ar, and fission track geochronology of sediment-hosted disseminated gold deposits at post-Betze, Carlin Trend, northeastern Nevada: Economic Geology, vol. 88 , no. 3, p. 622-646.

Bendat, J.S., and Piersol, A.G., 1971, Random Data: Analysis and Measurement Procedures: New York, Wiley Interscience, $407 \mathrm{p}$.

Clarke, J., Gamble, T.D., Goubau, W.M., Koch, R.H., and Miracky, R.F., 1983, Remote-reference magnetotellurics: Equipment and procedures: Geophysical Prospecting, vol. 31, p. 149-170.

Dobrin, M.D., and Savit, C.H., 1988, Introduction to Geophysical Prospecting (4th ed.): New York, McGraw-Hill, $867 \mathrm{p}$.

Eberhart-Phillips, D., Labson, V.F., Stanley, W.D., Michael, A.J. and Rodriguez, B.D., 1990, Preliminary velocity and resistivity models of the Loma Prieta Earthquake region: Geophysical Research Letters, vol. 17, no. 8, pp. 12351238 .

Eberhart-Phillips, D., Stanley, W. D., Rodriguez, B. D. and Lutter, W. J., 1995, Surface seismic and electrical methods to detect fluids related to faulting: Journal of Geophysical Research, vol. 100, no. B7, pp. 12,91912,936 .

EMI, 1996, MT-1 magnetotelluric system operation manual, version 3.2: ElectroMagnetic Instruments, Inc., Richmond, California, $220 \mathrm{p}$.

Gamble, T.D., Goubau, W.M. and Clarke, J., 1979a, Magnetotellurics with a remote magnetic reference: Geophysics, v. 44, no. 1, p. 53-68.

Gamble, T.D., Goubau, W.M. and Clarke, J., 1979b, Error analysis for remote reference magnetotellurics: Geophysics, v. 44, no. 5, p. 959-968.

Ilchik, R.P. and Barton, M.D., 1997, An amagmatic origin of Carlin-type gold deposits: Economic Geology, vol. 92, no. 3 , p. 269-288. 
Keller, G.V., 1987, Rock and mineral properties, in

Electromagnetic Methods in Applied Geophysics Theory:

M.N. Nabighian, Ed., Society of Exploration

Geophysicists, Tulsa, Oklahoma, v. 1, p. 1351.

Keller, G.V., 1989, Electrical properties, in Carmichael, R.S., Ed., Practical handbook of physical properties of rocks and minerals: CRC Press, Boca Raton, Florida, p. $359-427$.

Nelson, P.H. and Anderson, L.A., 1992, Physical properties of ash flow tuff from Yucca Mountain, Nevada: Journal of Geophysical Research, vol. 97, no. B5, p. 6823-6841.

Palacky, G.J., 1987, Resistivity characteristics of geologic targets, in Electromagnetic Methods in Applied Geophysics Theory: M.N. Nabighian, Ed., Society of Exploration Geophysicists, Tulsa, Oklahoma, vol. 1, p. 53129.

Radtke, A.S., 1985, Geology of the Carlin gold deposit, Nevada: U.S. Geological Survey Professional Paper 1267, $124 \mathrm{p}$.

Reddy, I.K., Rankin, D., and Phillips, R.J., 1977, Threedimensional modelling in magnetotelluric and magnetic variational sounding: Geophysics Journal of the Royal Astronomical society, vol. 51, p. 313-325.

Rodriguez, B.D., Stanley, W.D., and Williams, J.M., 1996, Axial structures within the Reelfoot rift delineated with magnetotelluric surveys: U.S. Geological Survey Professional Paper 1538-K, $30 \mathrm{p}$.

Rodriguez, B.D., 1998, Regional crustal structure beneath the Carlin Trend, Nevada, based on deep electrical geophysical measurements, in Tosdal, R.M., ed., Contributions to the Gold Metallogeny of Northern Nevada: U.S. Geological Survey Open-File Report 98-338, pp.15-19, $290 \mathrm{p}$.

Shawe, D.R., 1991, Structurally controlled gold trends imply large gold resources in Nevada, in Geology and ore deposits of the Great Basin, Symposium Proceedings: Raines, G.L., Lisle, R.E., Schafe, R.W., Wilkinson, W.H., Eds., Geological Society of Nevada, Reno, vol. 1, p. 199212 . 
Sillitoe, R.H. and Bonham, H.F., 1990, Sediment-hosted gold deposits; distal products of magmatic-hydrothermal systems: Geology, vol. 18, no. 2, p. 157-161.

Stanley, W.D., and Tinkler, R.D., 1983, A practical, low-noise coil system for magnetotellurics: U.S. Geological Survey Open-File Report 83-85, 18 p.

Stanley, W.D., Hoover, D.B., Sorey, M.L., Rodriguez, B.D. and Heran, W.D., 1991, Electrical geophysical investigations in the Norris-Mammoth corridor, Yellowstone National Park, and the adjacent Corwin Springs Known Geothermal Resources Area, in Sorey, M., ed., Effects of Potential Geothermal Development in the Corwin Springs KGRA, Montana, on the Thermal Features of Yellowstone National Park: Water Resources Division Report on Investigations No. 91-4052, pp. D1-D18, 205 p.

Stanley, W.D., Benz, H.M., Walters, M.A., and Rodriguez, B.D., 1997, Tectonic controls on magmatism and geothermal resources in The Geysers-Clear Lake region, California: integration of new geologic, earthquake tomography, seismicity, gravity and magnetotelluric data: U.S. Geological Survey Open-File Report 97-95, 40 p.

Sternberg, B.K., Washburne, J.C., and Pellerin, L., 1988, Correction for the static shift in magnetotellurics using transient electromagnetic soundings: Geophysics, vol. 53, p. 1459-1468.

Struhsacker, E.M., Jones, E., and Green, S.M., 1996, Roadside geology and precious-metal mineralization along the I-80 corridor, Reno to Elko, Nevada, in Struhsacker, E.M. and Green, S.M., eds., Geology and ore deposits of the American Cordillera - Field Trip Guidebook Compendium: Geological Society of Nevada, Reno, Nevada, p. 3.

Tosdal, R.M., 1998, Contributions to the gold metallogeny of northern Nevada: U.S. Geological Survey Open-File Report $98-338,290 \mathrm{p}$.

Vozoff, K., 1972, The magnetotelluric method in the exploration of sedimentary basins: Geophysics, vol. 37, p. 98-141. 
Vozoff, K., 1991, The magnetotelluric method, in Electromagnetic methods in applied geophysics: M.N. Nabighian, Ed., Society of Exploration Geophysicists, Tulsa, Oklahoma, vol. 2, part B, p. 641-711.

\section{APPENDIX}

\section{MAGNETOTELLURIC DATA PLOTS}

There are nine separate plots for each station:

1. Apparent Resistivity for the rotated maximum ( $x$ symbol) and minimum (o symbol) modes

2. Impedance Phase for the rotated maximum ( $x$ symbol) and minimum (o symbol) modes

3. Rotation Angle for the impedance tensor (corresponds to the direction of maximum apparent resistivity)

4. Impedance skew for the impedance tensor

5. Multiple Coherency for the rotated maximum ( $x$ symbol) and minimum (o symbol) modes of the electric field

6. Impedance Polar Plots (at 12 selected frequencies)

7. Tipper Magnitude for the vertical magnetic field

8. Tipper Strike for the vertical magnetic field, and

9. $\mathrm{HzHx}$ ( $\mathrm{x}$ symbol) and HzHy (o symbol) Coherency

Refer to the "Magnetotelluric Data" section in this report for an explanation of these plots. 


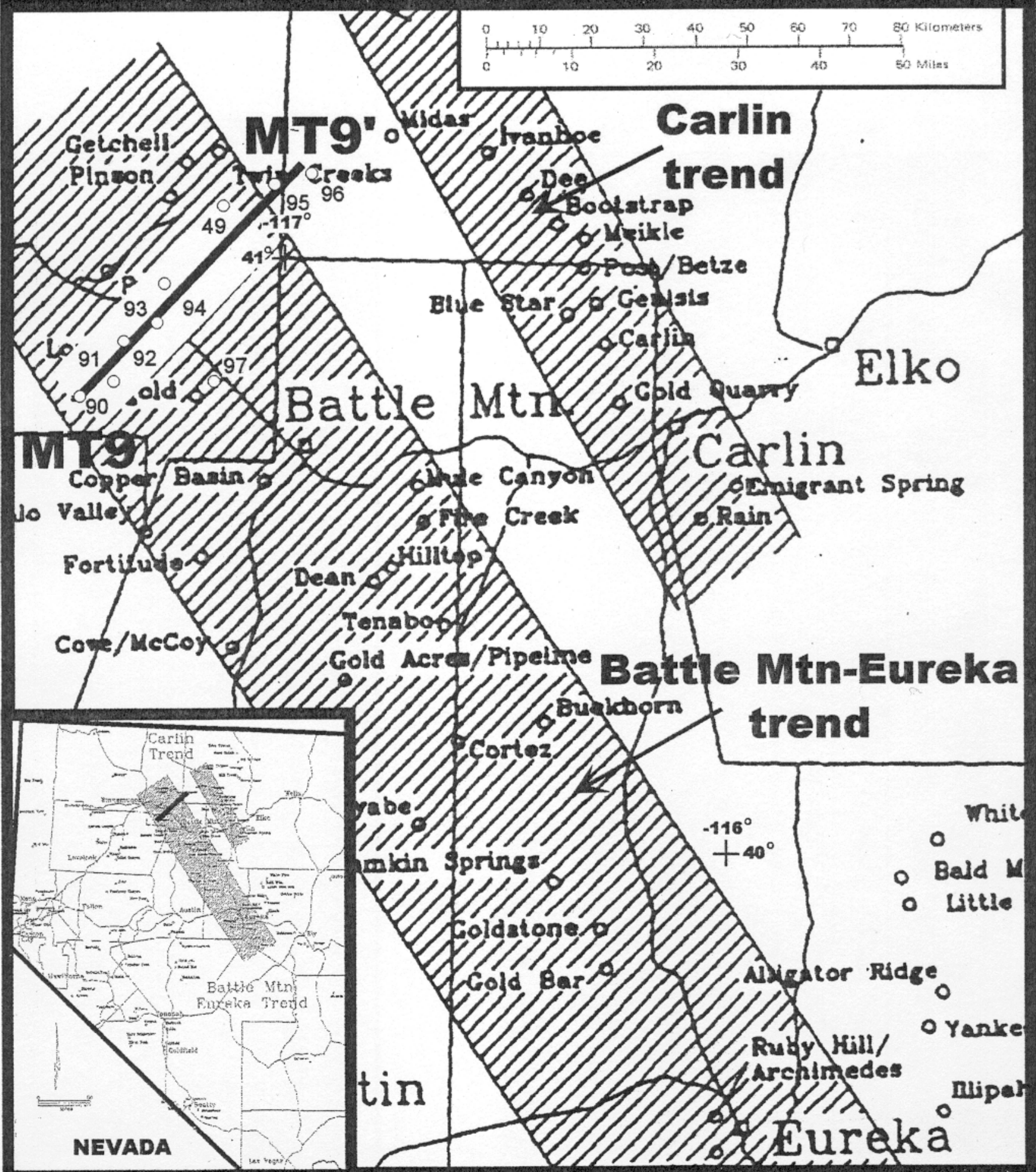

Figure 1. Index map. Magnetotelluric transect (MT9-MT9') acquired in 2000 in northeastern Nevada. Shaded, zones are two northwest-trending mineralized belts in northeastern Nevada, the well-known Carlin trend and the Battle Mountain-Eureka trend. Base map adapted from Struhsacker and others (1996). 
APPARENT RESISTIVITY

Winnemucca, NV 100K

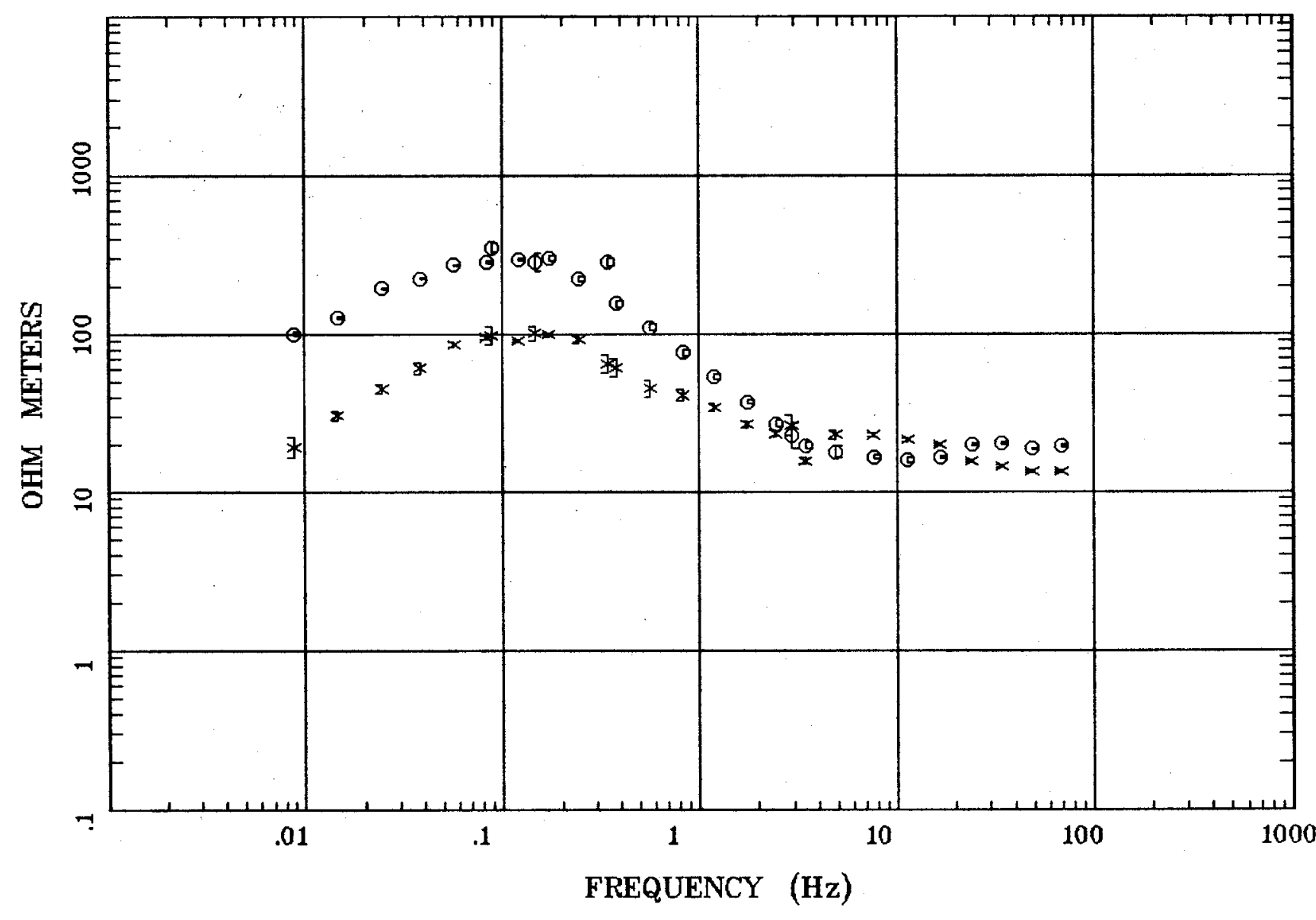

Client:

Remote: none

Acquired: 09:4 Jul 23, 2000

Survey Co:USGS

Rotation:

Filename: hr90b.avg

Channels: Ch1 Ch2 Ch3 Ch4 Ch5 Ch3 Ch4

Plotted: 11:06 Feb 06, 2001

$<$ EMI - ElectroMagnetic Instruments 
IMPEDANCE PHASE

Winnemucca, NV 100K

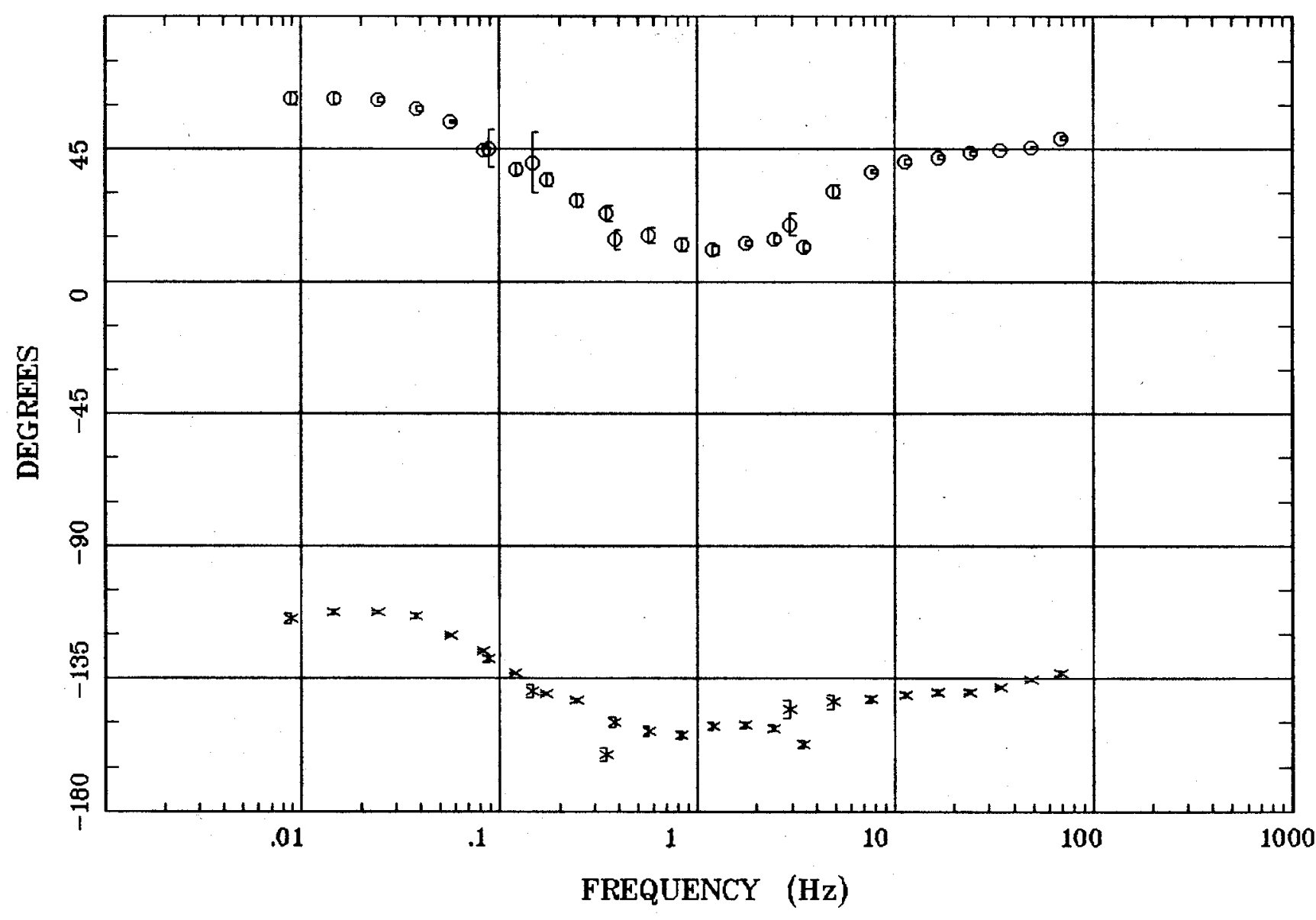

Client:

Remote: none

Acquired: 09:4 Jul 23, 2000 Survey Co:USGS
Rotation:

Filename: hr90b.avg

Channels: Ch1 Ch2 Ch3 Ch4 Ch5 Ch3 Ch4 Plotted: 11:06 Feb 06, 2001

< EMI - ElectroMagnetic Instruments 
Winnemucca, NV $100 \mathrm{~K}$

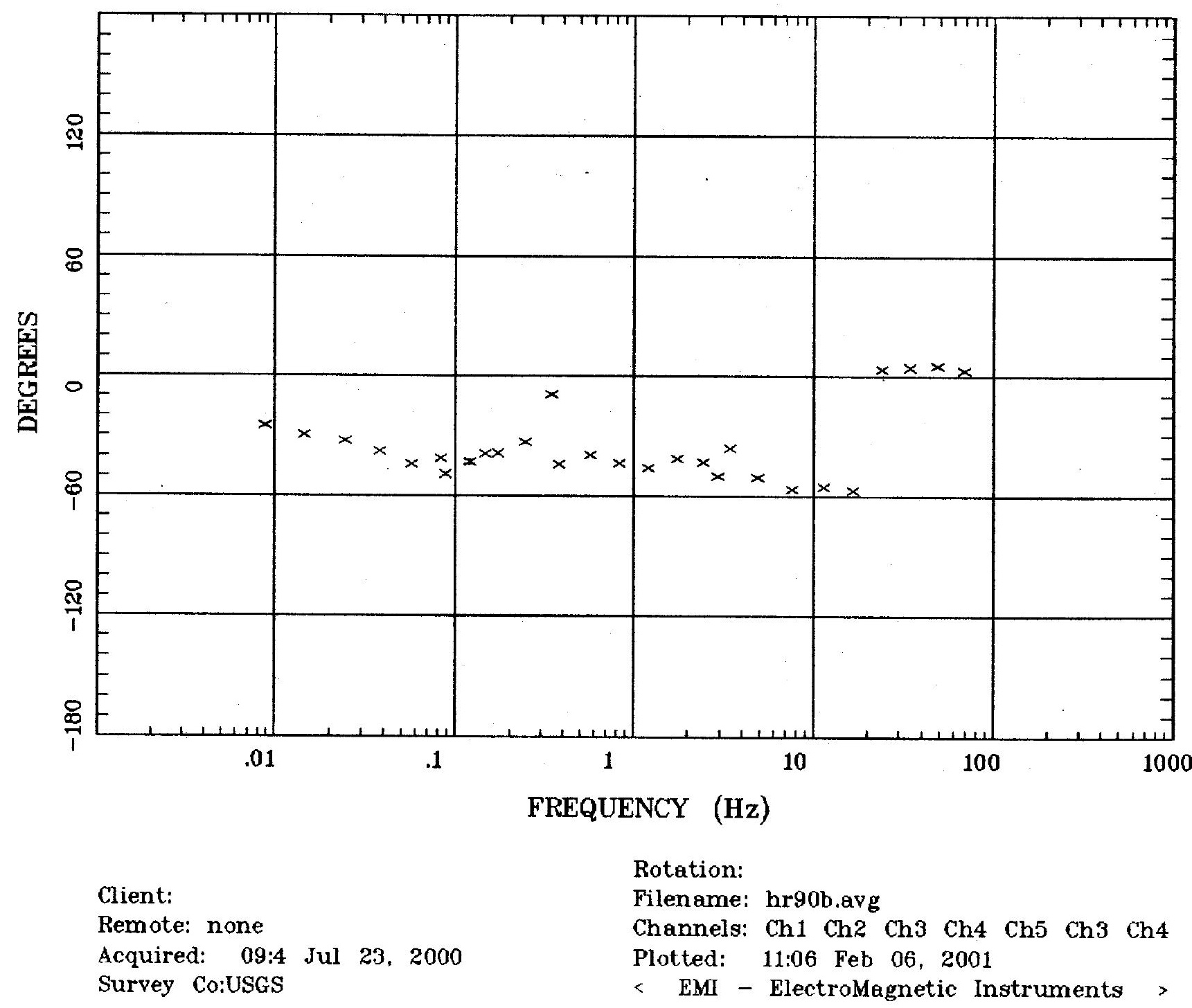




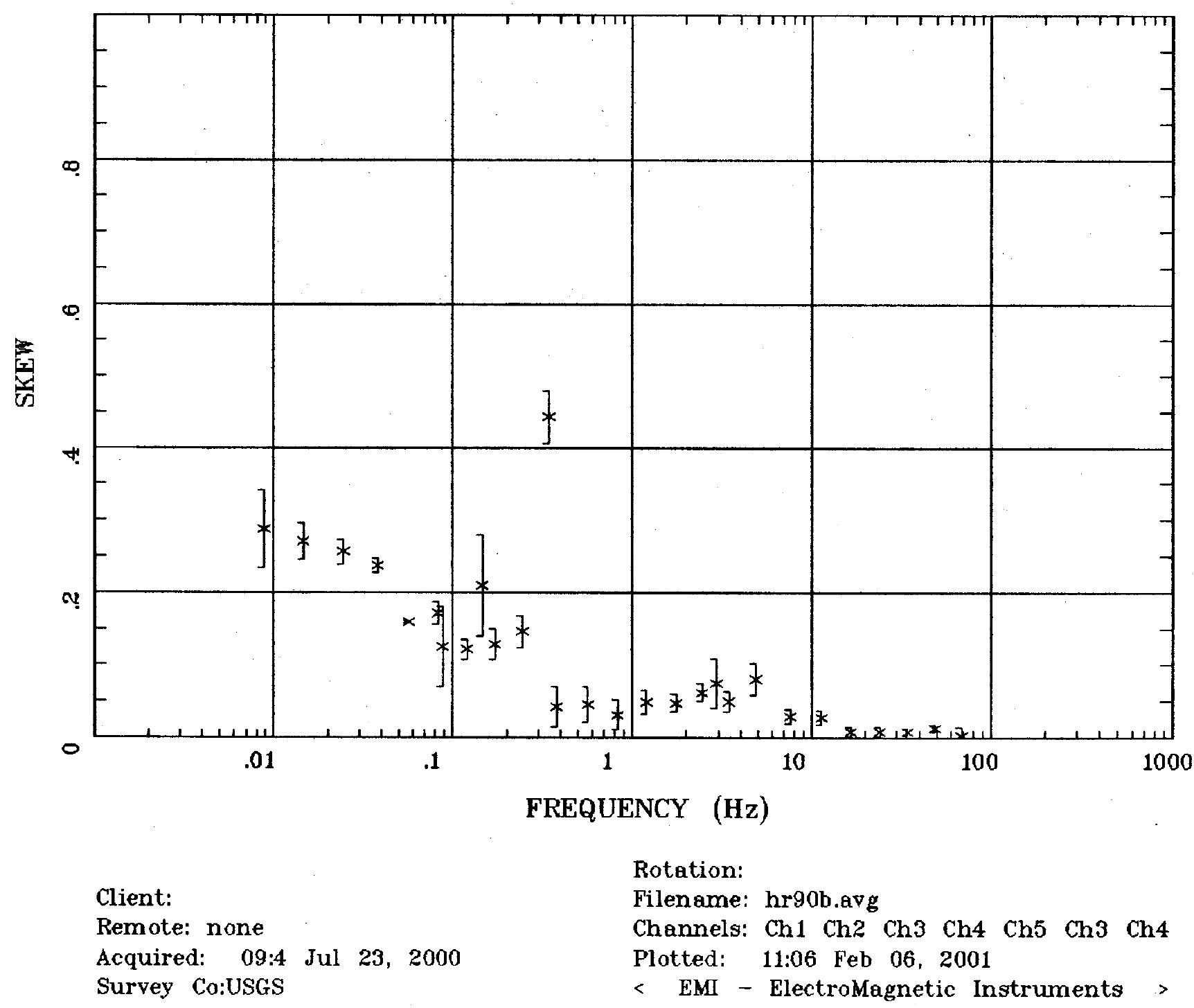


Station 90

E MULT Coh.

Winnemucca, NV $100 \mathrm{~K}$

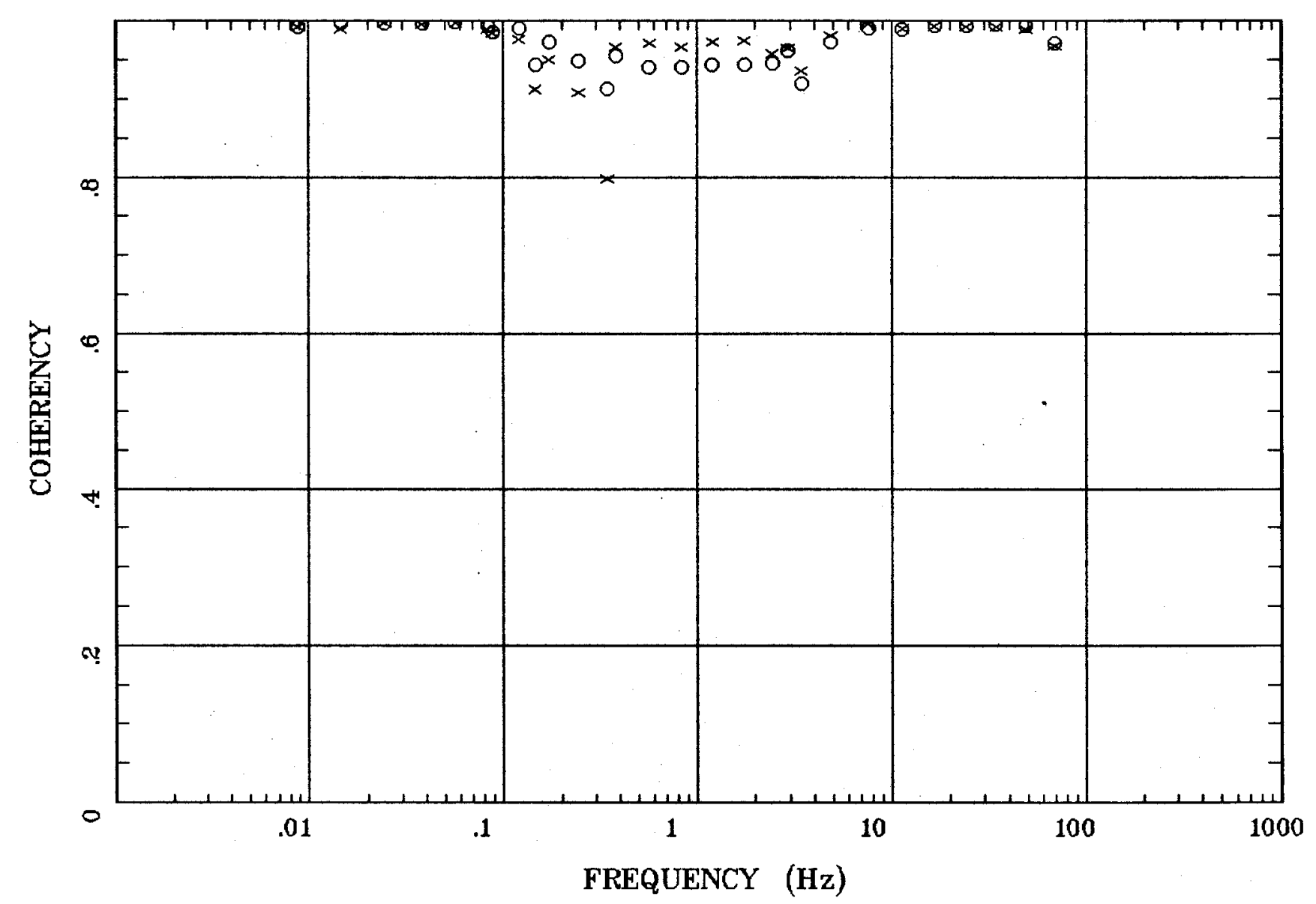

Client:

Remote: none

Acquired: 09:4 Jul 23, 2000

Survey Co:USGS

Rotation:

Filename: hr90b.avg

Channels: Ch1 Ch2 Ch3 Ch4 Ch5 Ch3 Ch4

Plotted: 11:06 Feb 06, 2001

< EMI - ElectroMagnetic Instruments > 
Station 90

POLAR PLOTS

Winnemucca, NV $100 \mathrm{~K}$

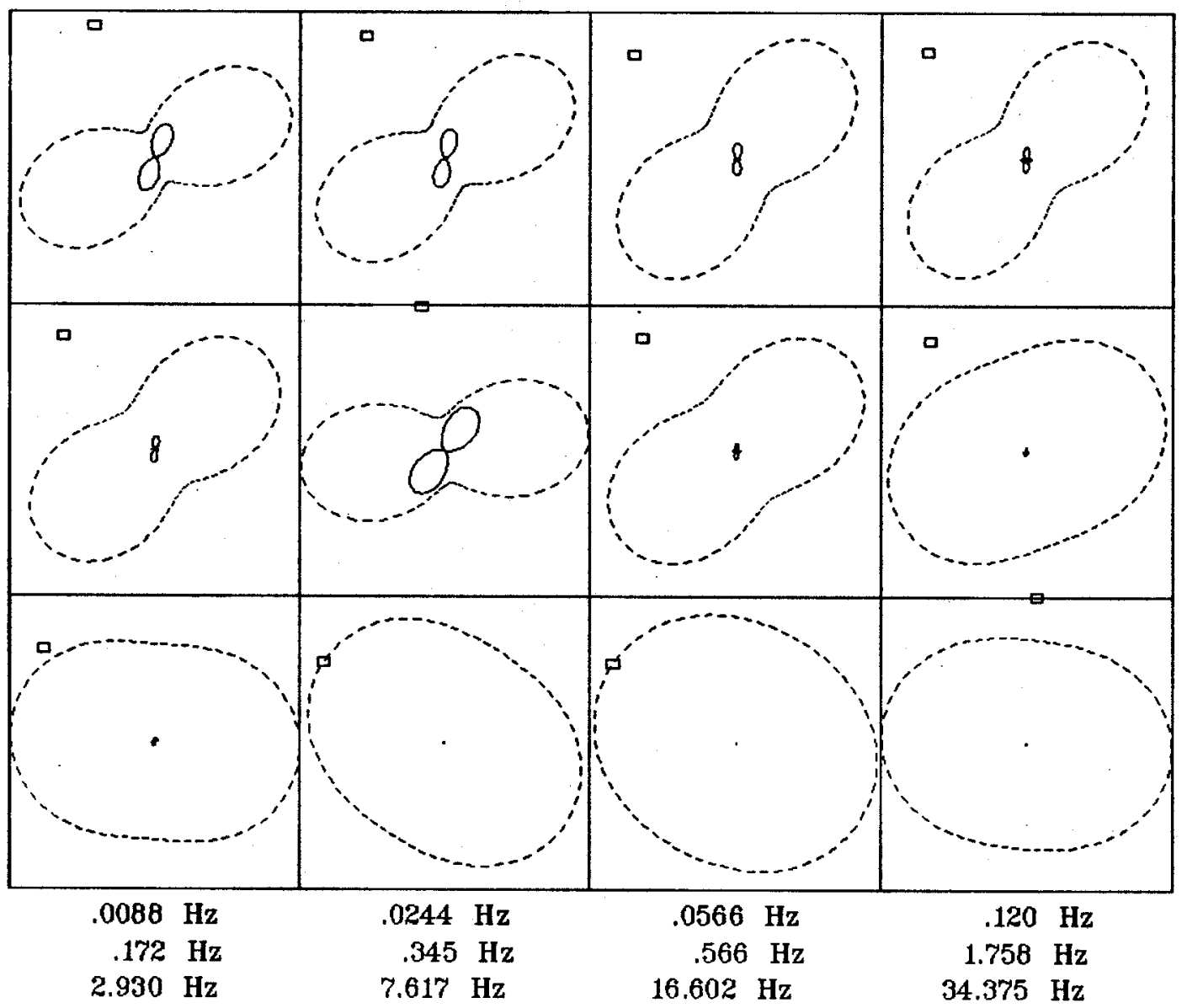

Client:

Rotation:

Filename: hr90b.avg

Remote: none

Channels: Ch1 Ch2 Ch3 Ch4 Ch5 Ch3 Ch4

Plotted: 11:06 Feb 06, 2001

Acquired: 09:4 Jul 23, 2000

Survey Ca:USGS

$<$ EMI - ElectroMagnetic Instruments > 


\section{Station 90}

TIPPER MAGNITUDE

Winnemucca, NV 100K

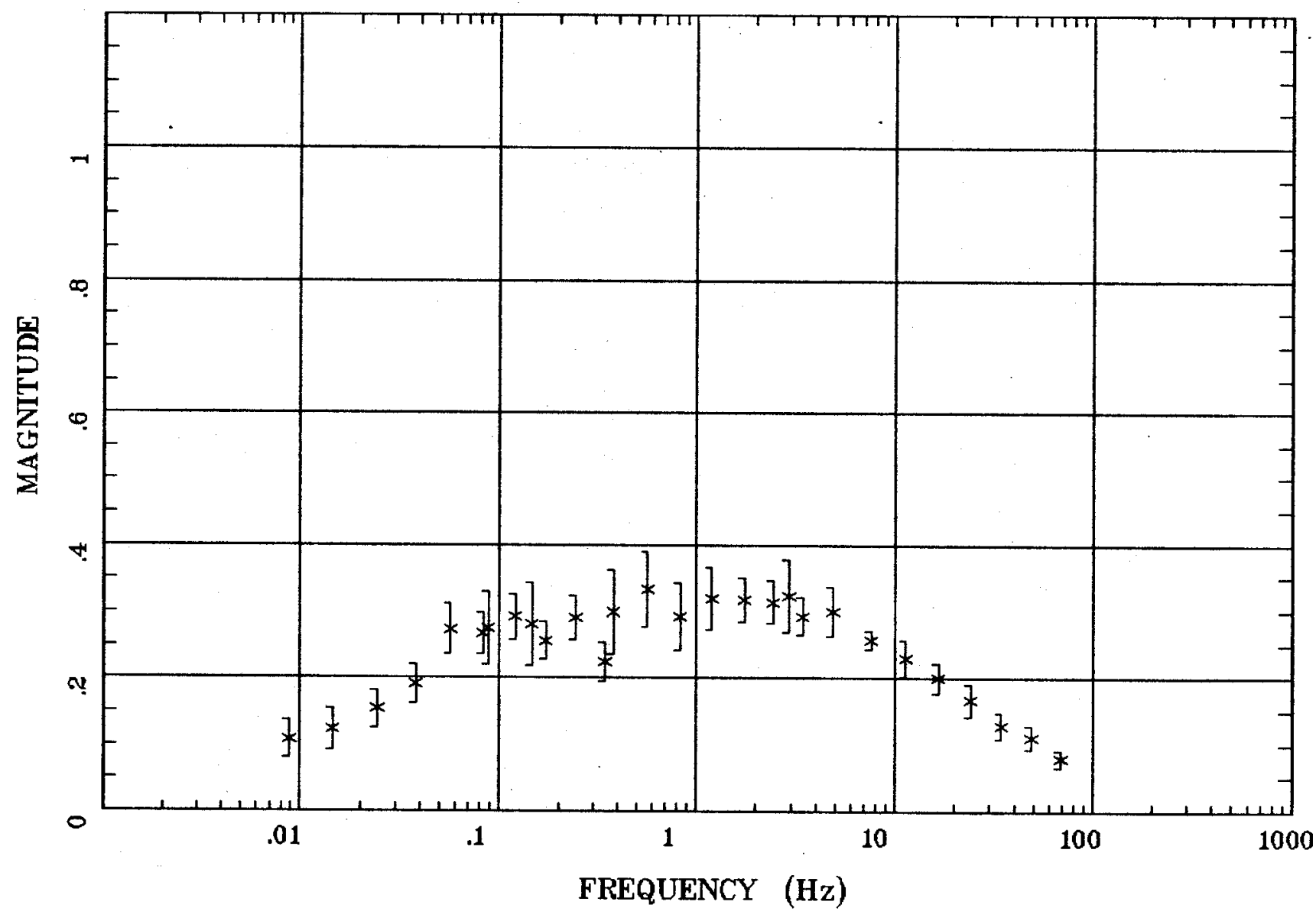

Client:

Remate: none

Acquired: 09:4 Jul 23, 2000 Survey Co:USGS
Rotation:

Filename: hr9ob.avg

Channels: Ch1 Ch2 Ch3 Ch4 Ch5 Ch3 Ch4 Plotted: 11:06 Feb 06, 2001

< EMI - ElectroMagnetic Instruments 
Station 90

TIPPER STRIKE

Winnemucca, NV 100K

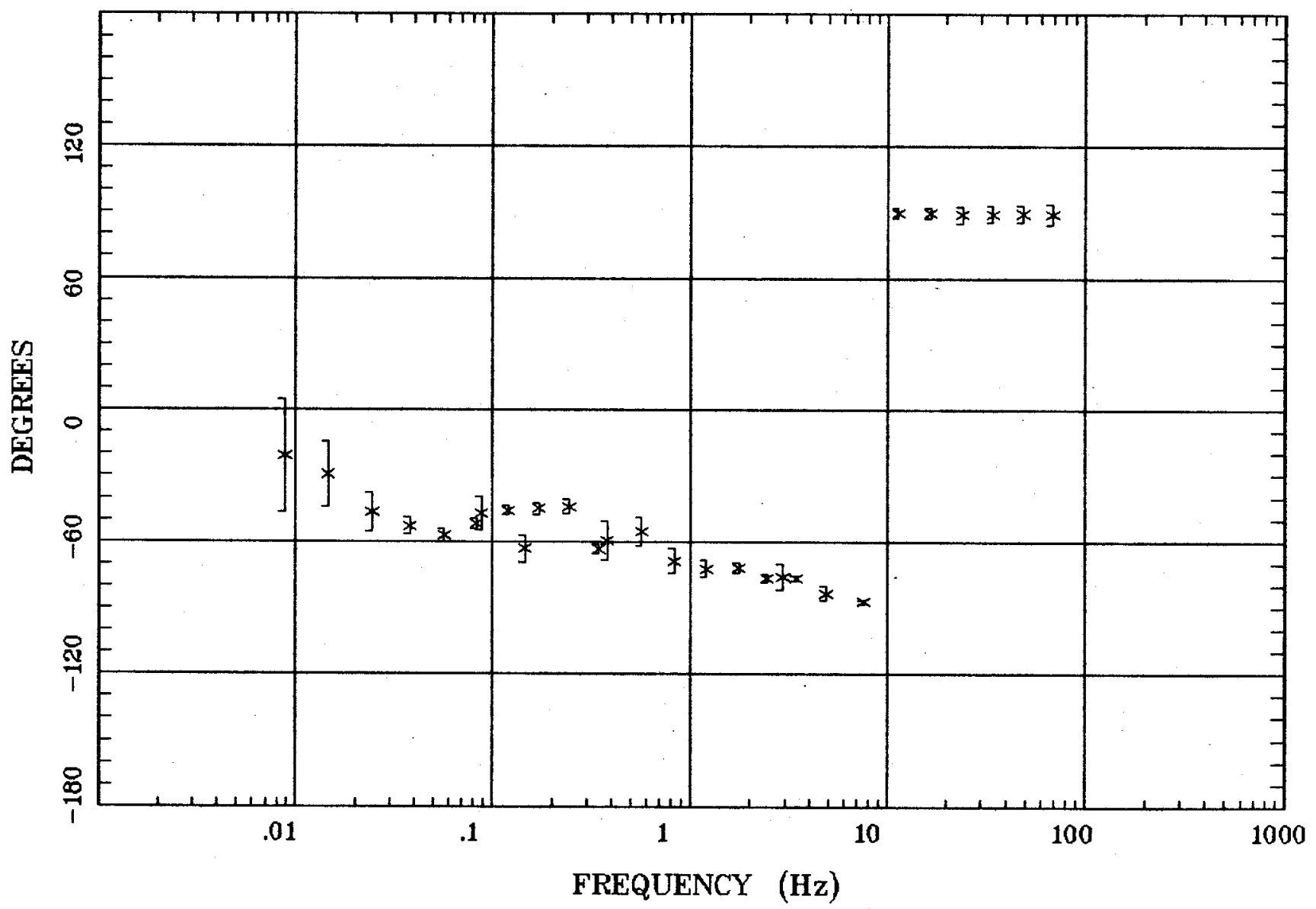

Client:

Remote: none

Acquired: 09:4 Jul 23, 2000

Filename: hr90b.avg

Channels: Ch1 Ch2 Ch3 Ch4 Ch5 Ch3 Ch4

Plotted: 11:06 Feb 06, 2001

Survey Co:USGS

< EMI - ElectroMagnetic Instruments 
Station 90

HzHx.x Coh HzHy.o

Winnemucca, NV $100 \mathrm{~K}$

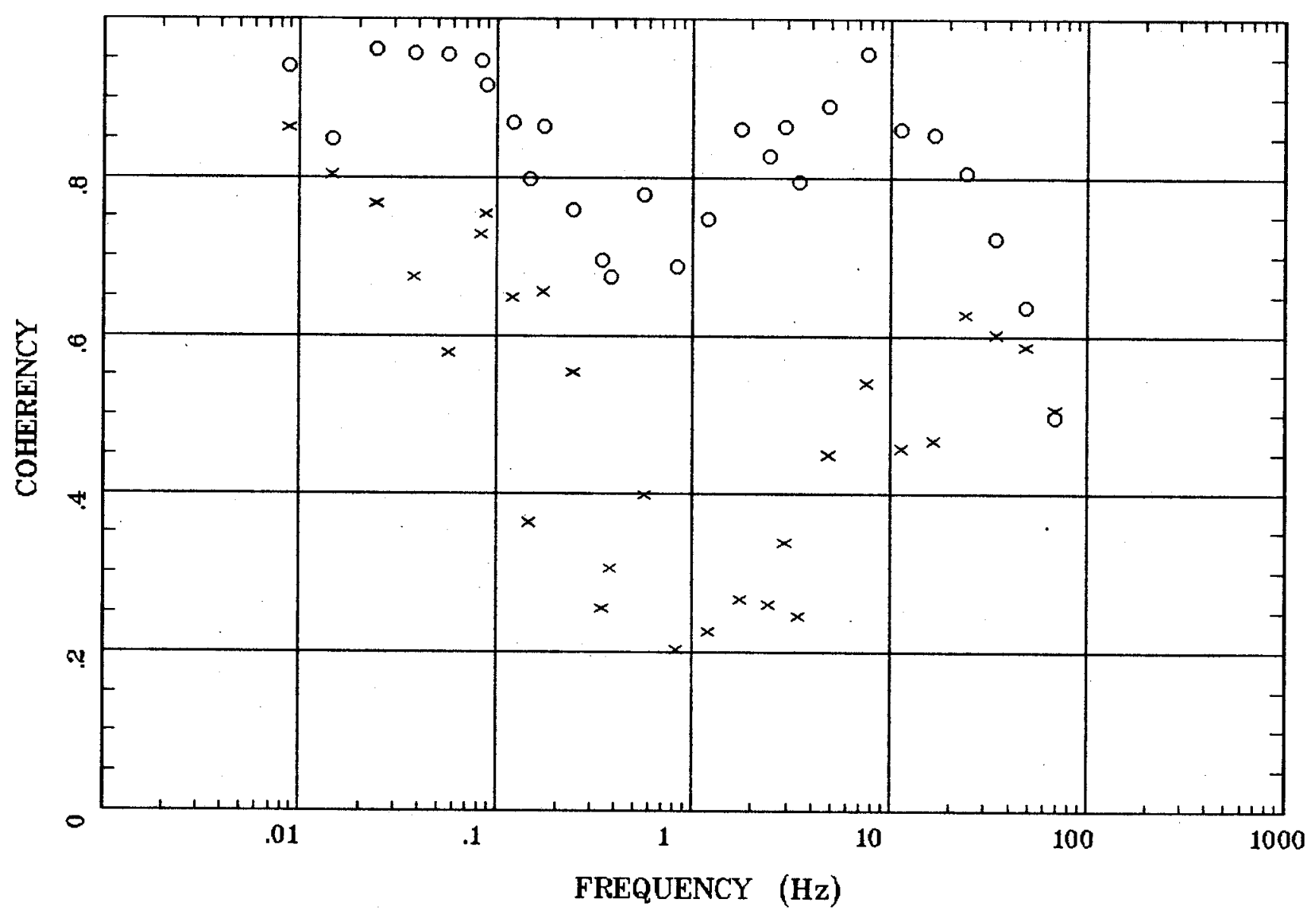

Rotation:

Client:

Filename: hr9ob.avg

Remote: none

Acquired: 09:4 Jul 23, 2000

Survey Co:USGS

Channels: Ch1 Ch2 Ch3 Ch4 Ch5 Ch3 Ch4

Plotted: 11:06 Feb 06, 2001

$<$ EMI - ElectroMagnetic Instruments > 
APPARENT RESISTIVITY

Winnemucca, NV 100K

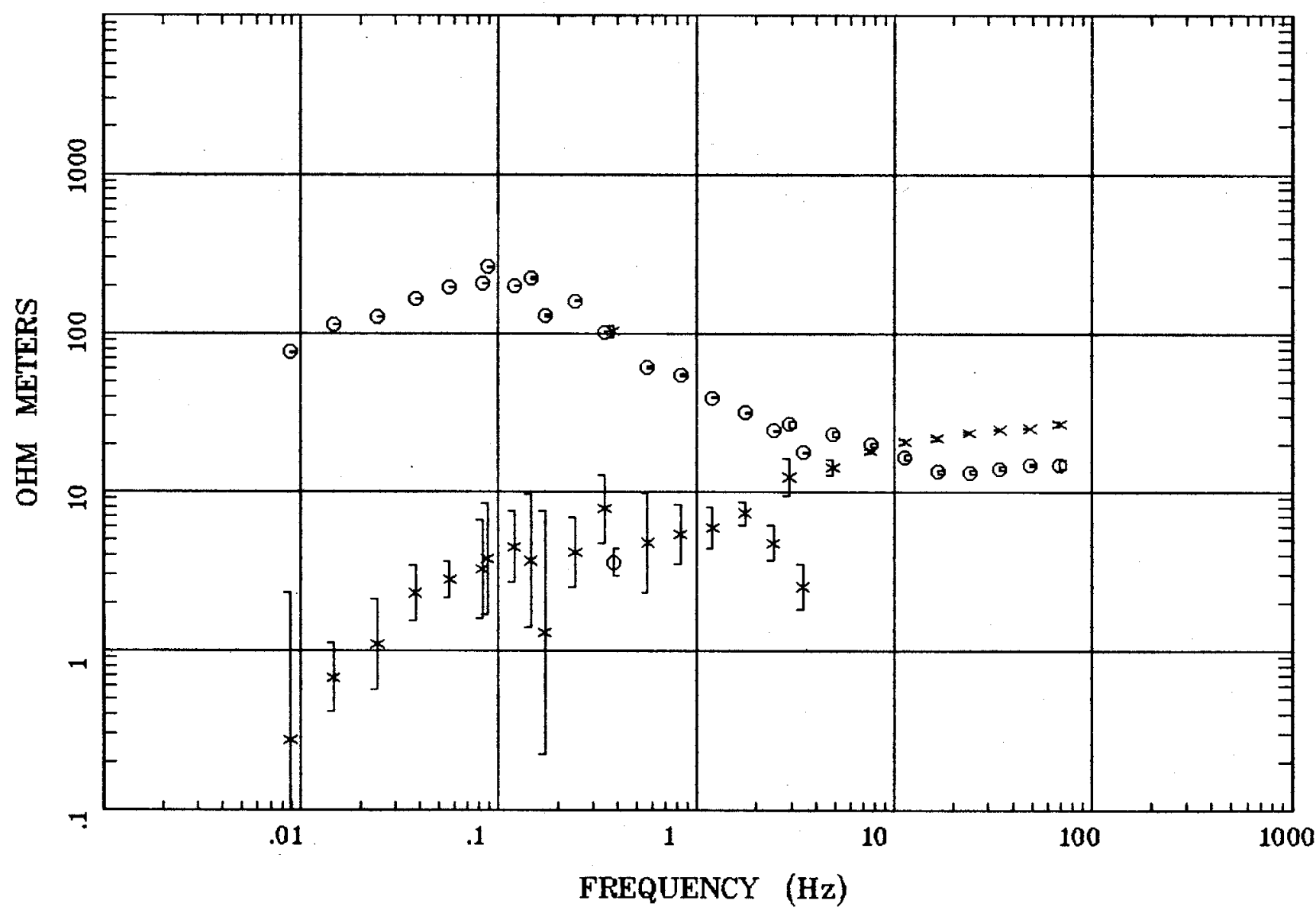

Client:

Remote: none

Acquired: 13:0 Jul 23, 2000

Survey Co:USGS
Rotation:

Filename: hr91b.avg

Channels: Ch1 Ch2 Ch3 Ch4 Ch5 Ch3 Ch4 Plotted: 11:07 Feb 06, 2001

- EMI - ElectroMagnetic Instruments 
IMPEDANCE PHASE

Winnemucca, NV 100K

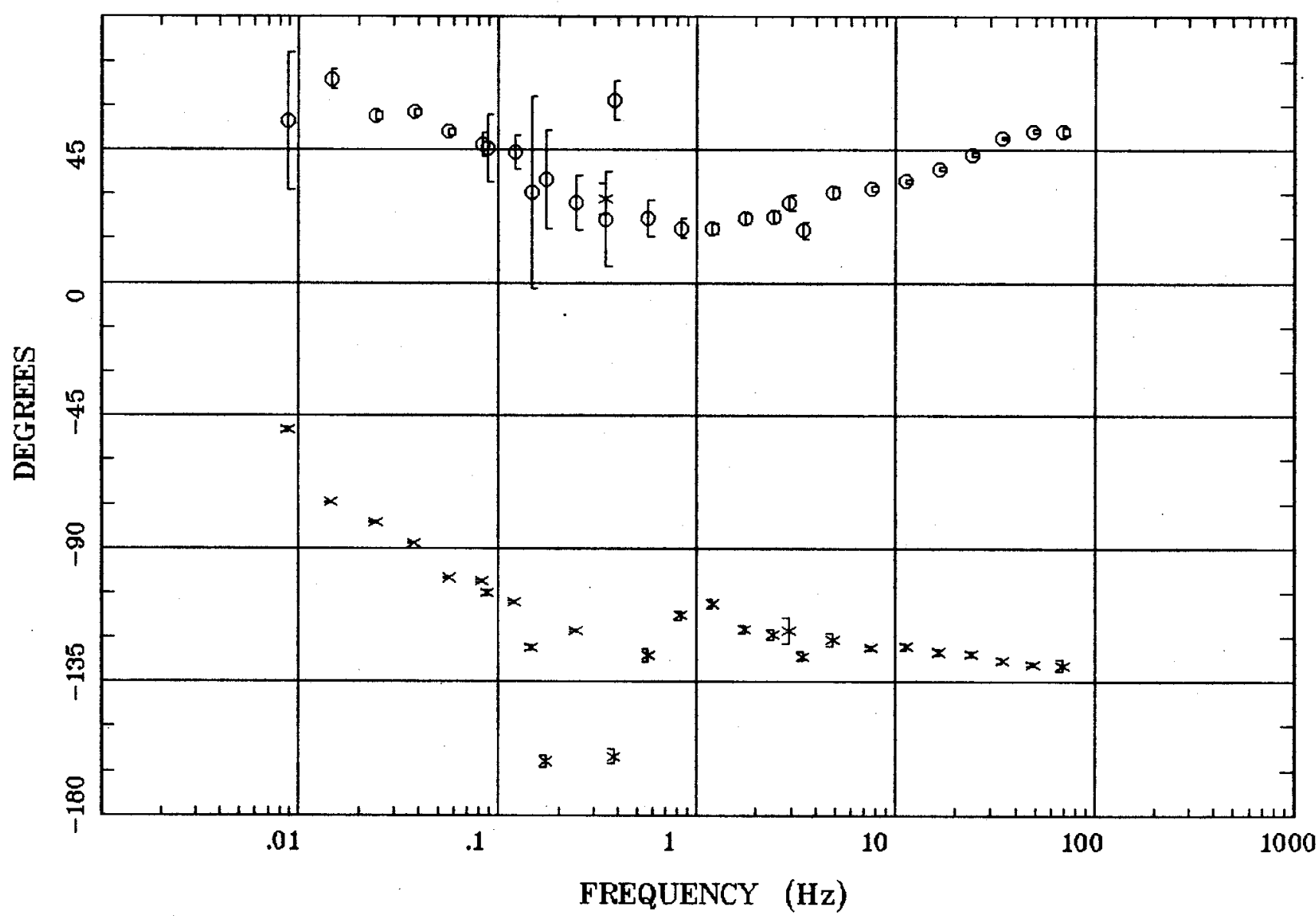

Client:

Remote: none

Acquired: 13:0 Jul 23, 2000 Survey Co:USGS
Rotation:

Filename: hr91b.avg

Channels: Ch1 Ch2 Ch3 Ch4 Ch5 Ch3 Ch4

Plotted: 11:07 Feb 06, 2001

< EMI - ElectroMagnetic Instruments > 


\section{Station 91}

ROTATION ANGLE

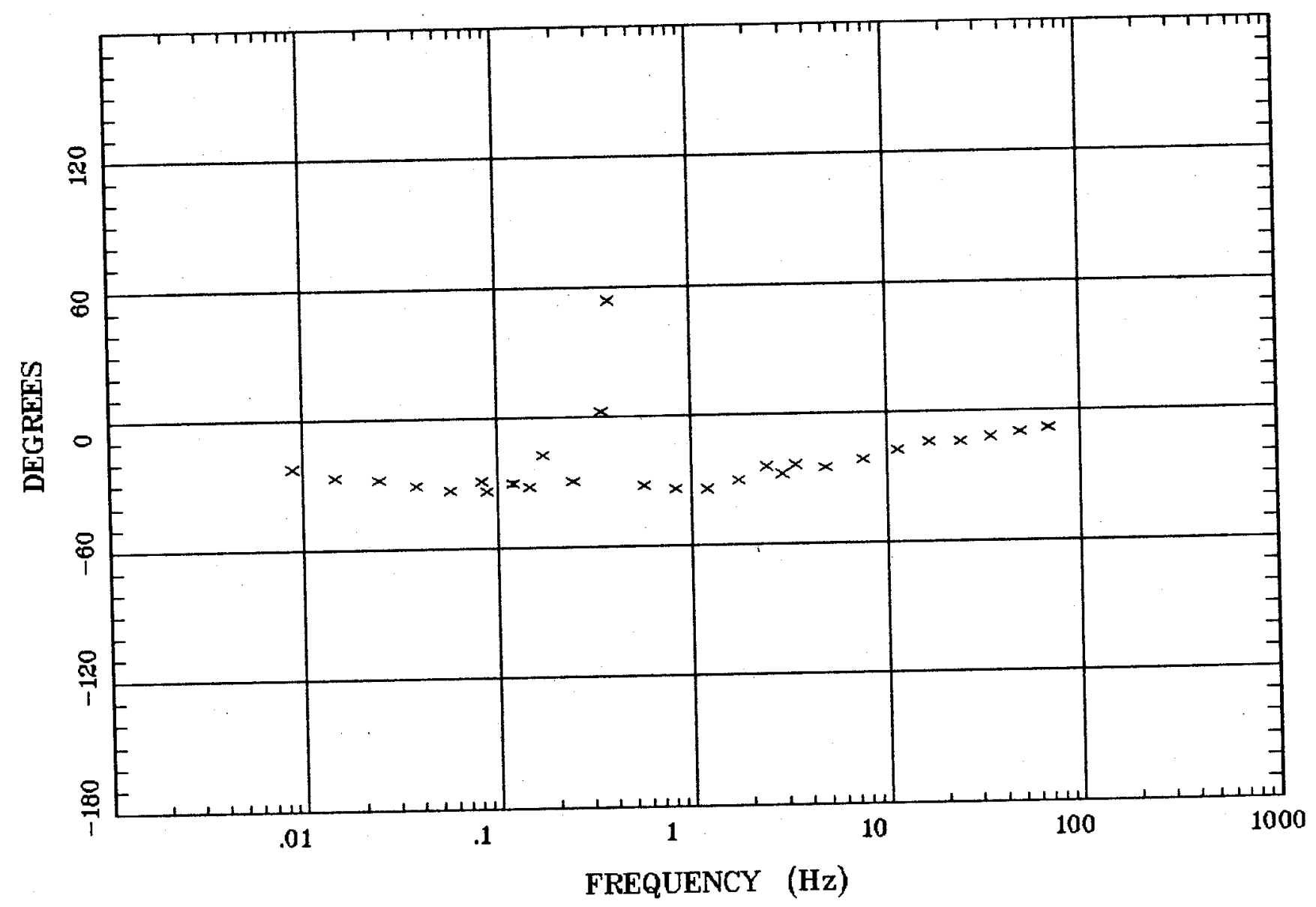

Client:

Remote: none

Acquired: 13:0 Jul 23, 2000

Survey Co:USGS
Rotation:

Filename: hr91b.avg

Channels: Ch1 Ch2 Ch3 Ch4 Ch5 Ch3 Ch4

Plotted: 11:07 Feb 06, 2001

< EMI - ElectroMagnetic Instruments > 
Station 91

IMPEDANCE SKEW

Winnemucca, NV $100 \mathrm{~K}$

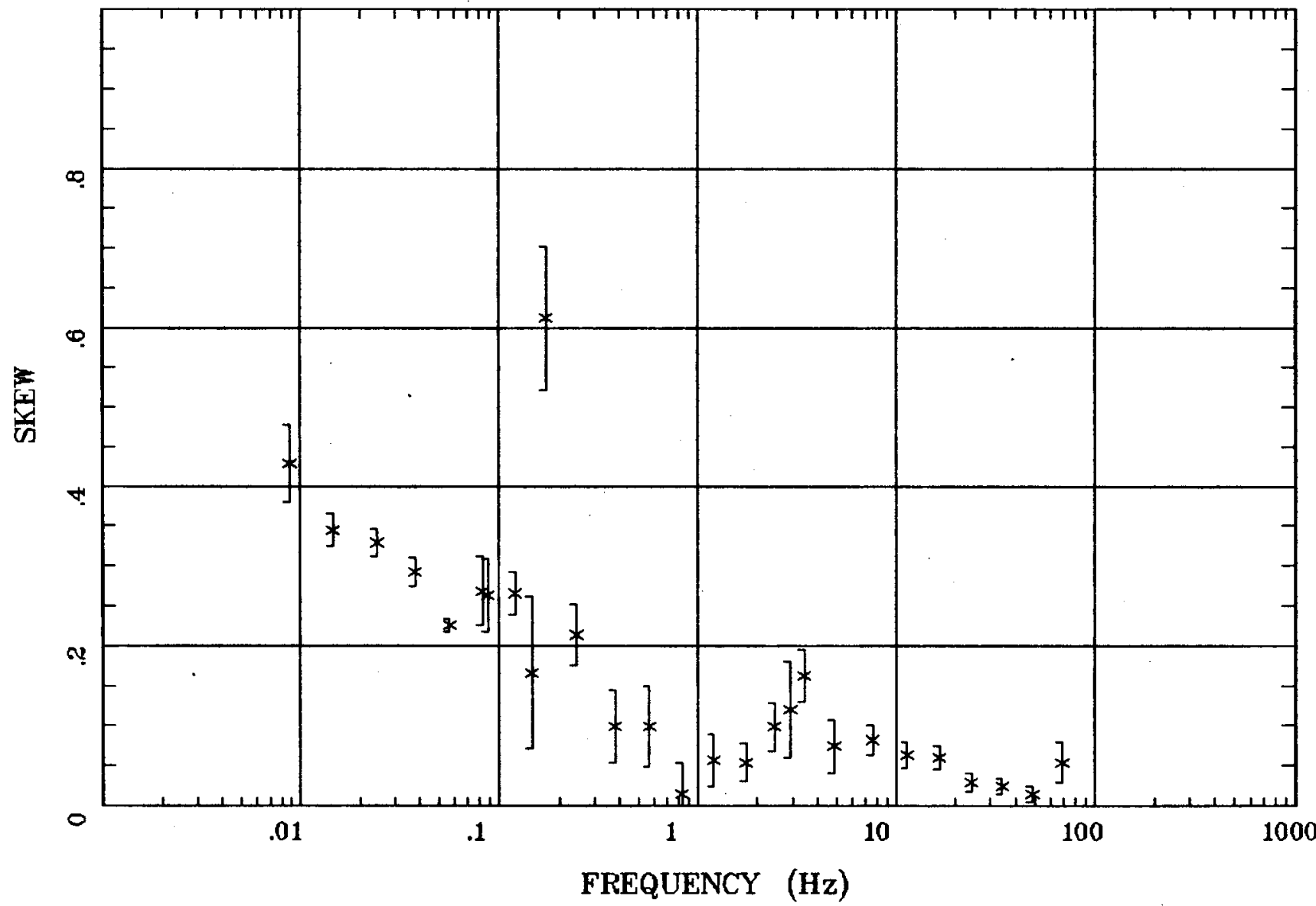


E MULT Coh. Winnemucca, NV 100K

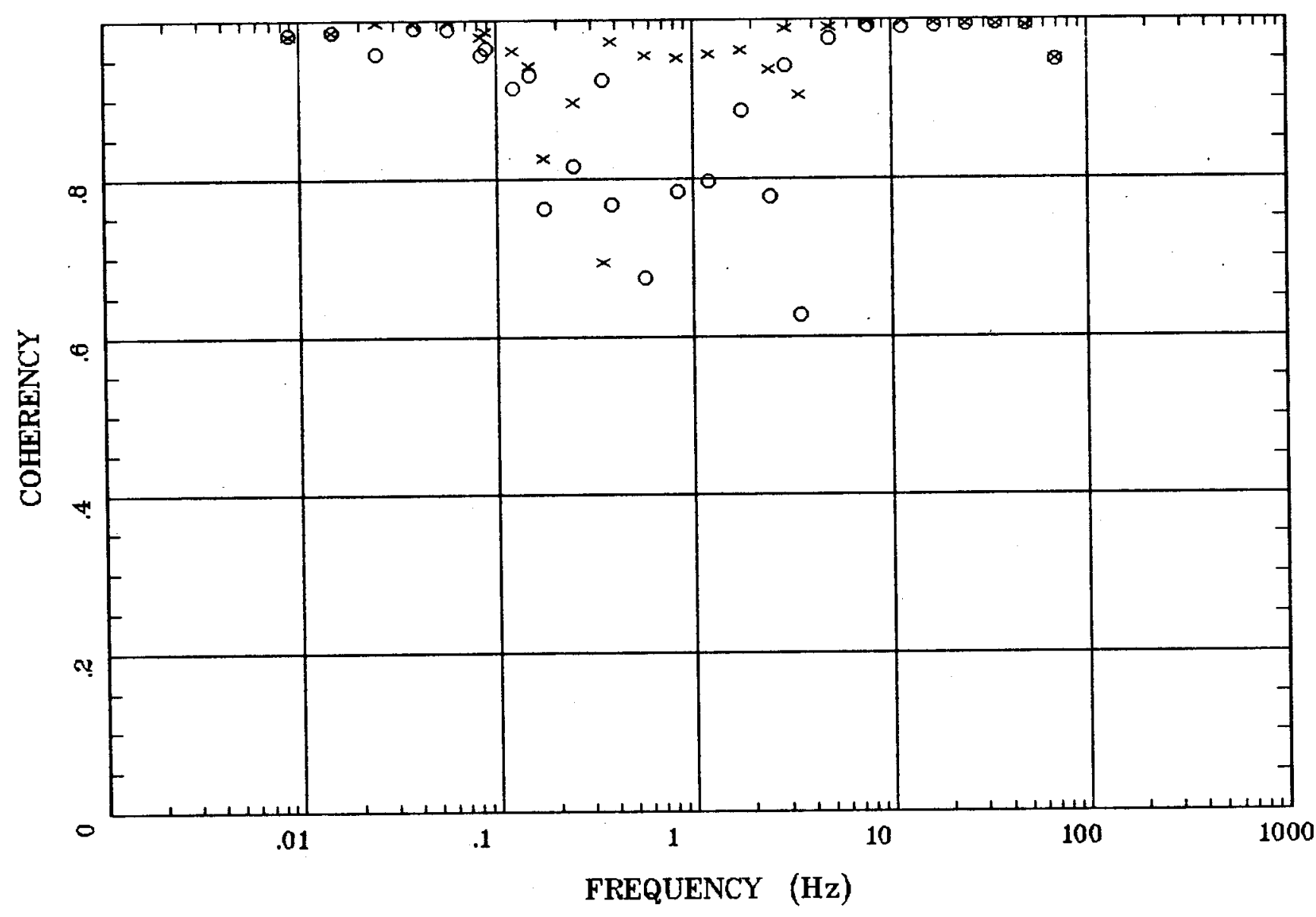

Client:

Remote: none

Acquired: 13:0 Jul 23, 2000

Survey Co:USGS
Rotation:

Filename: hrg1b.avg

Channels: Ch1 Ch2 Ch3 Ch4 Ch5 Ch3 Ch4 Plotted: 11:07 Feb 06, 2001

< EMI - ElectroMagnetic Instruments > 


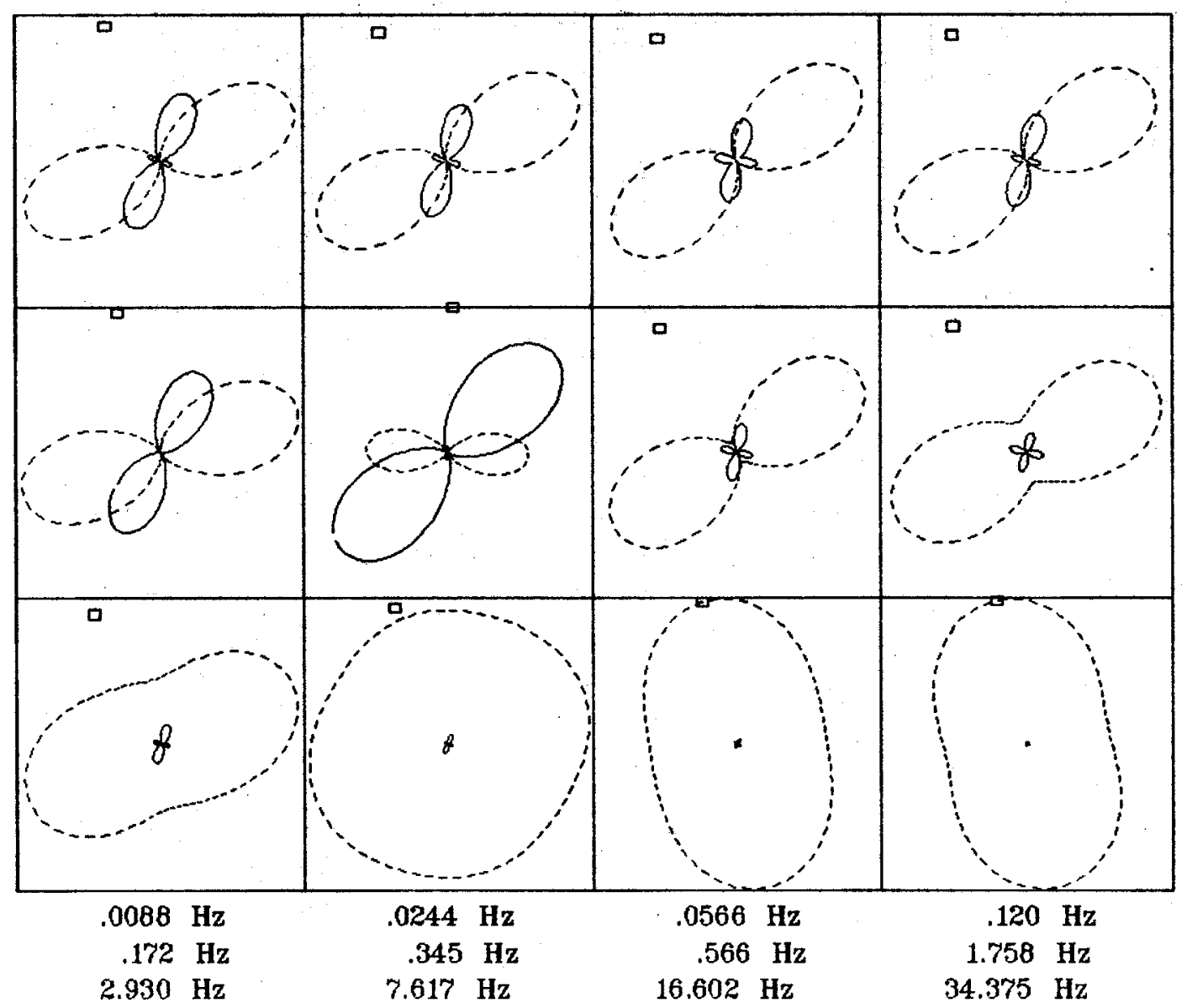

Client:

Remote: none

Acquired: 13:0 Jul 23, 2000

Survey Co:USGS
Rotation:

Filename: hr91b.avg

Channels: Ch1 Ch2 Ch3 Ch4 Ch5 Ch3 Ch4

Plotted: 11:07 Feb 06, 2001

< EMI - ElectroMagnetic Instruments > 
Winnemucca, NV 100K

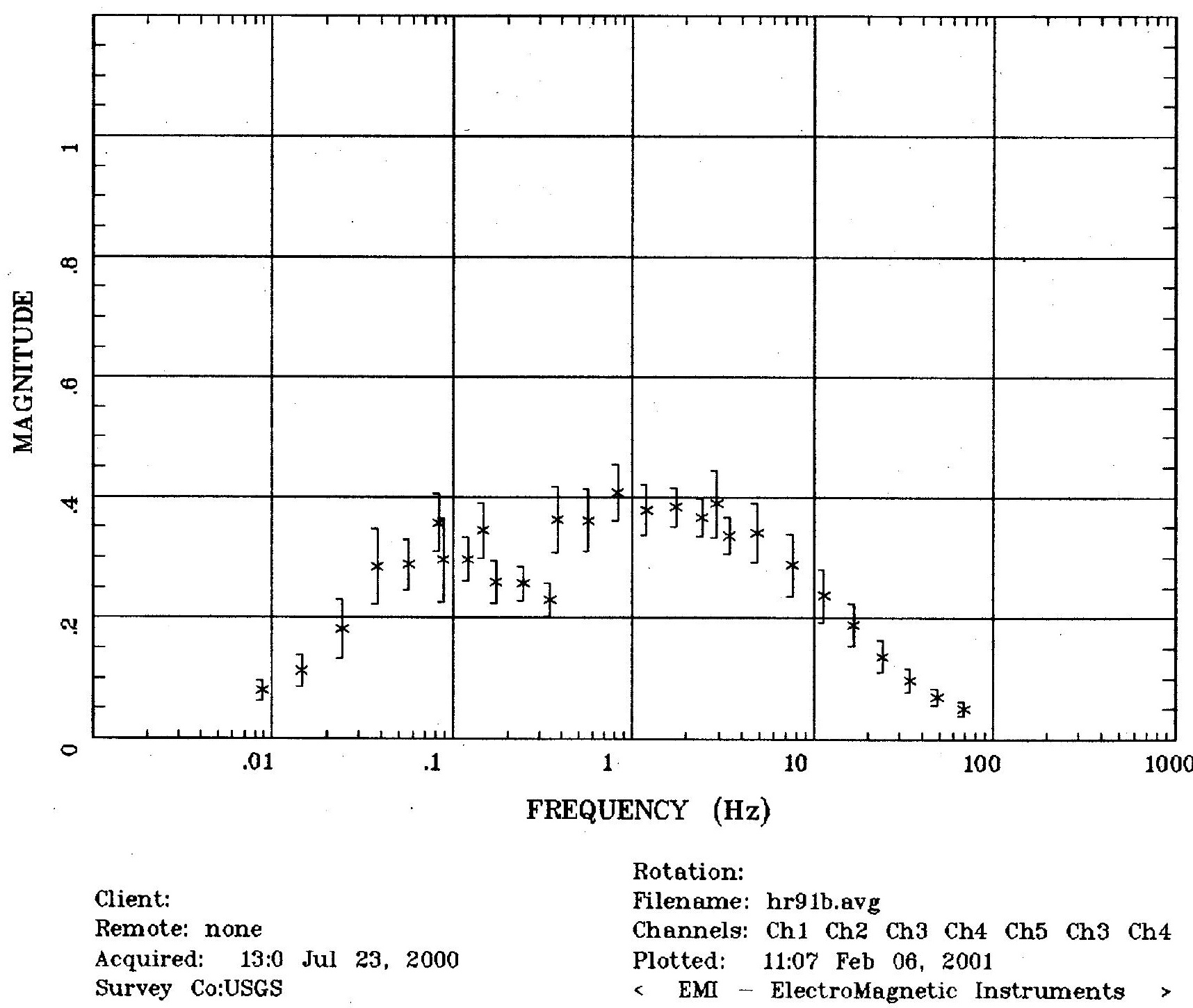


TIPPER STRIKE

Winnemucce, NV $100 \mathrm{~K}$

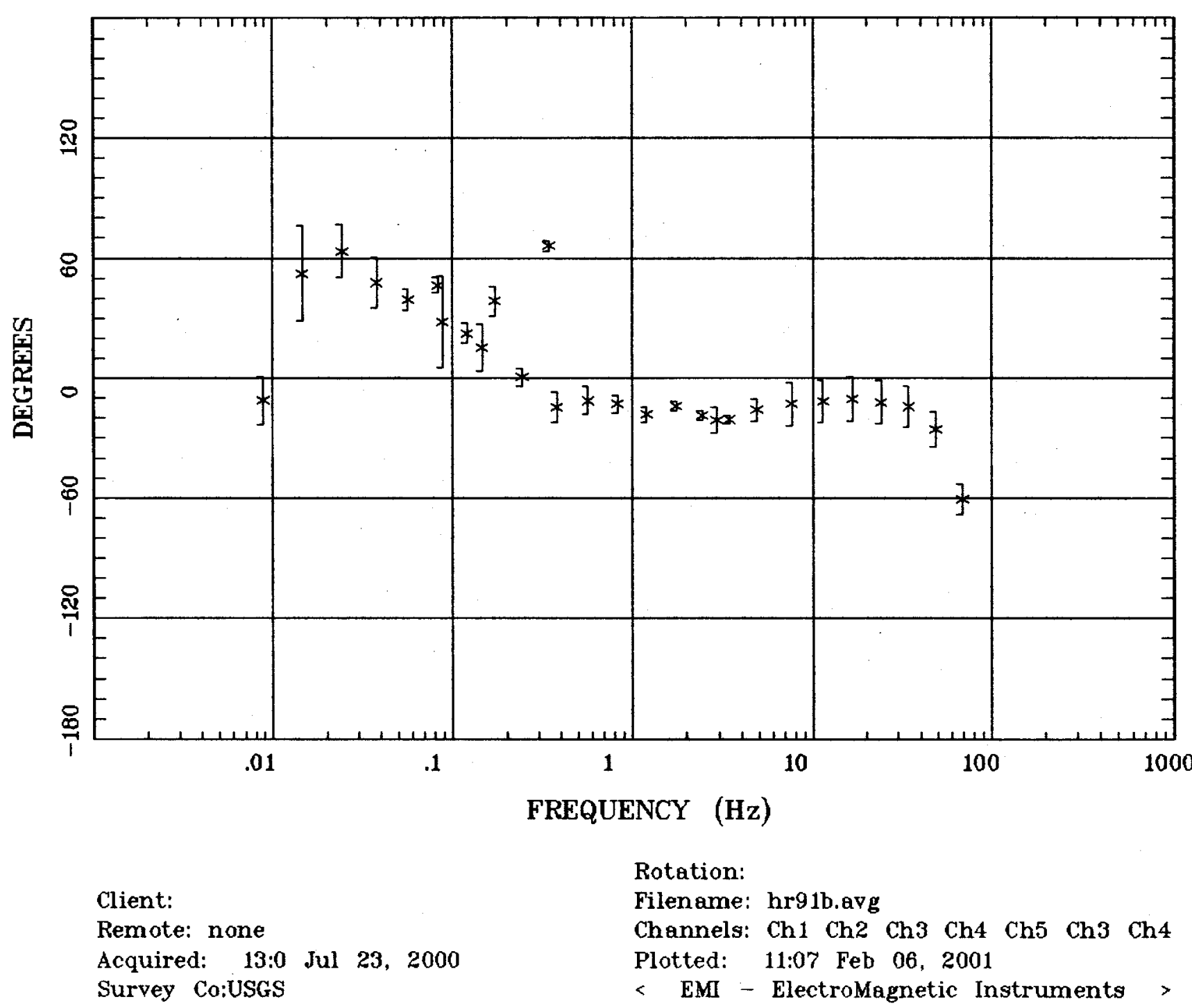


Station 91

HzHx.x Coh HzHy.o

Winnemucca, NV $100 \mathrm{~K}$

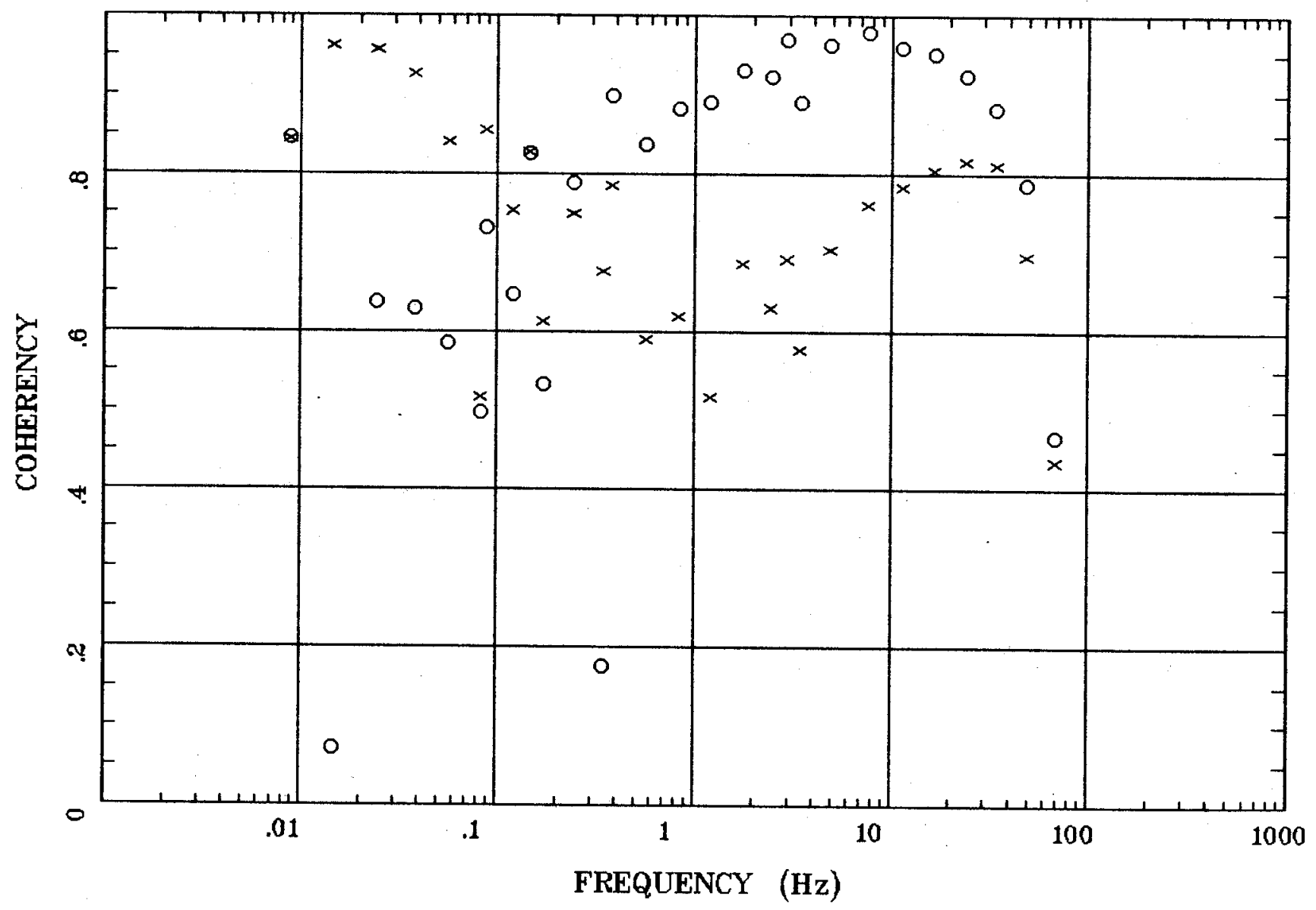

Client:

Remote: none

Acquired: 13:0 Jul 23, 2000

Survey Co:USGS
Rotation:

Filename: hr91b.avg

Channels: Ch1 Ch2 Ch3 Ch4 Ch5 Ch3 Ch4

Plotted: 11:07 Feb 06, 2001

< EMI - ElectroMagnetic Instruments > 
APPARENT RESISTIVITY Winnemucca, NV 100K

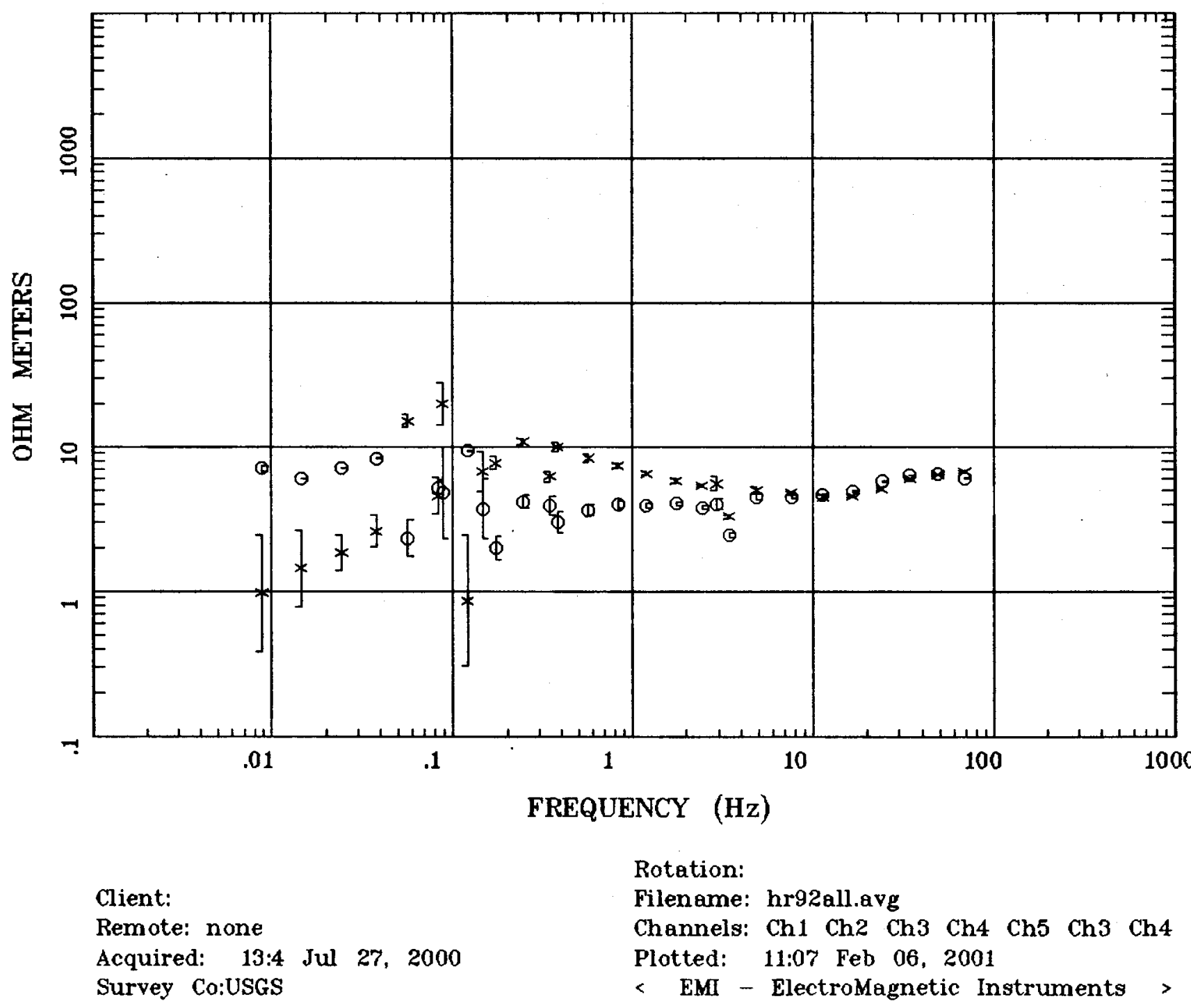


Winnemucca, NV 100K

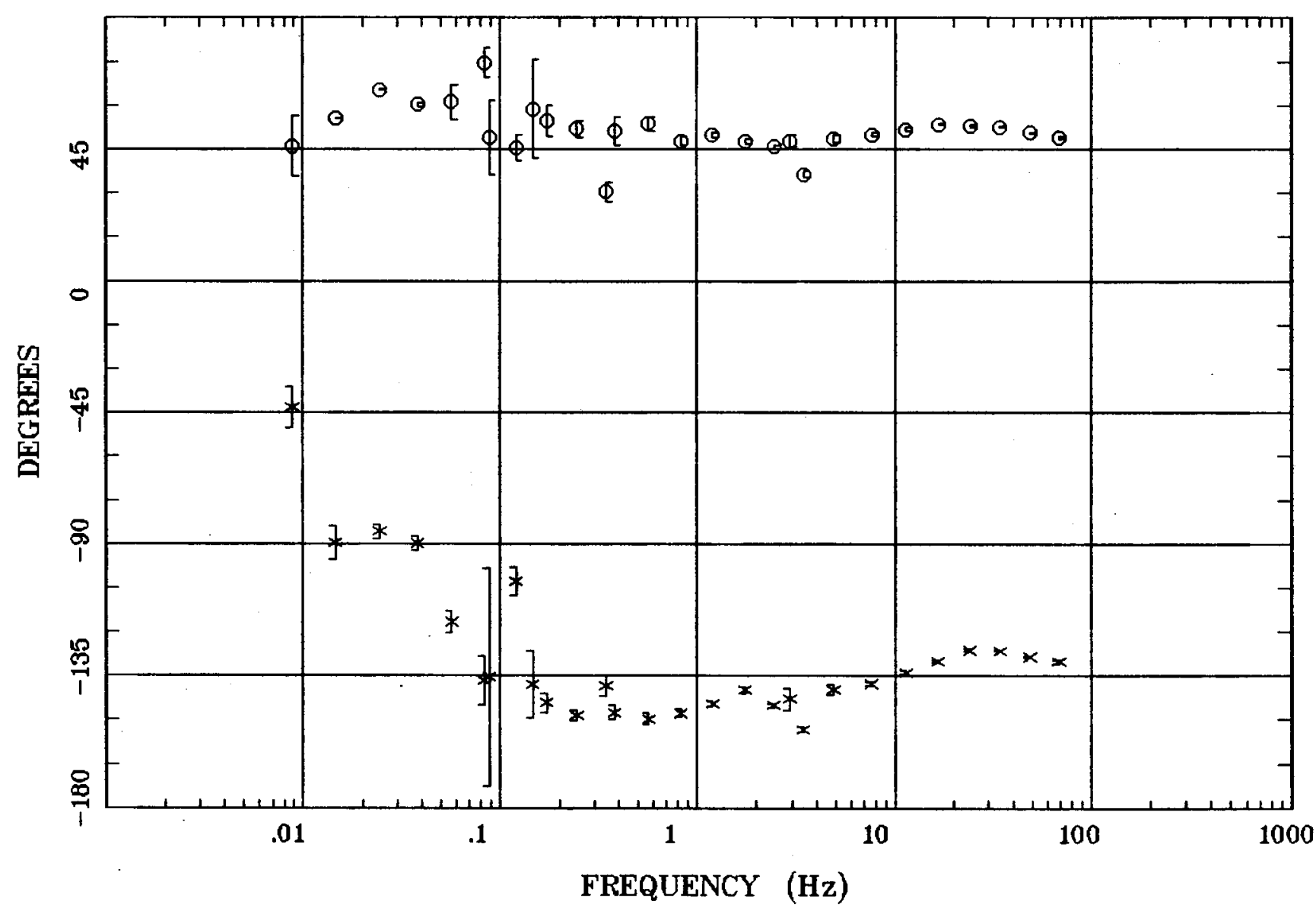

Client:

Remote: none

Acquired: 13:4 Jul 27, 2000 Survey Co:USGS
Rotation:

Filename: hr92all.avg

Channels: Ch1 Ch2 Ch3 Ch4 Ch5 Ch3 Ch4

Plotted: 11:07 Feb 06, 2001

< EMI - ElectroMagnetic Instruments > 


\section{Station 92}

ROTATION ANGLE

Winnemucca, NV 100K

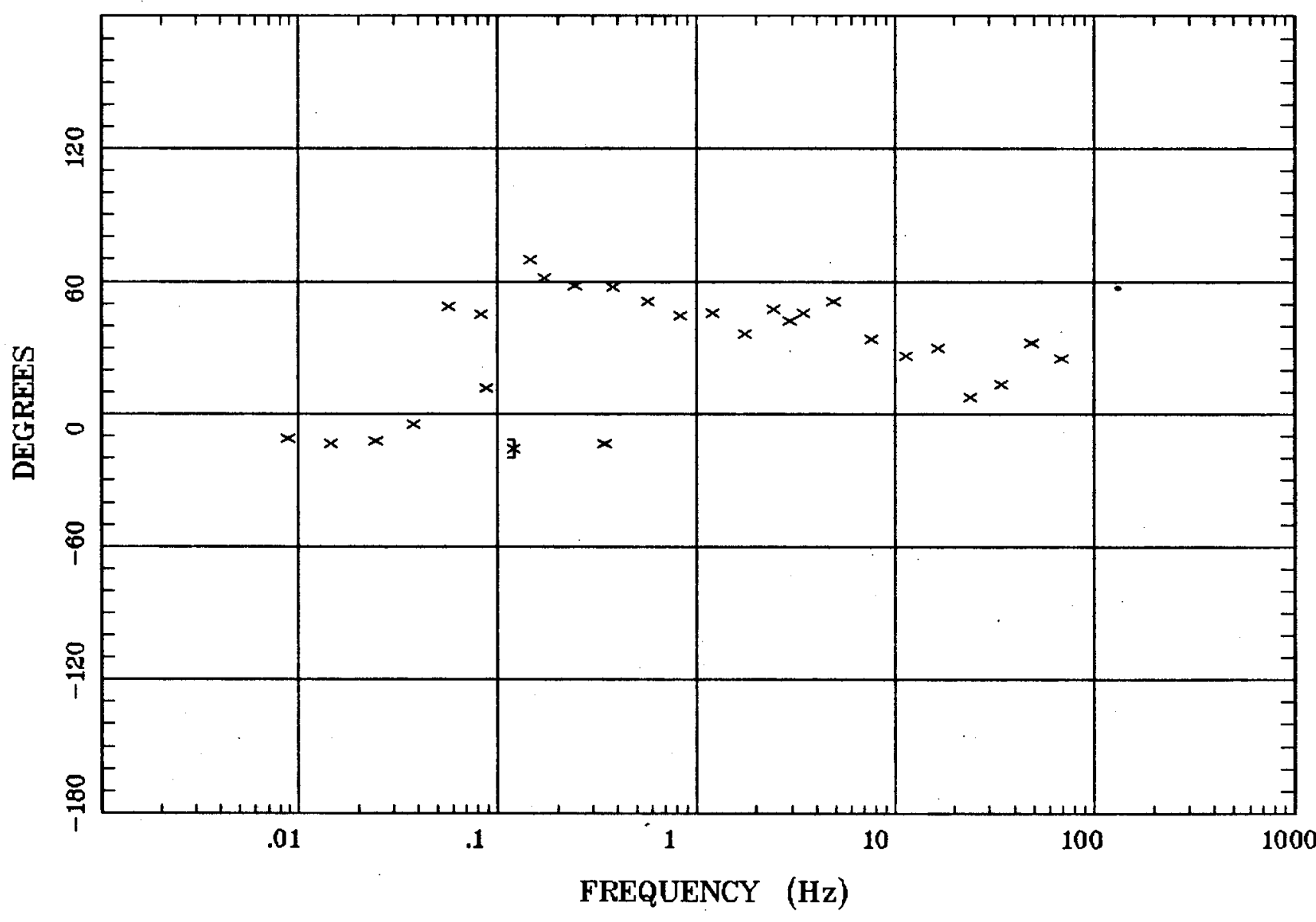

Client:

Remote: none

Acquired: 13:4 Jul 27, 2000

Survey Co:USGS
Rotation:

Filename: hr92all.avg

Channels: Ch1 Ch2 Ch3 Ch4 Ch5 Ch3 Ch4

Plotted: 11:07 Feb 06, 2001

< EMI - ElectroMagnetic Instruments 


\section{Station 92}

IMPEDANCE SKEW

Winnemucca, NV 100K

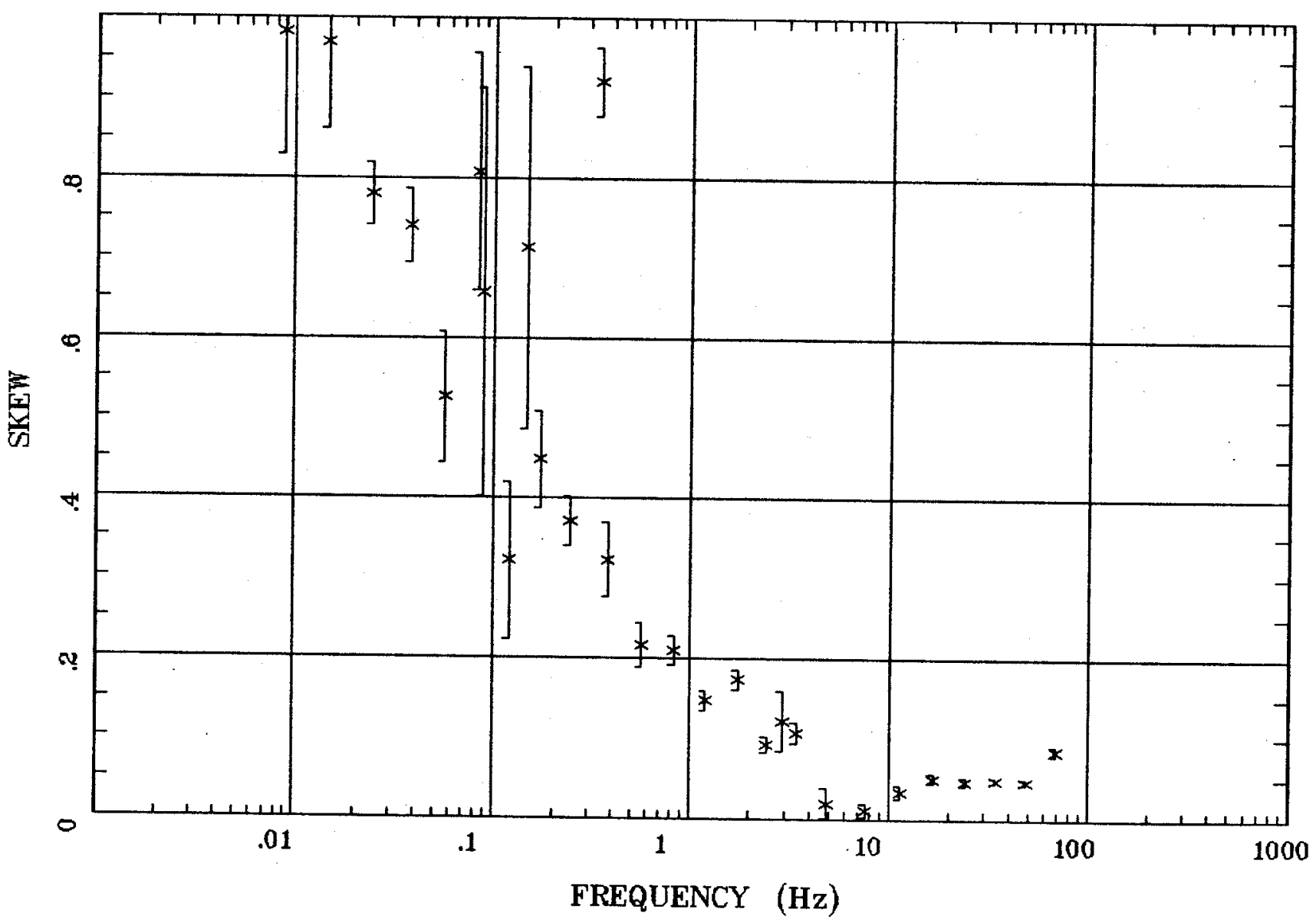

Client:

Remote: none

Acquired: 13:4 Jul 27, 2000 Survey Co:USGS
Rotation:

Filename: hr92all.avg

Channels: Ch1 Ch2 Ch3 Ch4 Ch5 Ch3 Ch4 Plotted: 11:07 Feb 06, 2001

< EMI - ElectroMagnetic Instruments 
Station 92

E MULT Coh.

Winnemucca, NV 100K

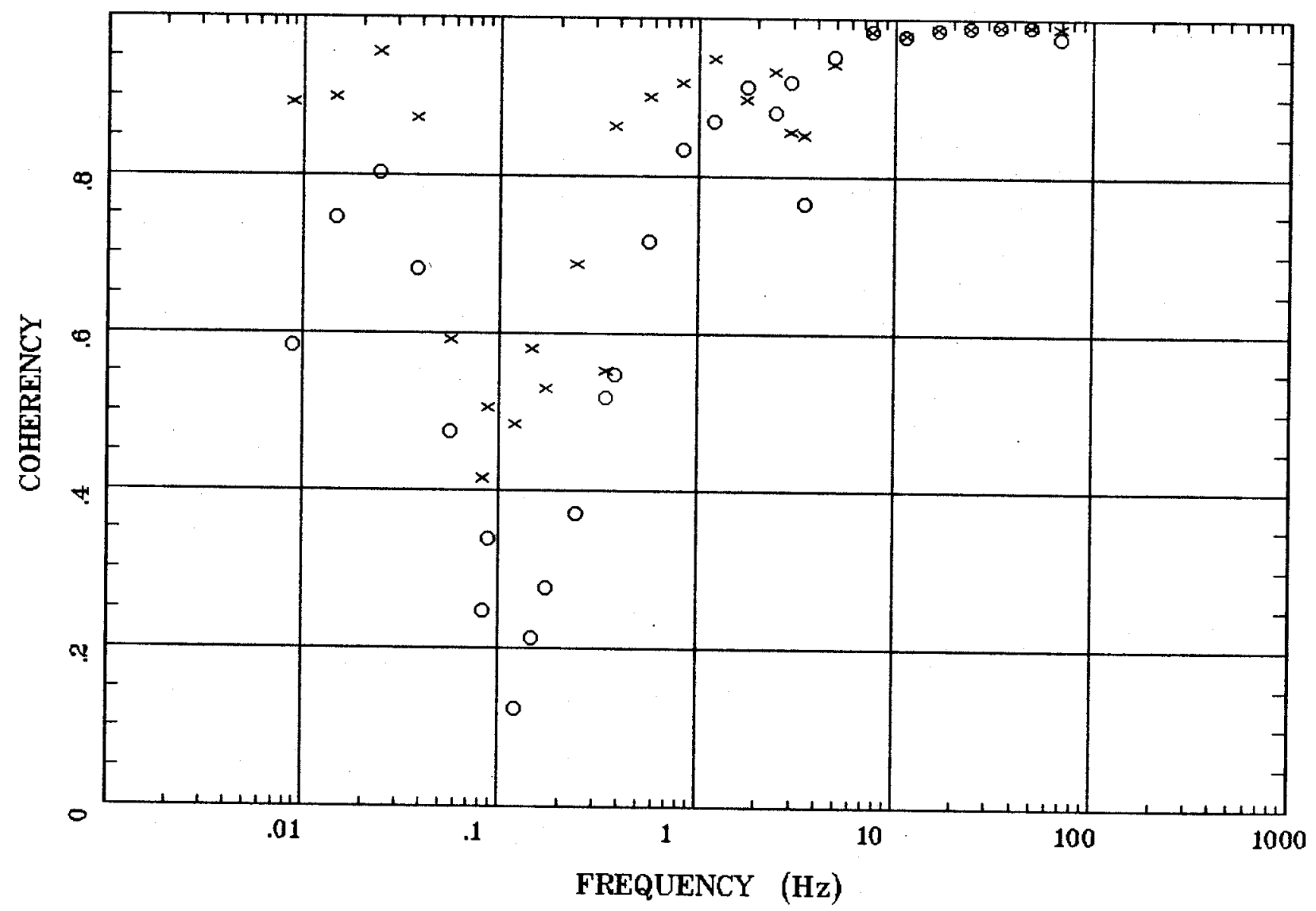

Client:

Remote: none

Acquired: 13:4 Jul 27, 2000

Survey Co:USGS
Rotation:

Filename: hr92all.avg

Channels: Ch1 Ch2 Ch3 Ch4 Ch5 Ch3 Ch4

Plotted: 11:07 Feb 06, 2001

< EMI - ElectroMagnetic Instruments > 


\section{Station 92}

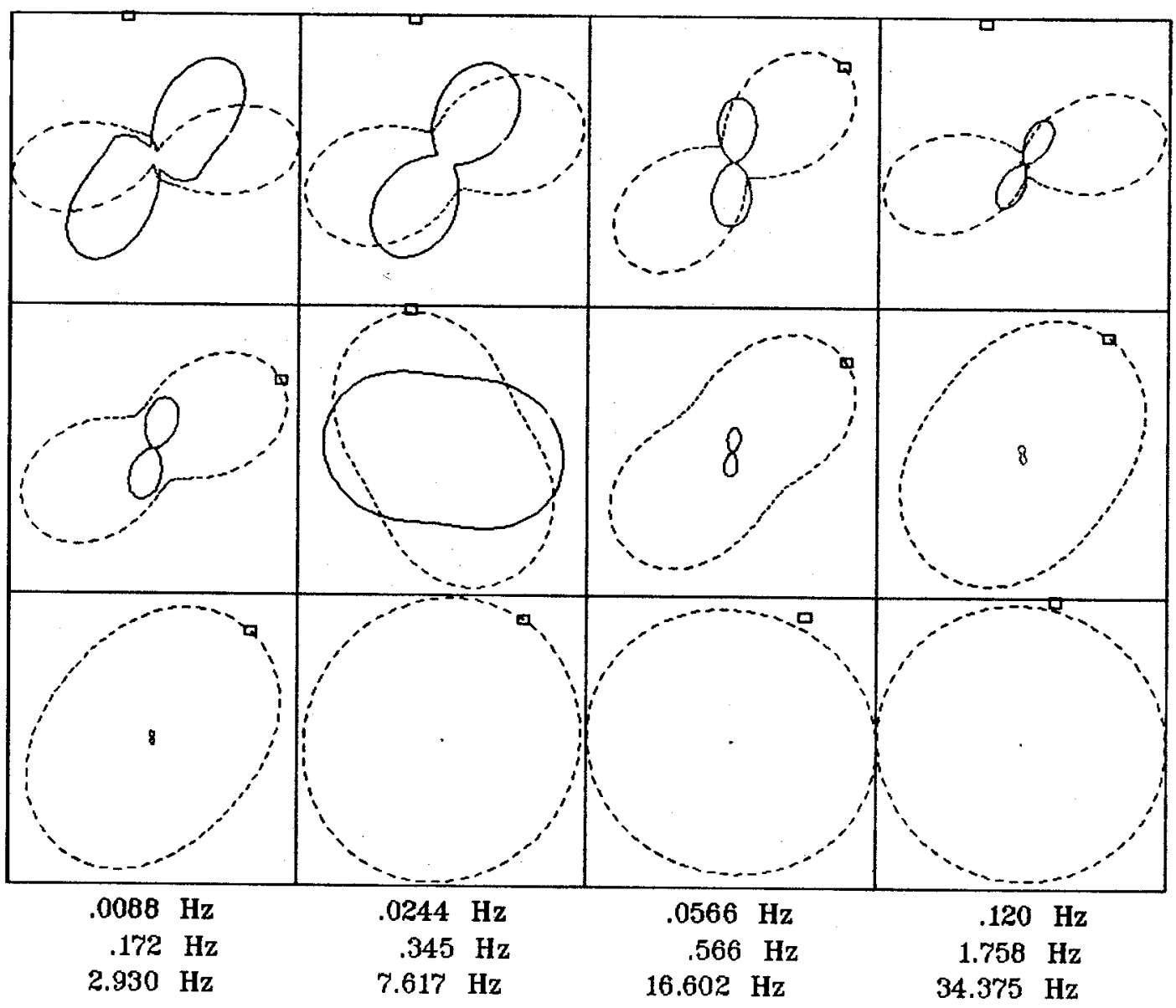

Client:

Remote: none

Acquired: 13:4 Jul 27, 2000 Survey Co:USGS
Rotation:

Filename: hr92all.avg

Channels: Ch1 Ch2 Ch3 Ch4 Ch5 Ch3 Ch4

Plotted: 11:07 Feb 06, 2001

C EMI - ElectroMagnetic Instruments 
Winnemucca, NV 100K

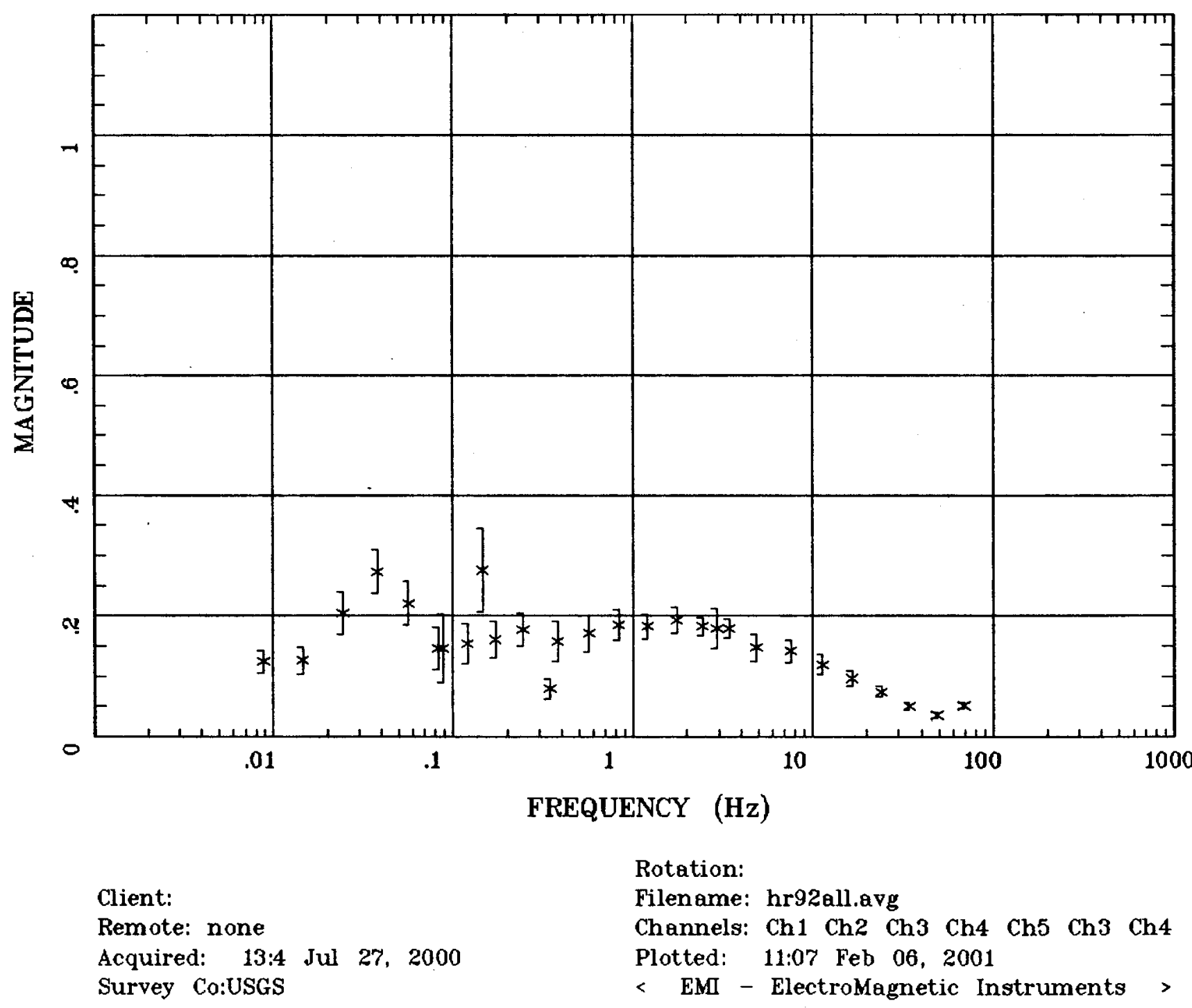


TIPPER STRIKE

Winnemucca, NV $100 \mathrm{~K}$

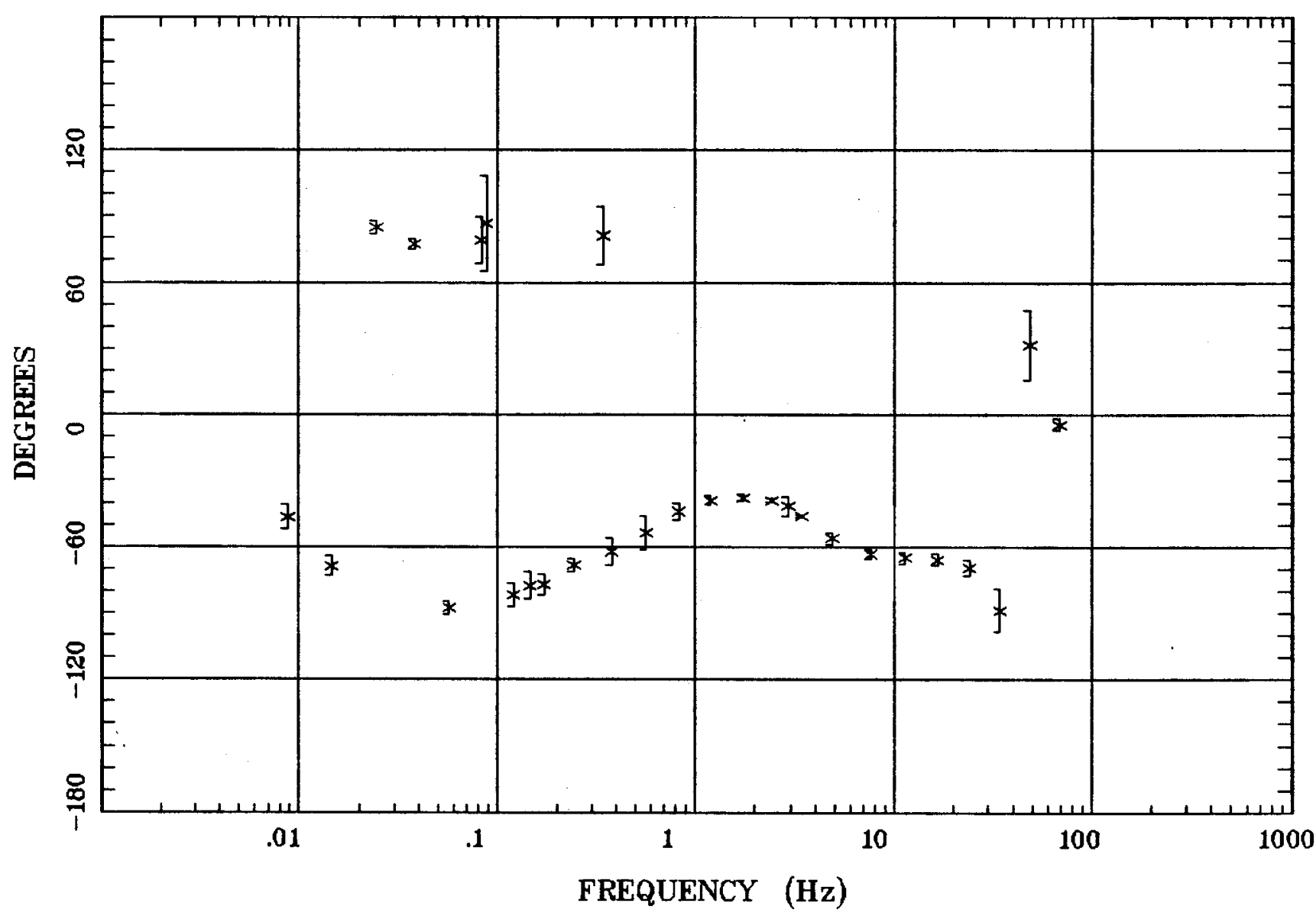

Client:

Remote: none

Acquired: 13:4 Jul 27, 2000

Survey Co:USGS
Rotation:

Filename: hr92all.avg

Channels: Ch1 Ch2 Ch3 ch4 Ch5 Ch3 Ch4

Plotted: 11:07 Feb 06, 2001

< EMI - ElectroMagnetic Instruments > 
HzHx.x Coh HzHy.o

Winnemucca, NV 100K

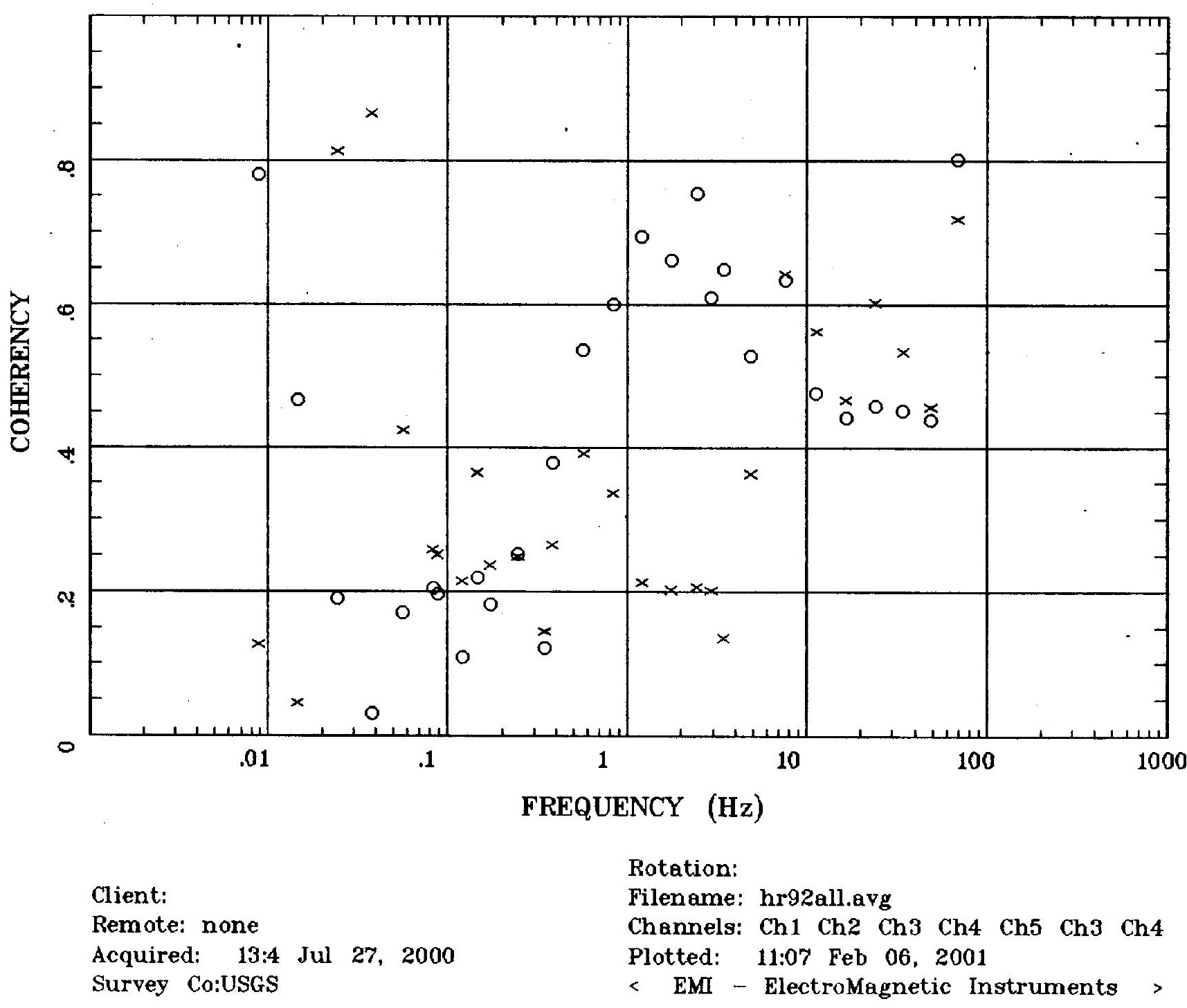




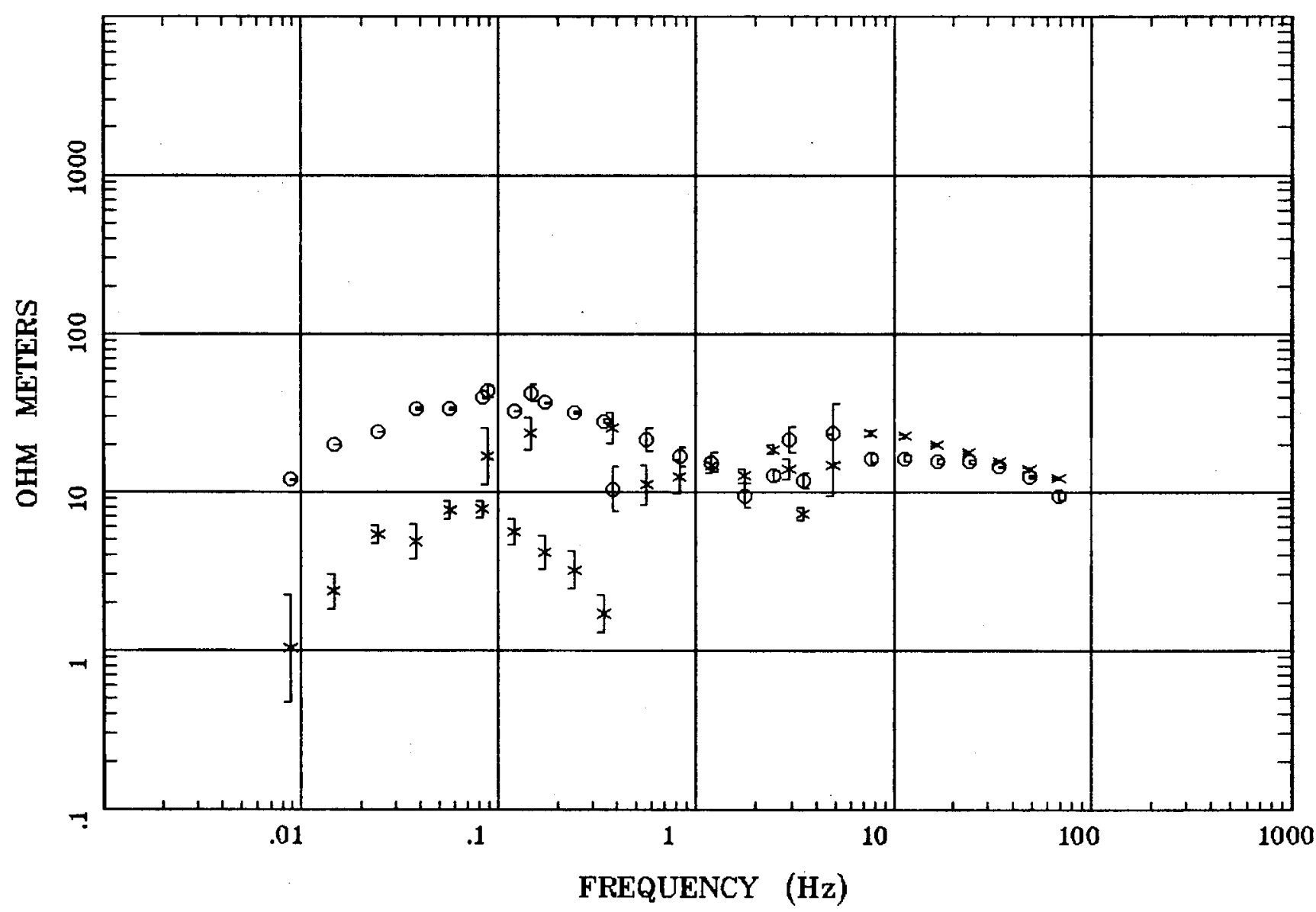

Client:

Remote: none

Acquired: 09:2 Jul 28, 2000 Survey Co:USGS
Rotation:

Filename: hr93b.avg

Channels: Ch1 Ch2 Ch3 Ch4 Ch5 Ch3 Ch4

Platted: 11:08 Feb 06, 2001

< EMI - ElectroMagnetic Instruments > 
Winnemucca, NV 100K

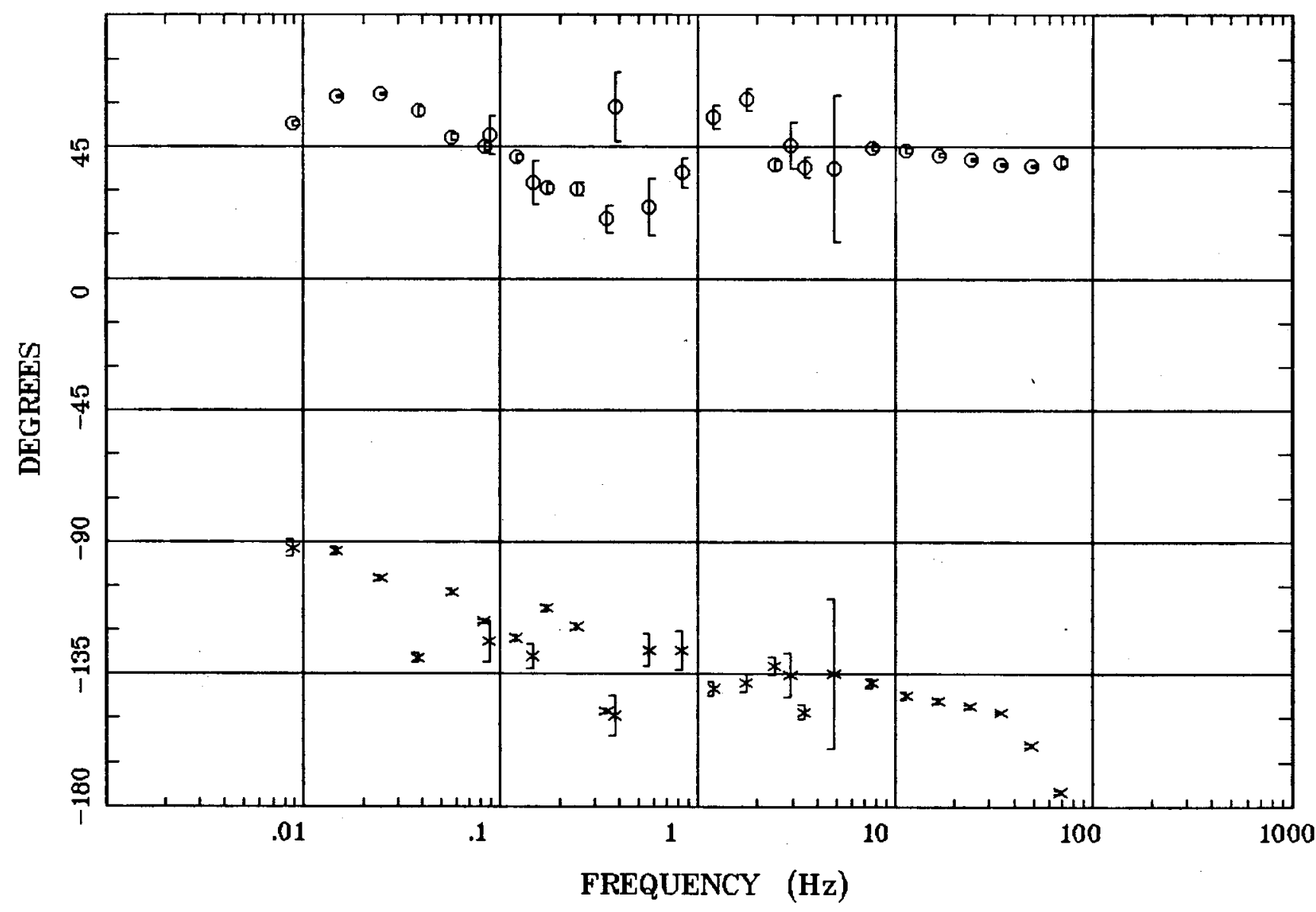

Client:

Remote: none

Acquired: 09:2 Jul 28, 2000 Survey Co:USGS
Rotation:

Filename: hr93b.avg

Channels: Ch1 Ch2 Ch3 Ch4 Ch5 Ch3 Ch4 Plotted: 11:08 Feb 06, 2001

< EMI - ElectroMagnetic Instruments > 
Station 93

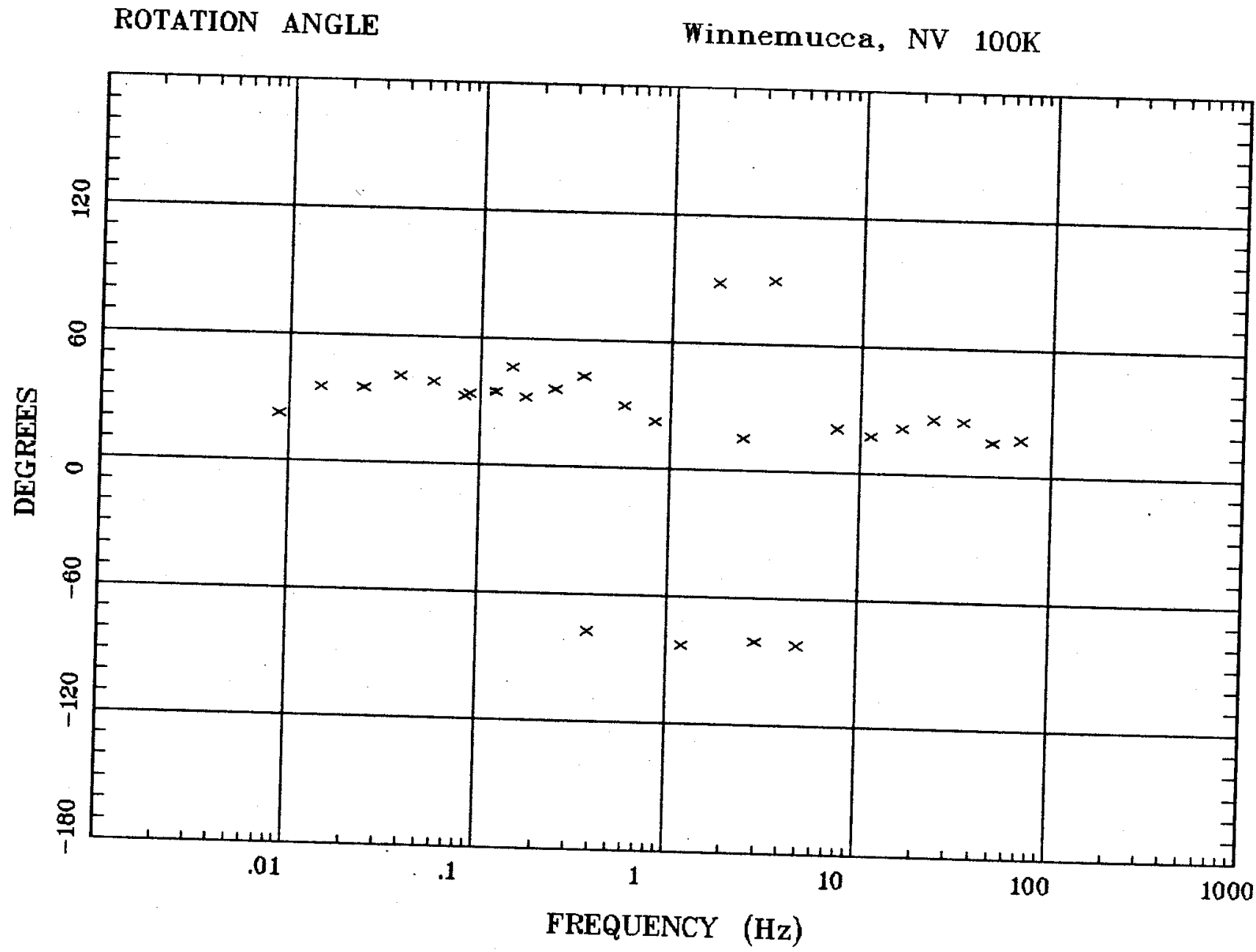

Client:

Remote: none

Acquired: 09:2 Jul 28, 2000

Survey Co:USGS
Rotation:

Filename: hr93b.avg

Channels: Ch1 Ch2 Ch3 Ch4 Ch5 Ch3 Ch4

Plotted: 11:08 Feb 06, 2001

< EMI - ElectroMagnetic Instruments > 


\section{Station 93}

IMPEDANCE SKEW

Winnemucca, NV $100 \mathrm{~K}$

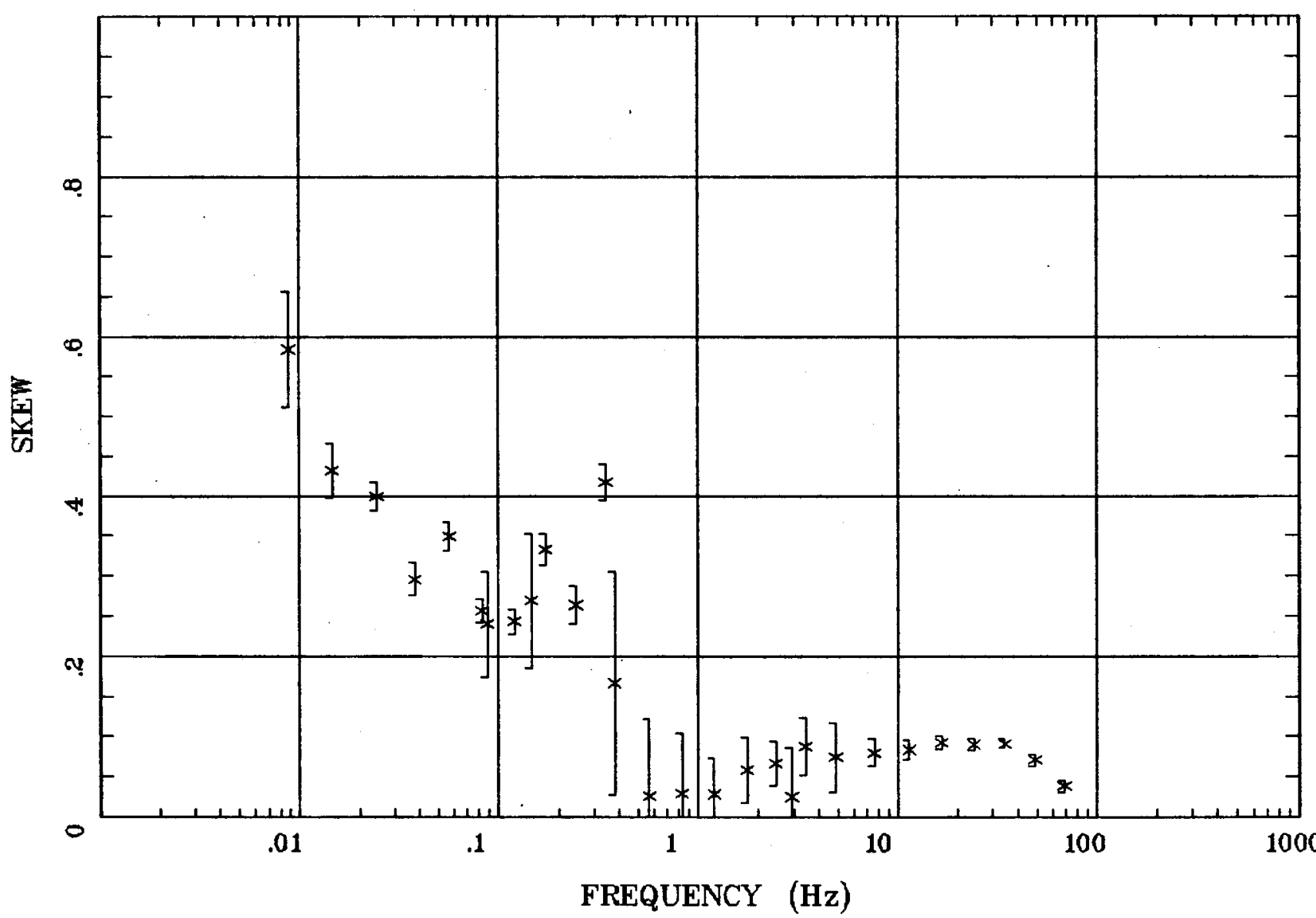




\section{E MULT Coh.}

Winnemucca, NV $100 \mathrm{~K}$

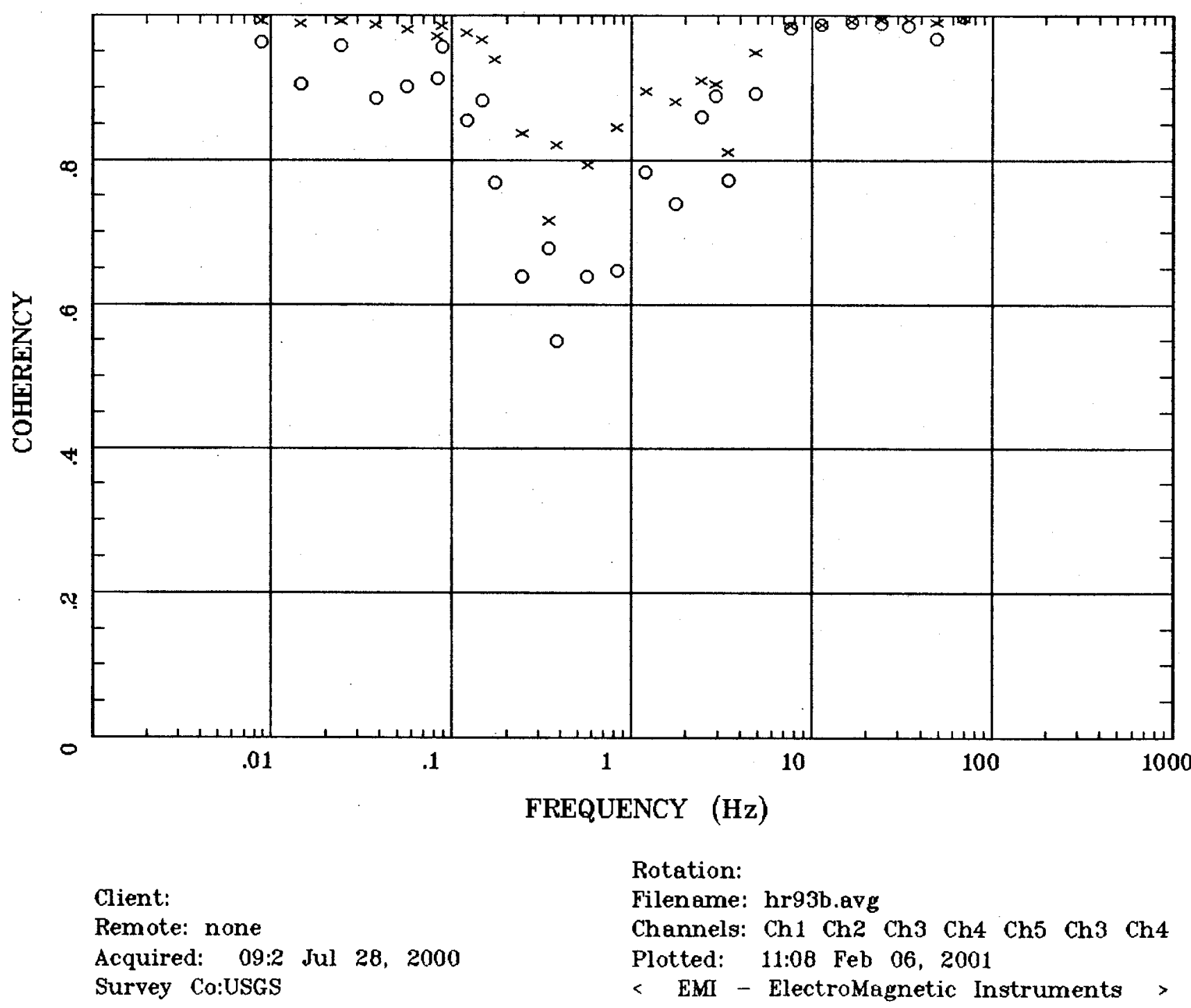




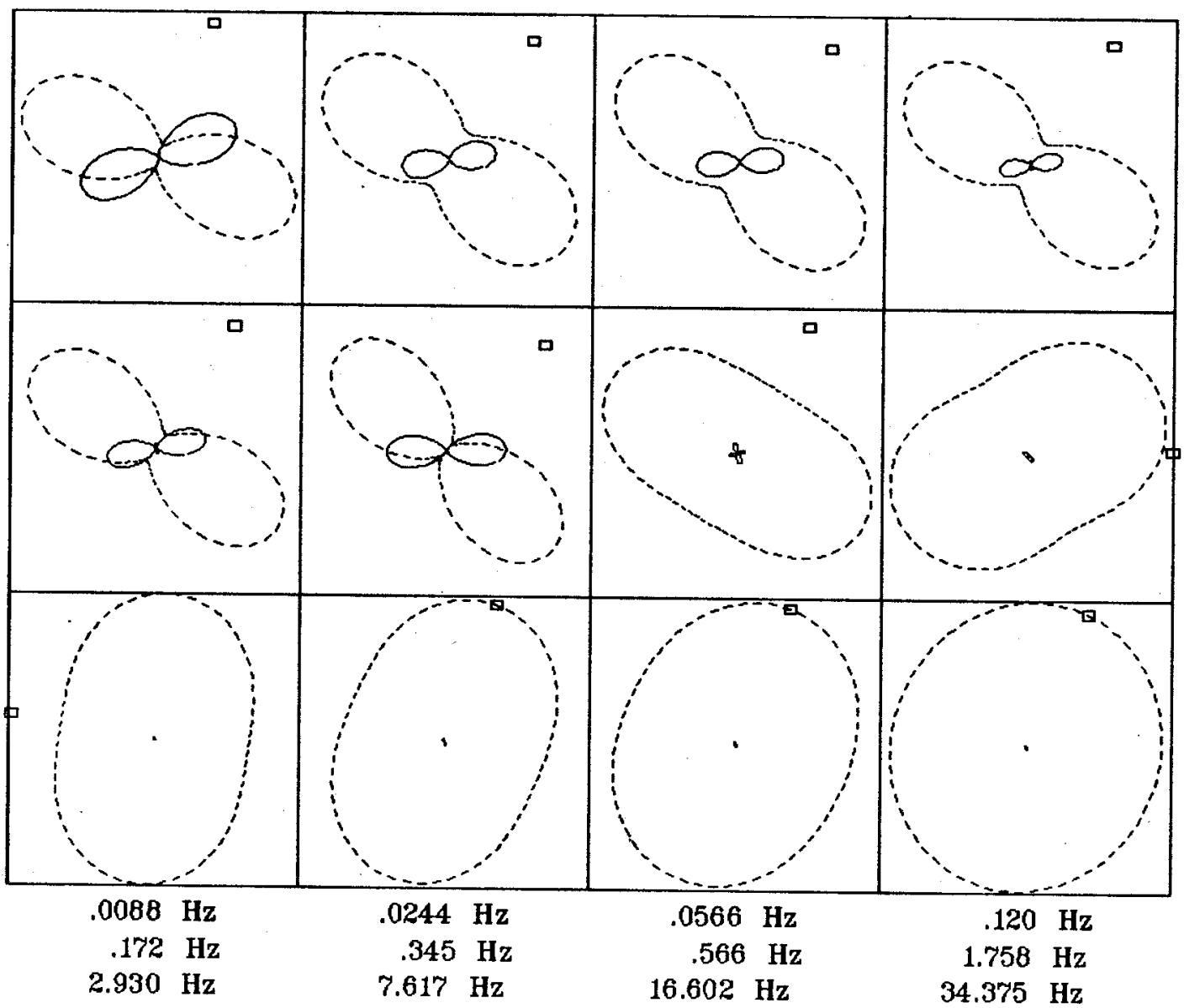

Client:

Remote: none

Acquired: 09:2 Jul 28, 2000 Survey Co:USGS
Rotation:

Filename: hr93b.avg

Channels: Ch1 Ch2 Ch3 Ch4 Ch5 Ch3 Ch4 Plotted: 11:08 Feb 06, 2001

$<$ EMI - ElectroMagnetic Instruments > 


\section{Station 93}

TIPPER MAGNITUDE

Winnemucca, NV $100 \mathrm{~K}$

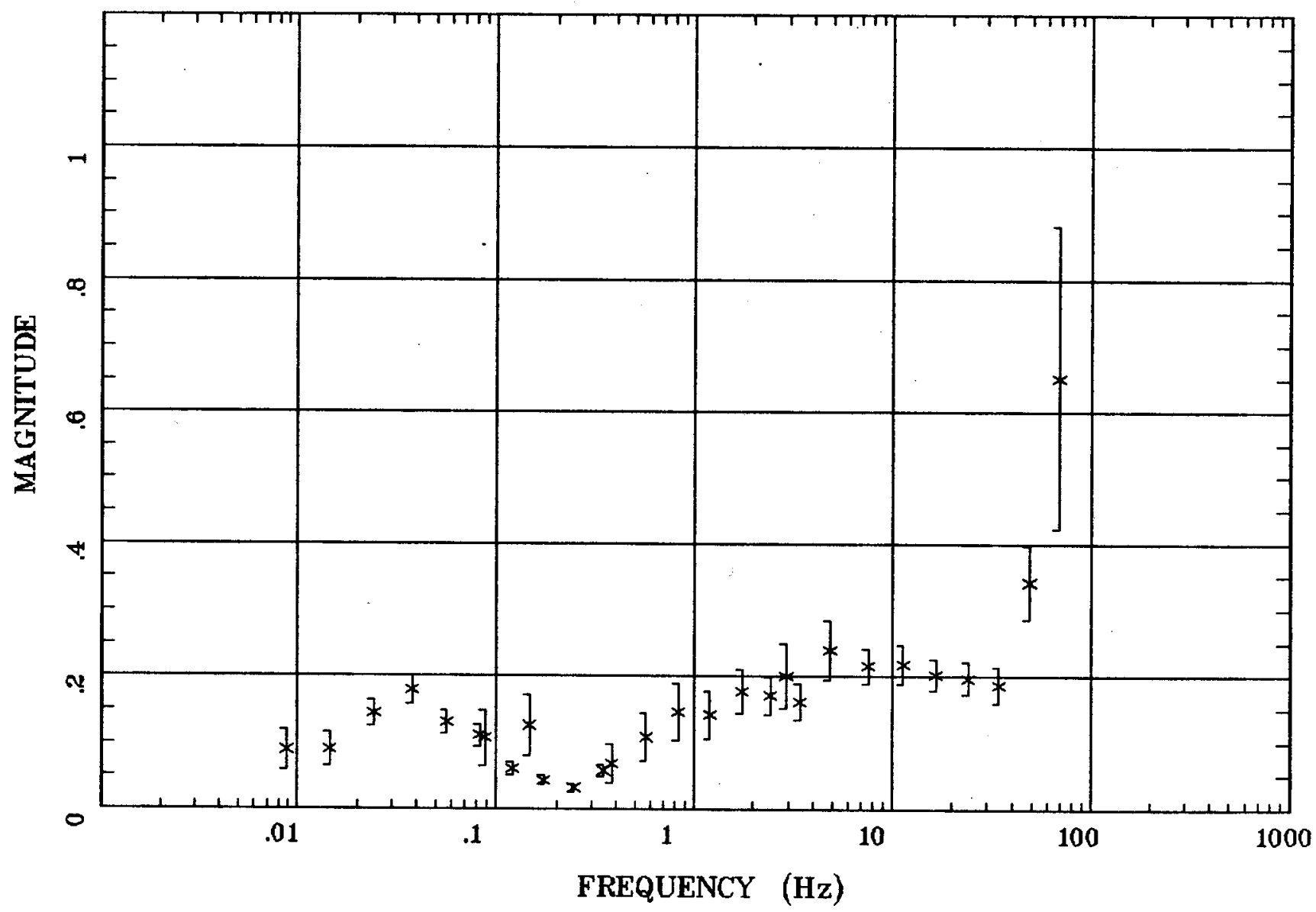

Client:

Remote: none

Acquired: 09:2 Jul 28, 2000

Survey Co:USGS

\section{Rotation:}

Filename: hr93b.avg

Channels: Ch1 Ch2 Ch3 Ch4 Ch5 Ch3 Ch4

Plotted: 11:08 Feb 06, 2001

< EMI - ElectroMagnetic Instruments > 


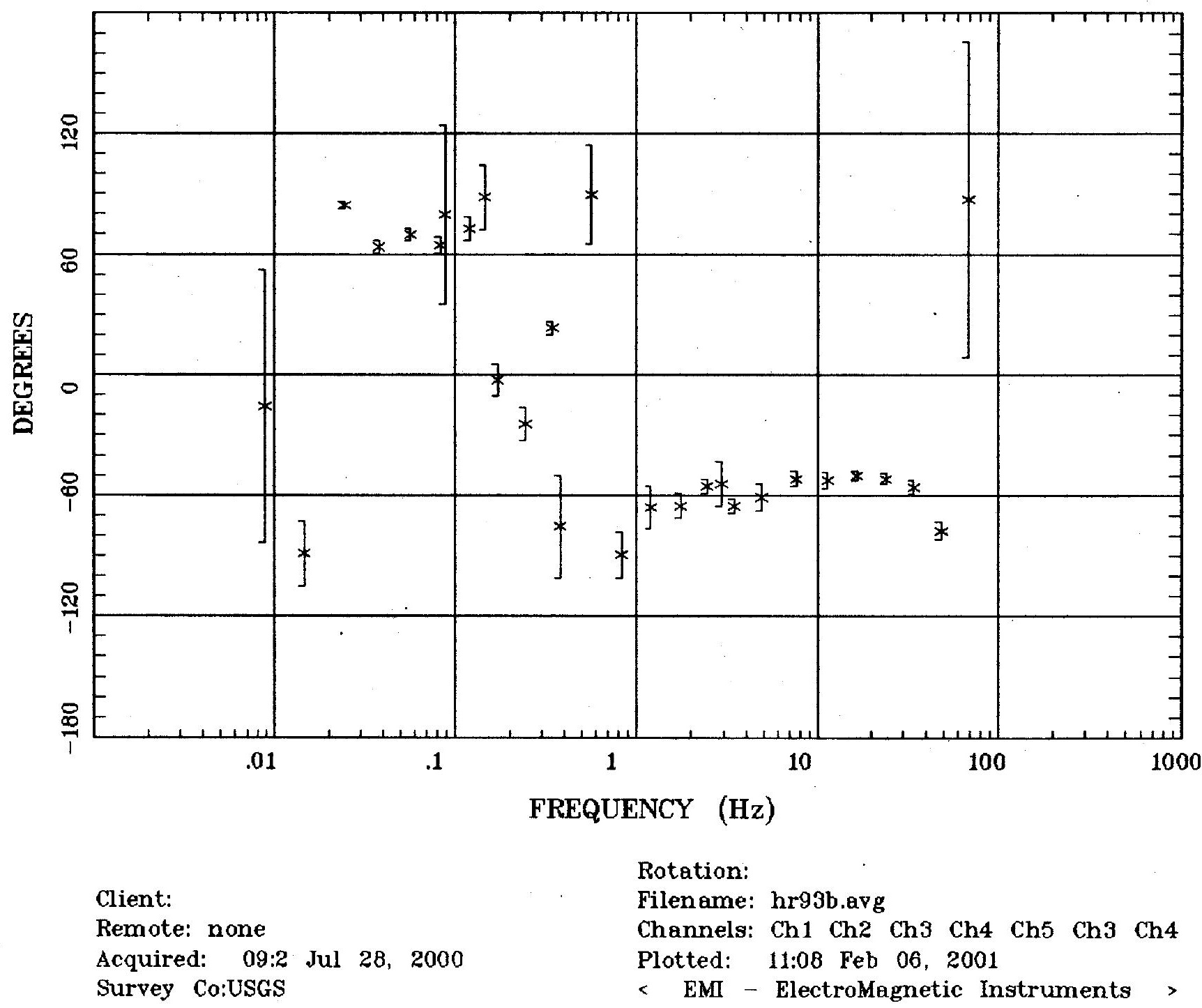


Station 93

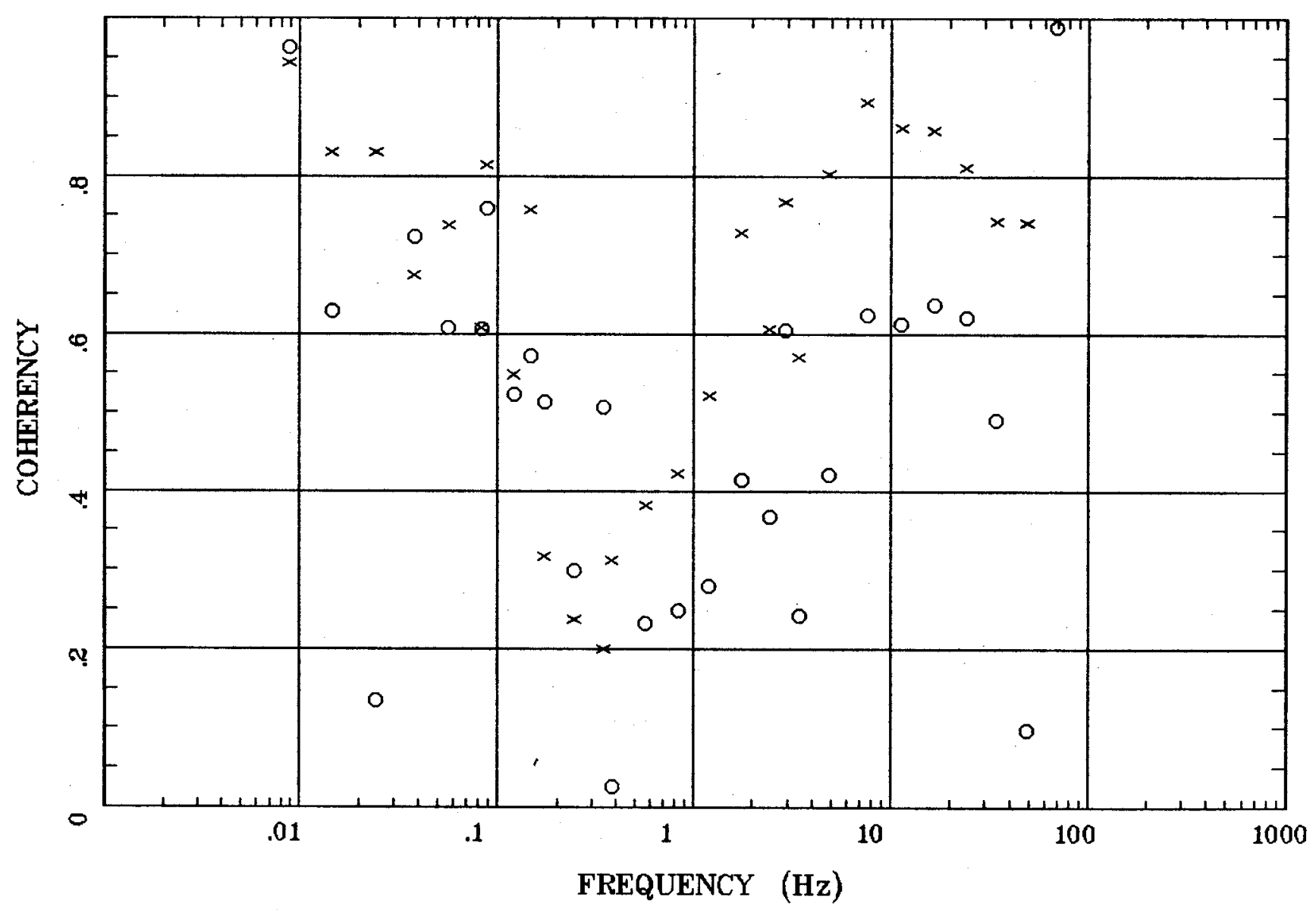

Client:

Remote: none

Acquired: 09:2 Jul 28, 2000

Survey Co:USGS
Rotation:

Filename: hr93b.avg

Channels: Ch1 Ch2 Ch3 Ch4 Ch5 Ch3 Ch4

Plotted: 11:08 Feb 06, 2001

< EMI - ElectroMagnetic Instruments 
APPARENT RESISTIVITY

Winnemucca, NV 100K

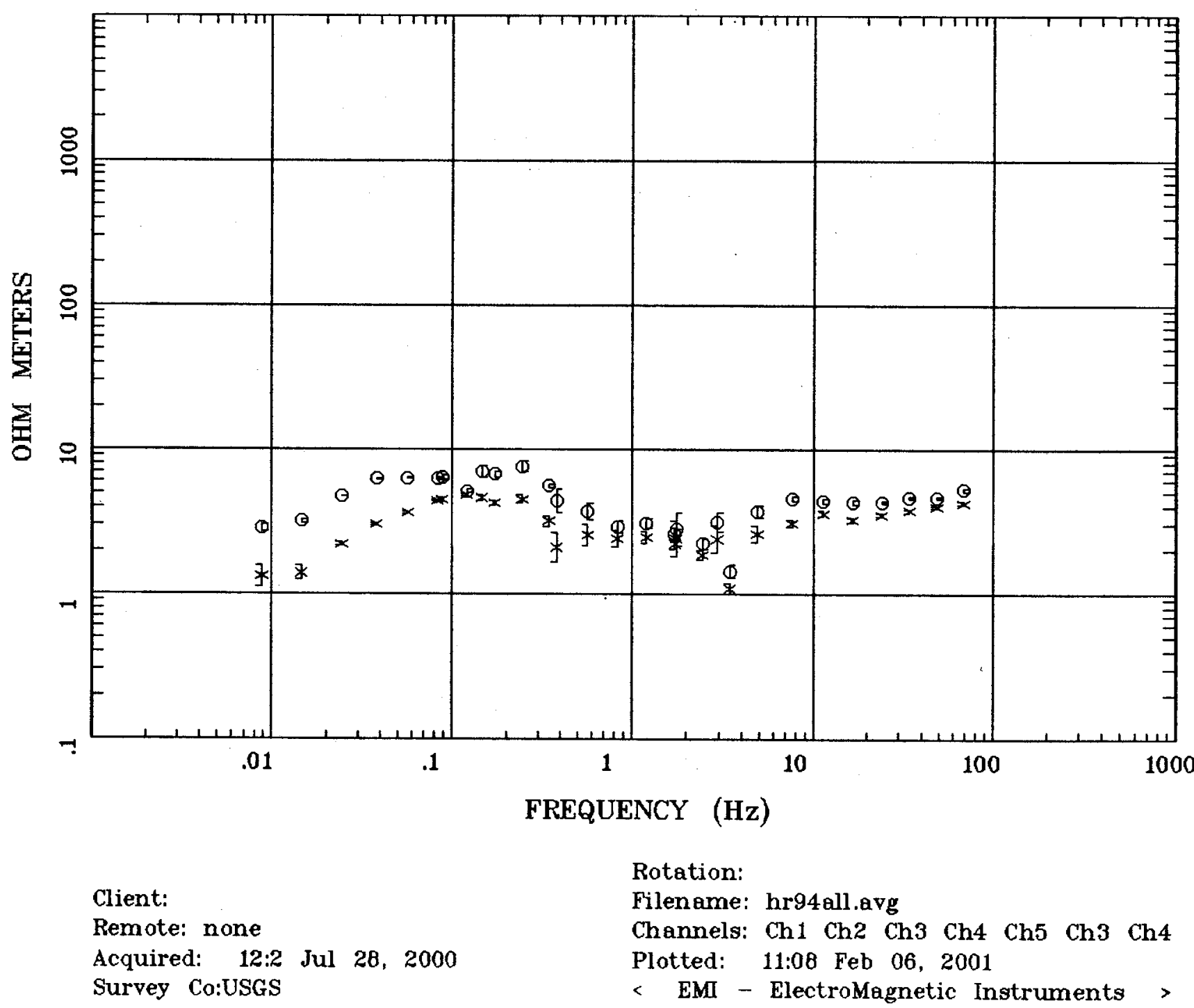




\section{Station 94}

IMPEDANCE PHASE

Winnemucca, NV $100 \mathrm{~K}$

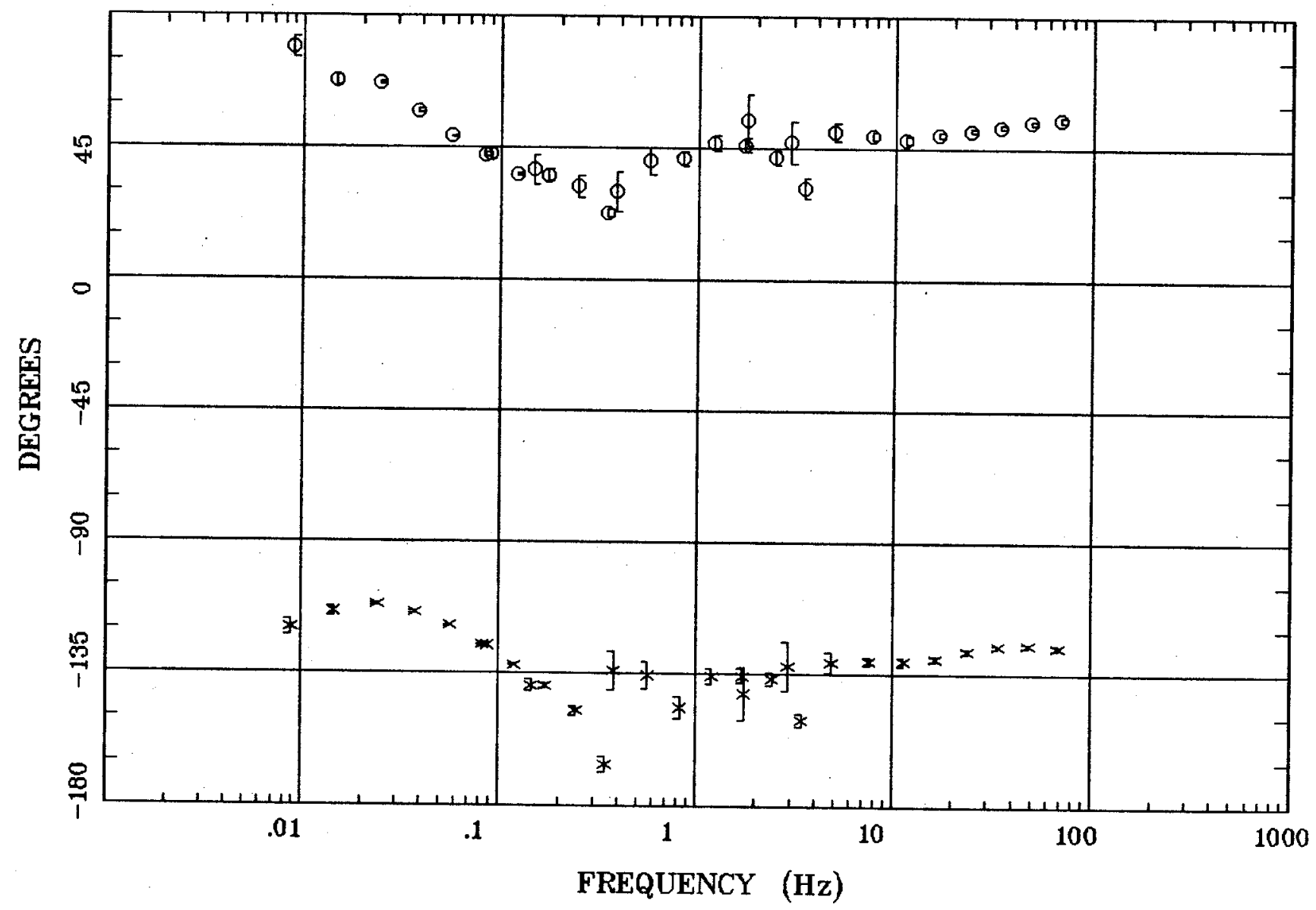

Client:

Remote: none

Acquired: 12:2 Jul 28, 2000

Survey Co:USGS
Rotation:

Filename: hr94all.avg

Channels: Ch1 Ch2 Ch3 Ch4 Ch5 Ch3 Ch4

Plotted: 11:08 Feb 06, 2001

< EMI - ElectroMagnetic Instruments > 
Station 94

ROTATION ANGLE

Winnemucca, NV $100 \mathrm{~K}$

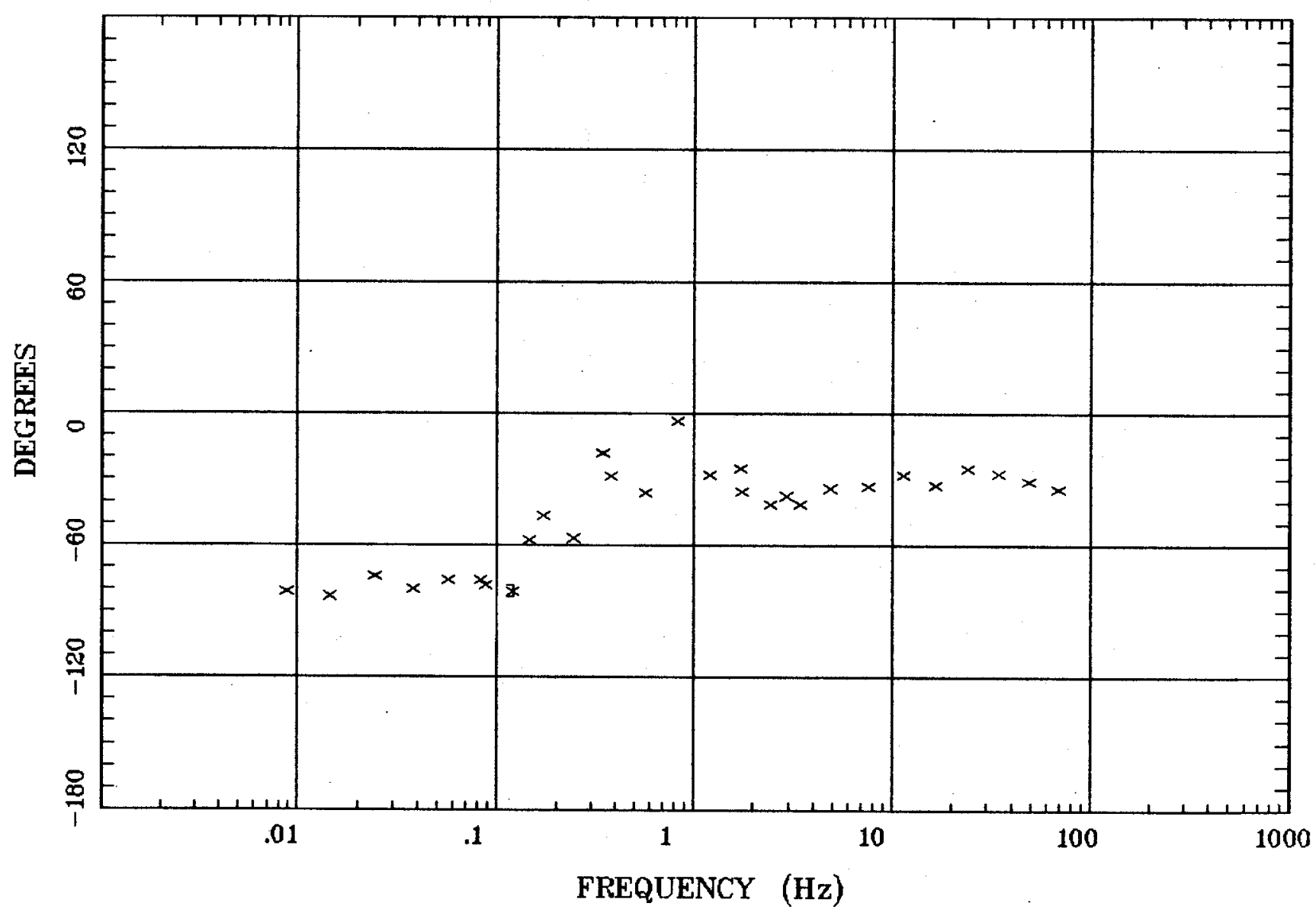

Client:

Remote: none

Acquired: 12:2 Jul 28, 2000

Survey Co:USGS
Rotation:

Filename: hr94all.avg

Channels: Ch1 Ch2 Ch3 Ch4 Ch5 Ch3 Ch4

Plotted: 11:08 Feb 06, 2001

$<$ EMI - ElectroMagnetic Instruments 
Winnemucca, NV $100 \mathrm{~K}$

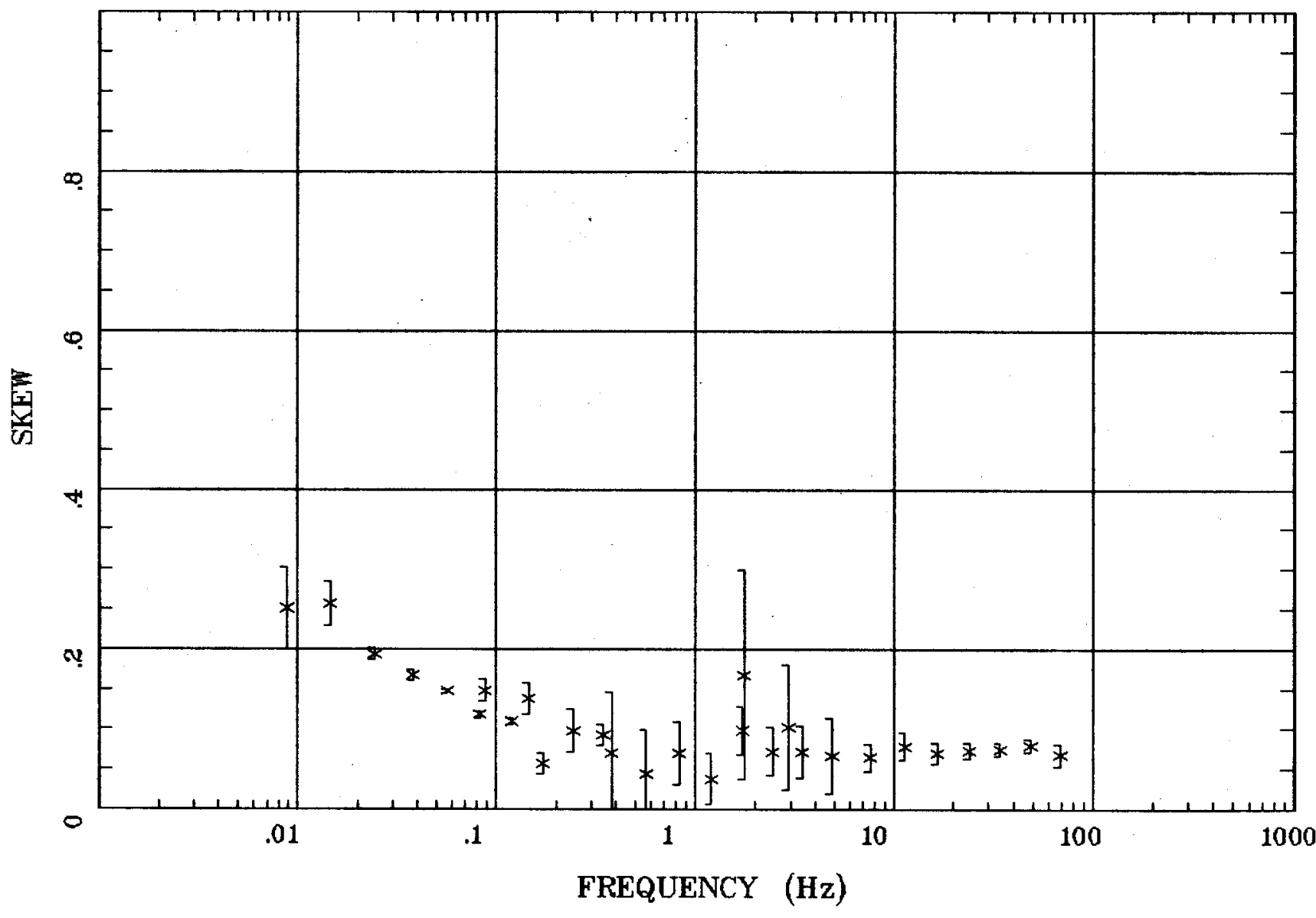

Client:

Remote: none

Acquired: 12:2 Jul 28, 2000

Survey Co:USGS
Rotation:

Filename: hr94all.avg

Channels: Ch1 Ch2 Ch3 Ch4 Ch5 Ch3 Ch4

Plotted: 11:08 Feb 06, 2001

< EMI - ElectroMagnetic Instruments 
Station 94

E MULT Coh.

Winnemucca, NV 100K

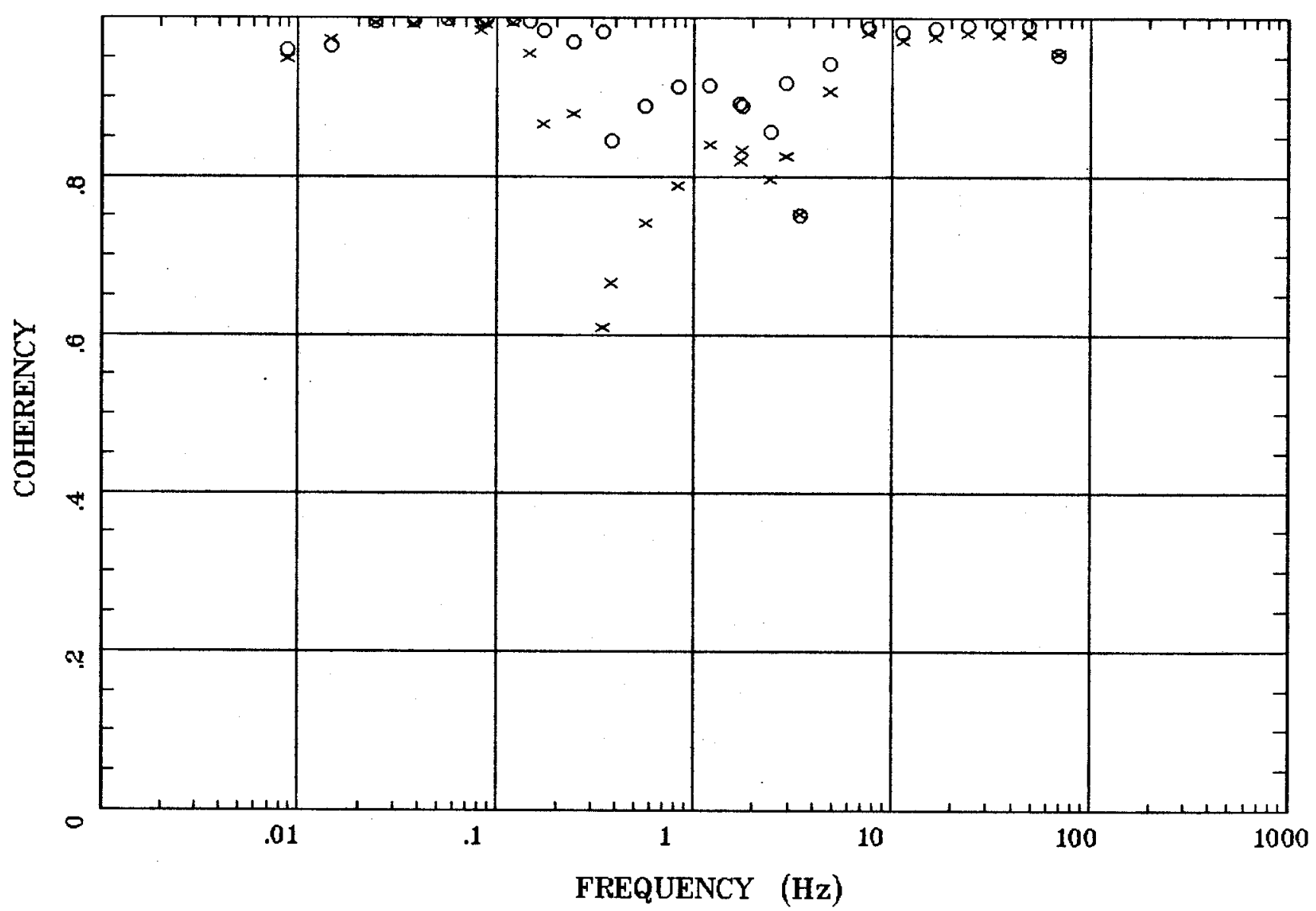

Client:

Remote: none

Acquired: 12:2 Jul 28, 2000 Survey Ca:USGS

Rotation:

Filename: hr94all.avg

Channels: Ch1 Ch2 Ch3 Ch4 Ch5 Ch3 Ch4

Plotted: 11:08 Feb 06, 2001

$<$ EMI - ElectroMagnetic Instruments 


\section{Winnemucca, NV 100K}

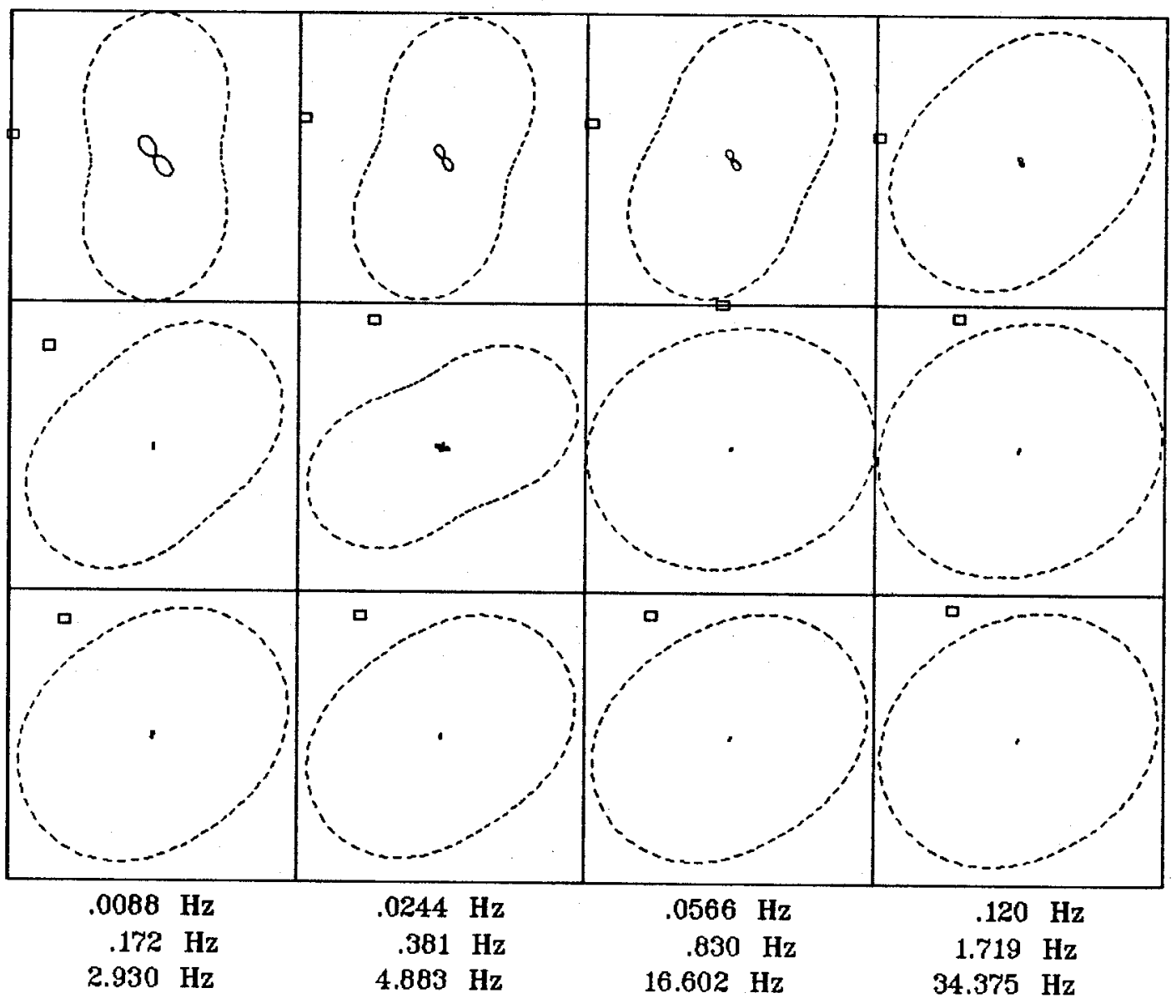

Client:

Remote: none

Acquired: 12:2 Jul 28, 2000 Survey Co:USGS
Rotation:

Filename: hr94all.avg

Channels: Ch1 Ch2 Ch3 Ch4 Ch5 Ch3 Ch4 Plotted: 11:08 Feb 06, 2001

$<$ EMI - ElectroMagnetic Instruments > 
Station 94

Winnemucca, NV $100 \mathrm{~K}$

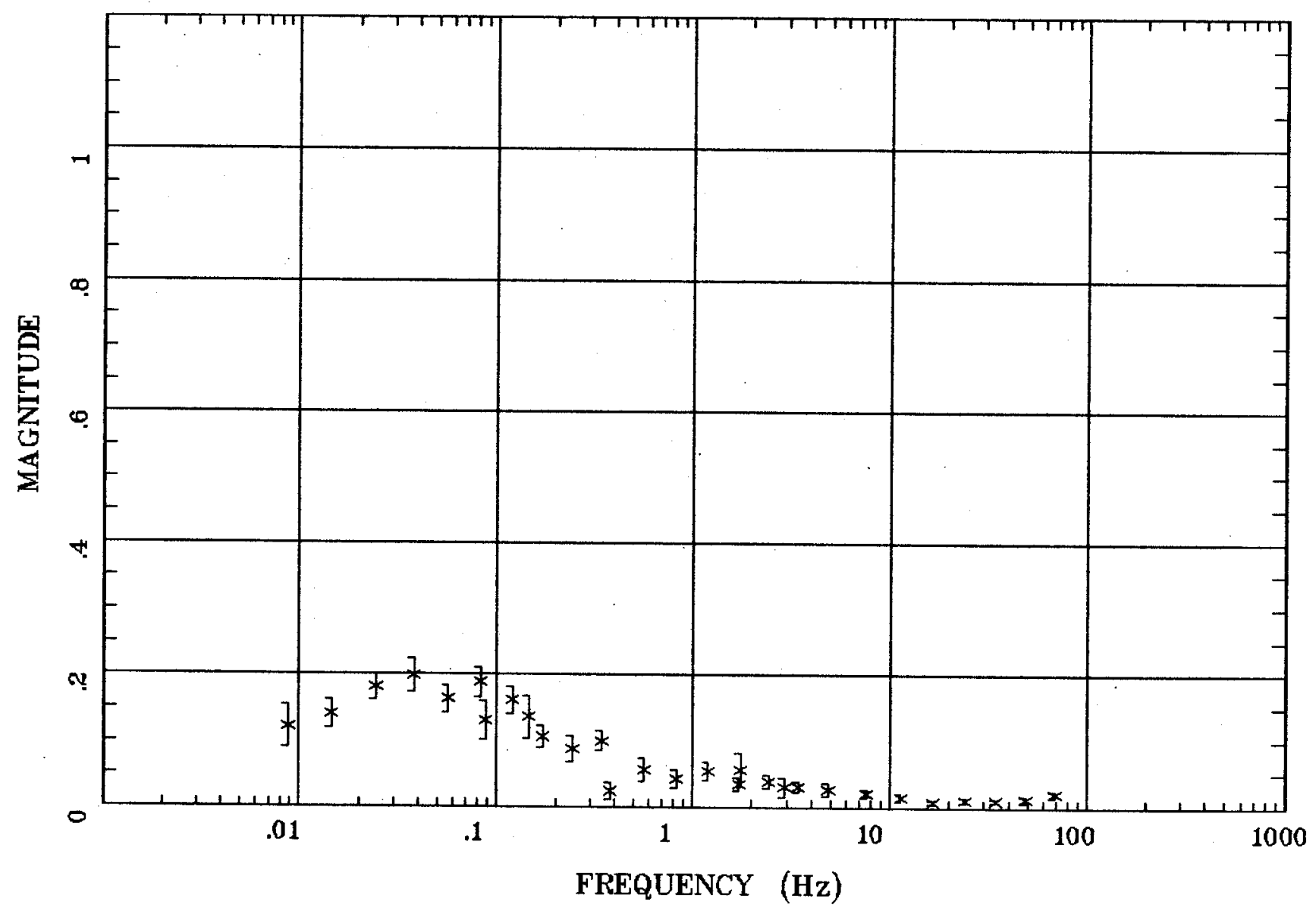

Client:

Remote: none

Acquired: 12:2 Jul 28, 2000

Survey Co:USGS
Rotation:

Filename: hr94all.avg

Channels: Ch1 Ch2 Ch3 Ch4 Ch5 Ch3 Ch4 Plotted: 11:08 Feb 06, 2001

< EMI - ElectroMagnetic Instruments > 
TIPPER STRIKE

Winnemucca, NV 100K

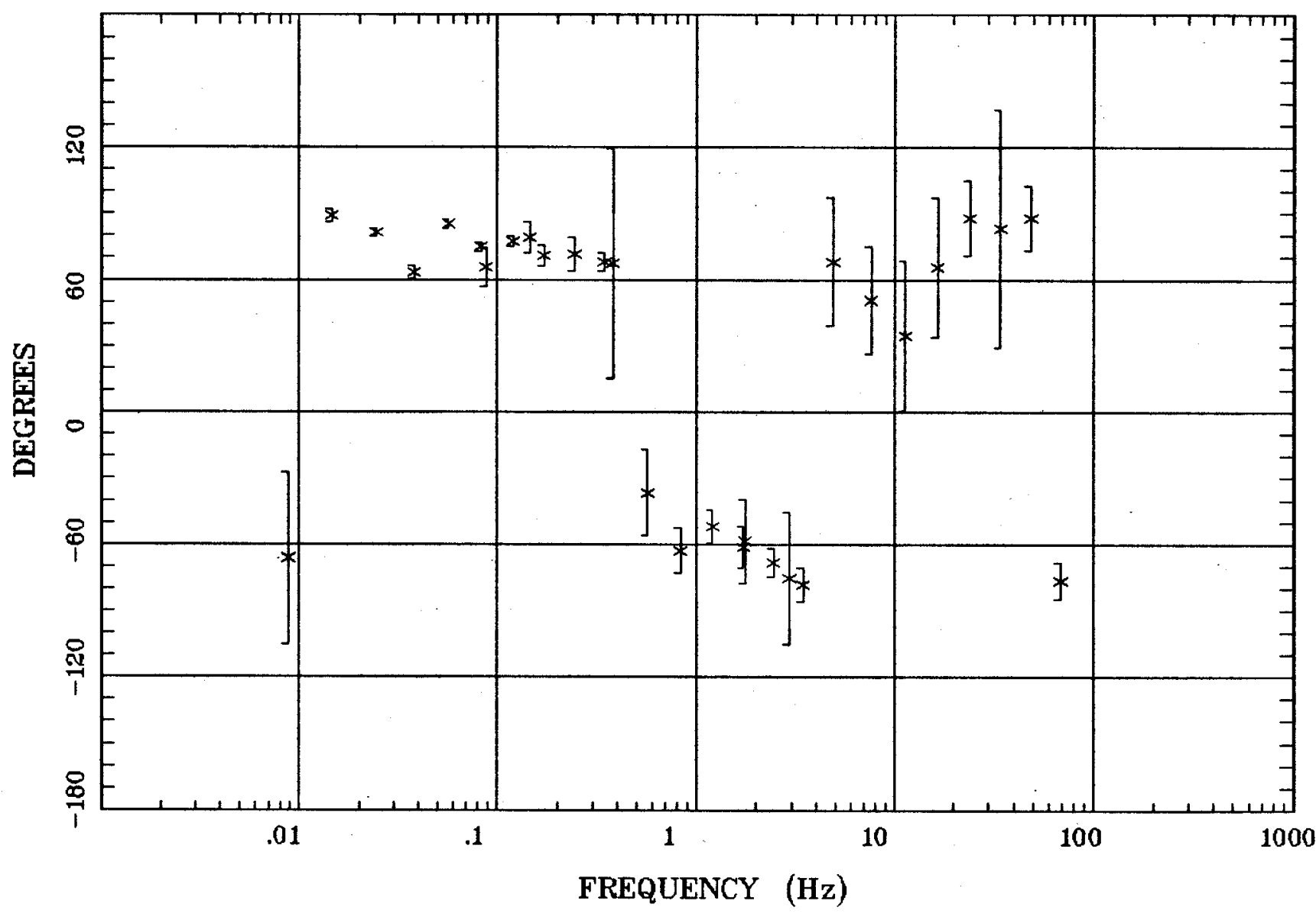

Client:

Remote: none

Acquired: $12: 2$ Jul 28, 2000

Survey Co:USGS
Rotation:

Filename: hr94all.avg

Channels: Ch1 Ch2 Ch3 Ch4 Ch5 Ch3 Ch4

Plotted: 11:08 Feb 06, 2001

$<$ EMI - ElectroMagnetic Instruments > 


\section{HzHx.x Coh HzHy.o}

Station 94

Winnemucca, NV 100K

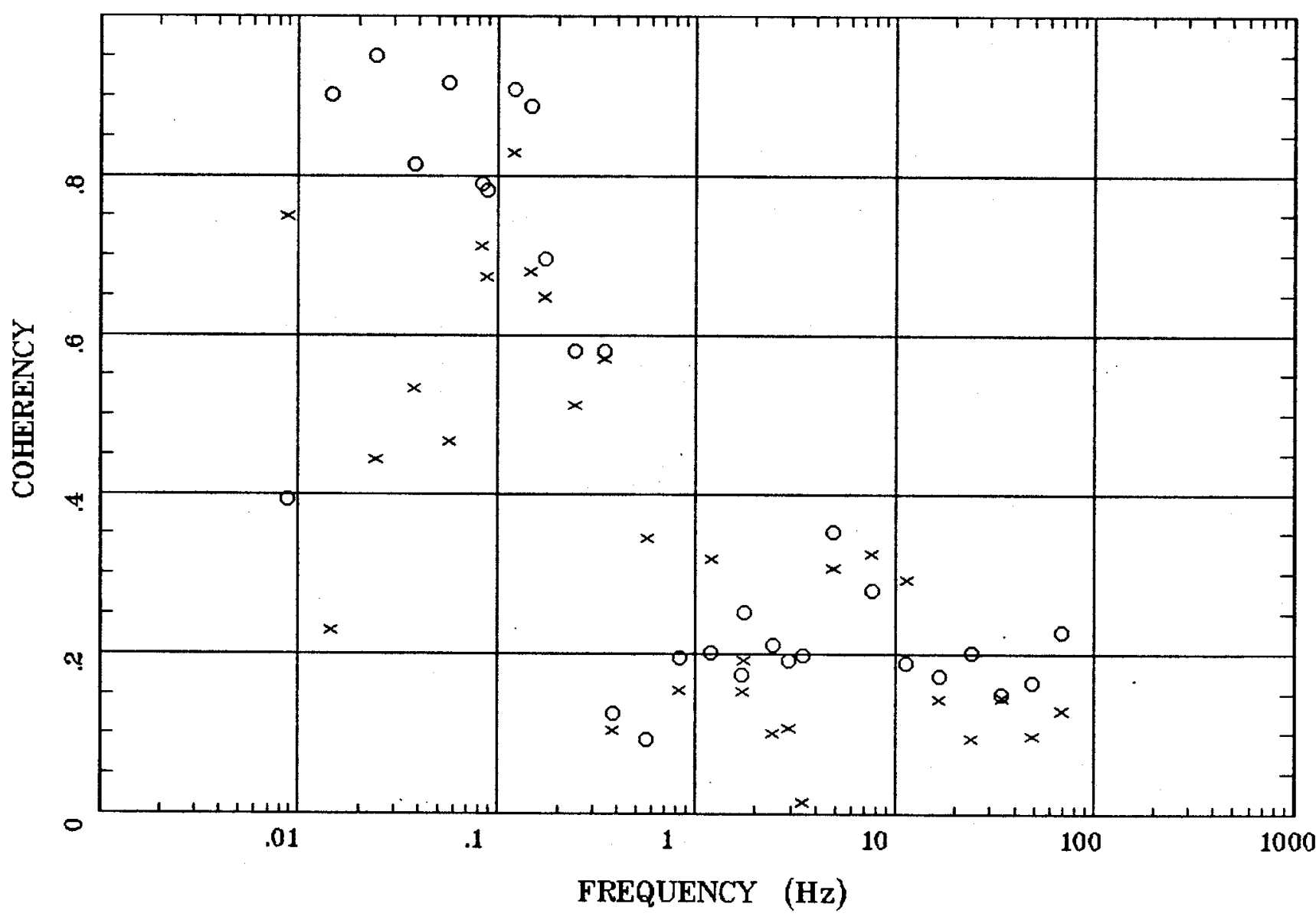

Client:

Remote: none

Acquired: 12:2 Jul 28, 2000

Survey Co:USGS
Rotation:

Filename: hr94all.avg

Channels: Ch1 Ch2 Ch3 Ch4 Ch5 Ch3 Ch4

Plotted: 11:08 Feb 06, 2001

< EMI - ElectroMagnetic Instruments 
APPARENT RESISTIVITY Osgood Mtns, NV 100K

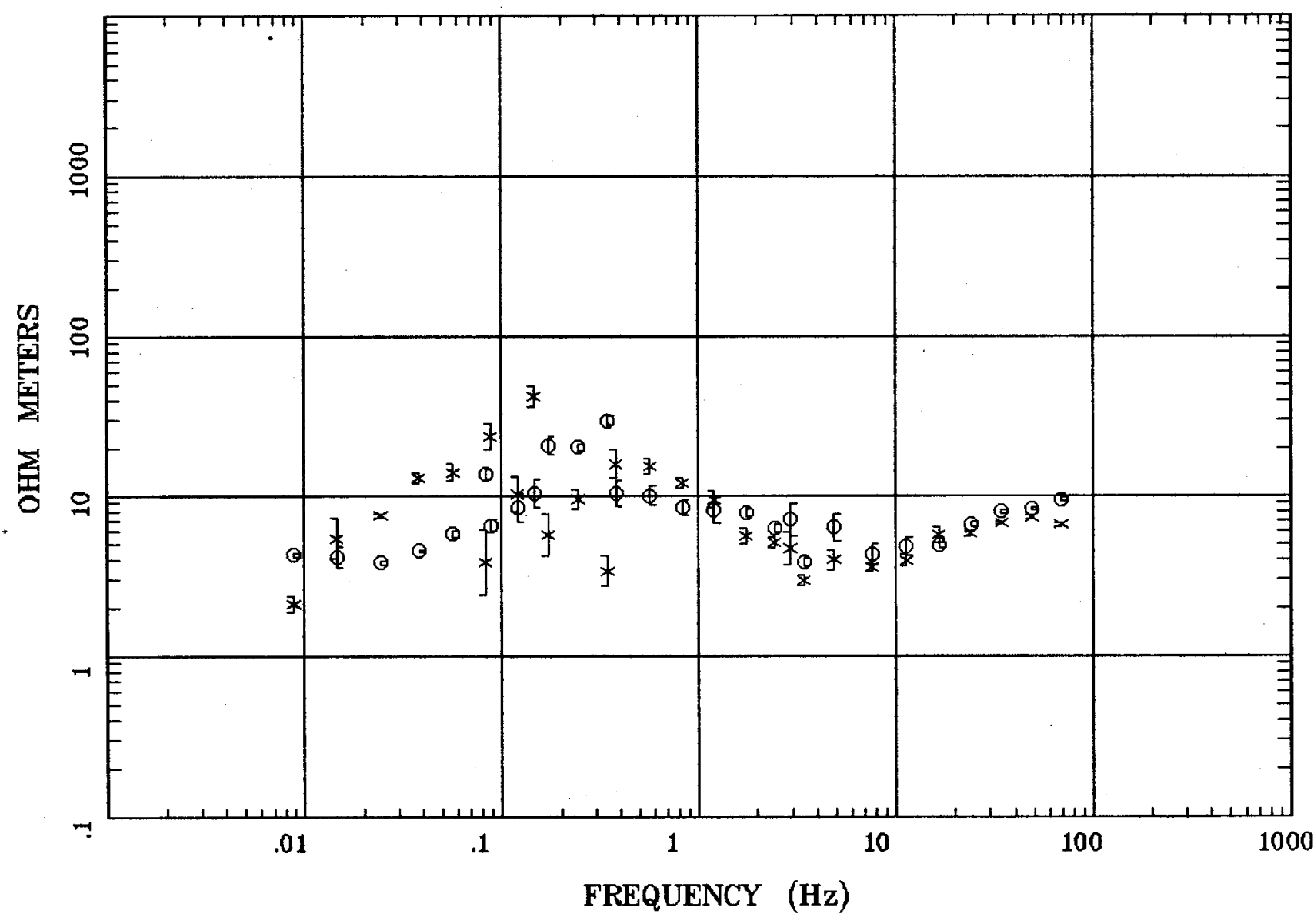

Client:

Remote: none

Acquired: 14:4 Jul 22, 2000

Survey Co:USGS
Rotation:

Filename: hr49a.avg

Channels: Ch1 Ch2 Ch3 Ch4 Ch5 Ch3 Ch4

Plotted: 11:06 Feb 06, 2001

< EMI - ElectroMagnetic Instruments > 
IMPEDANCE PHASE

Osgood Mtns, NV 100K

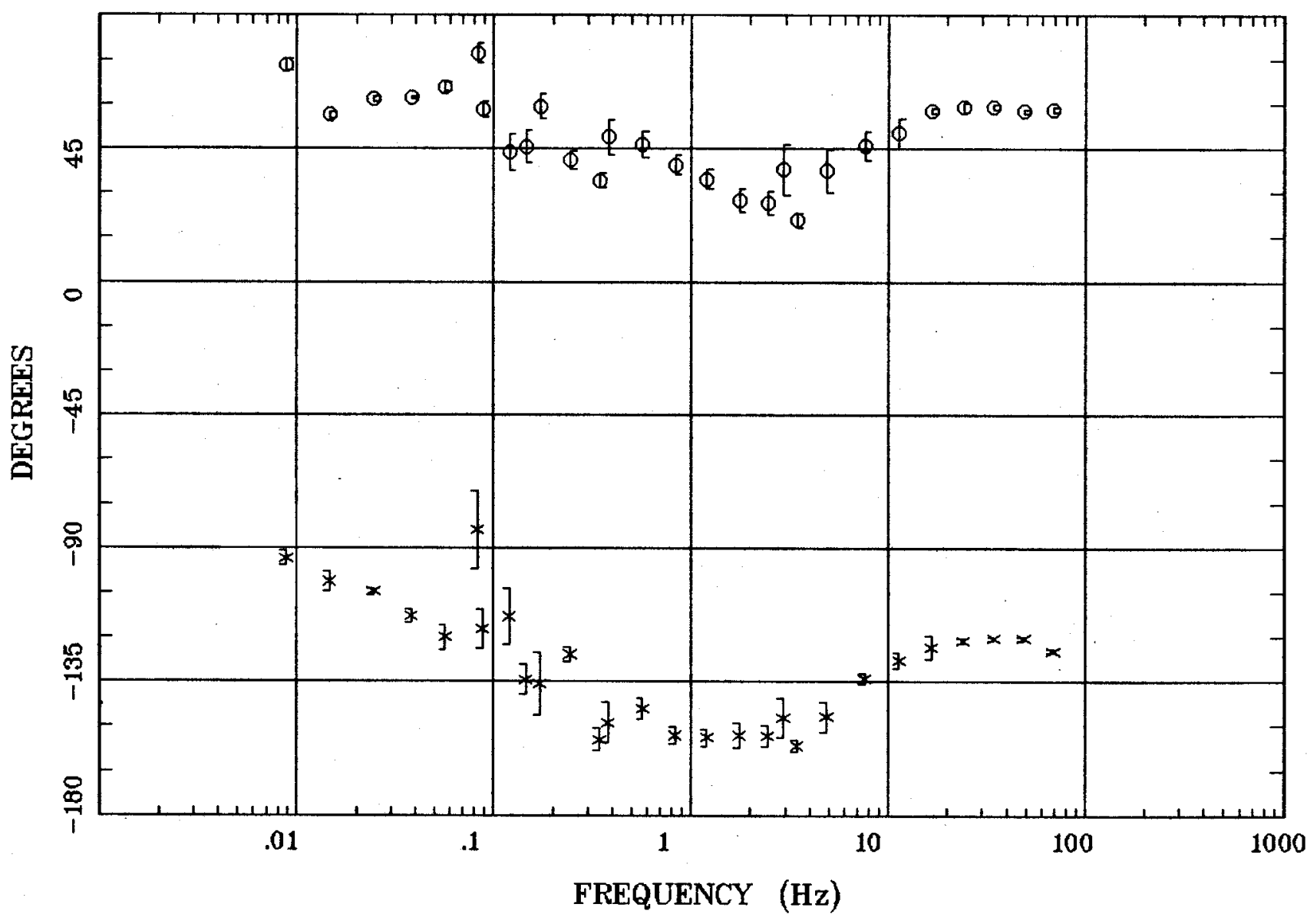

Client:

Remote: none

Acquired: 14:4 Jul 22, 2000

Survey Co:USGS
Rotation:

Filename: hr49a.avg

Channels: Ch1 Ch2 Ch3 Ch4 Ch5 Ch3 Ch4

Plotted: 11:06 Feb 06, 2001

< EMI - ElectroMagnetic Instruments > 
Osgood Mtns, NV 100K

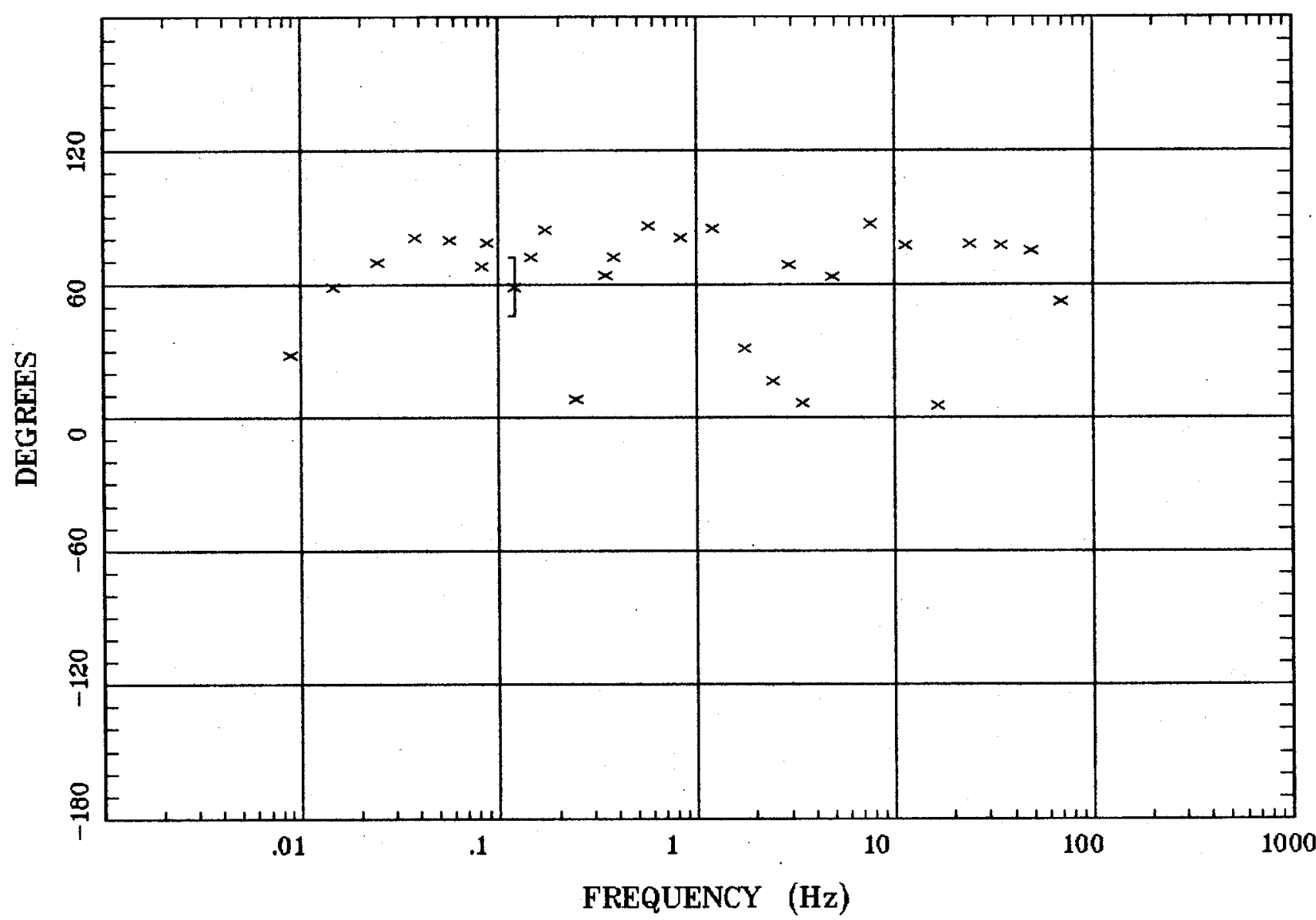

Client:

Remote: none

Acquired: 14:4 Jul 22, 2000 Survey Co:USGS
Rotation:

Filename: hr49a.avg

Channels: Ch1 Ch2 Ch3 Ch4 Ch5 Ch3 Ch4 Plotted: 11:06 Feb 06, 2001

$<$ EMI - ElectroMagnetic Instruments 
IMPEDANCE SKEW

Osgood Mtns, NV 100K

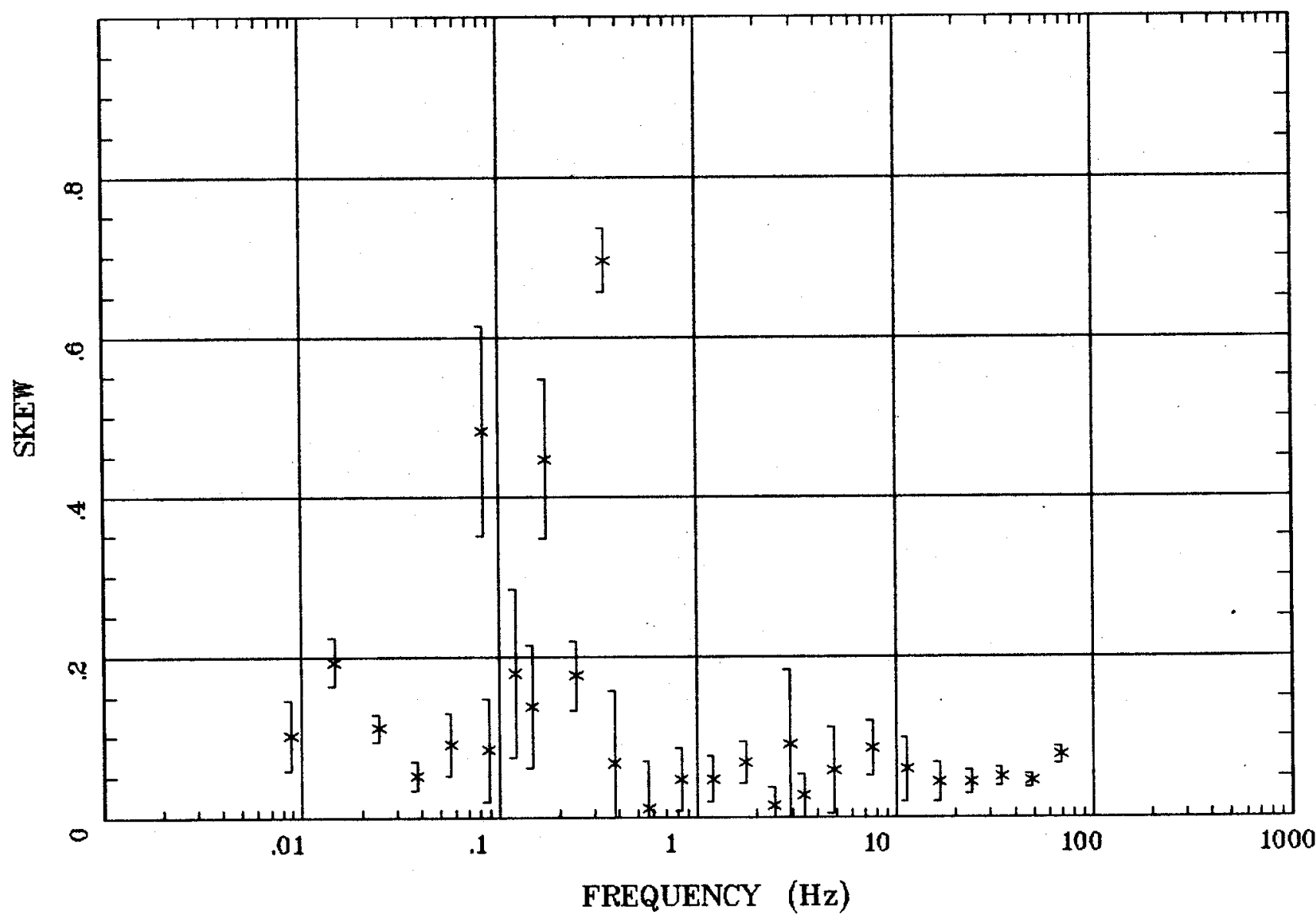

Client:

Remote: none

Acquired: 14:4 Jul 22, 2000

Survey Co:USGS
Rotation:

Filename: hr49a.avg

Channels: Ch1 Ch2 Ch3 Ch4 Ch5 Ch3 Ch4 Plotted: 11:06 Feb 06, 2001

$<$ EMI - ElectroMagnetic Instruments 
E MULT Coh.

Osgood Mtns, NV 100K

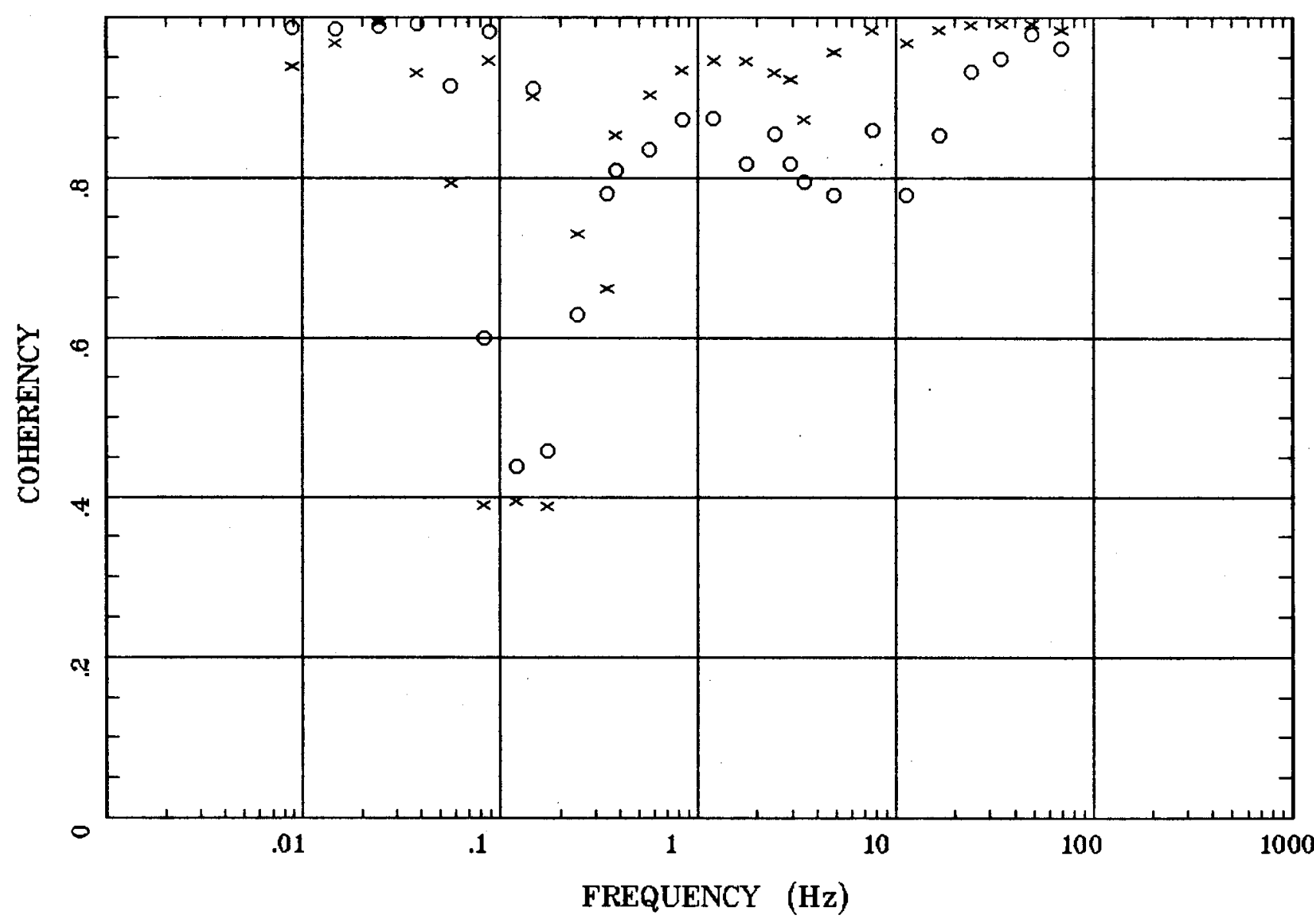

Client:

Remote: none

Acquired: 14:4 Jul 22, 2000 Survey Co:USGS
Rotation:

Filename: hr49a.avg

Channels: Ch1 Ch2 Ch3 Ch4 Ch5 Ch3 Ch4 Plotted: 11:06 Feb 06, 2001

$<$ EMI - ElectroMagnetic Instruments 


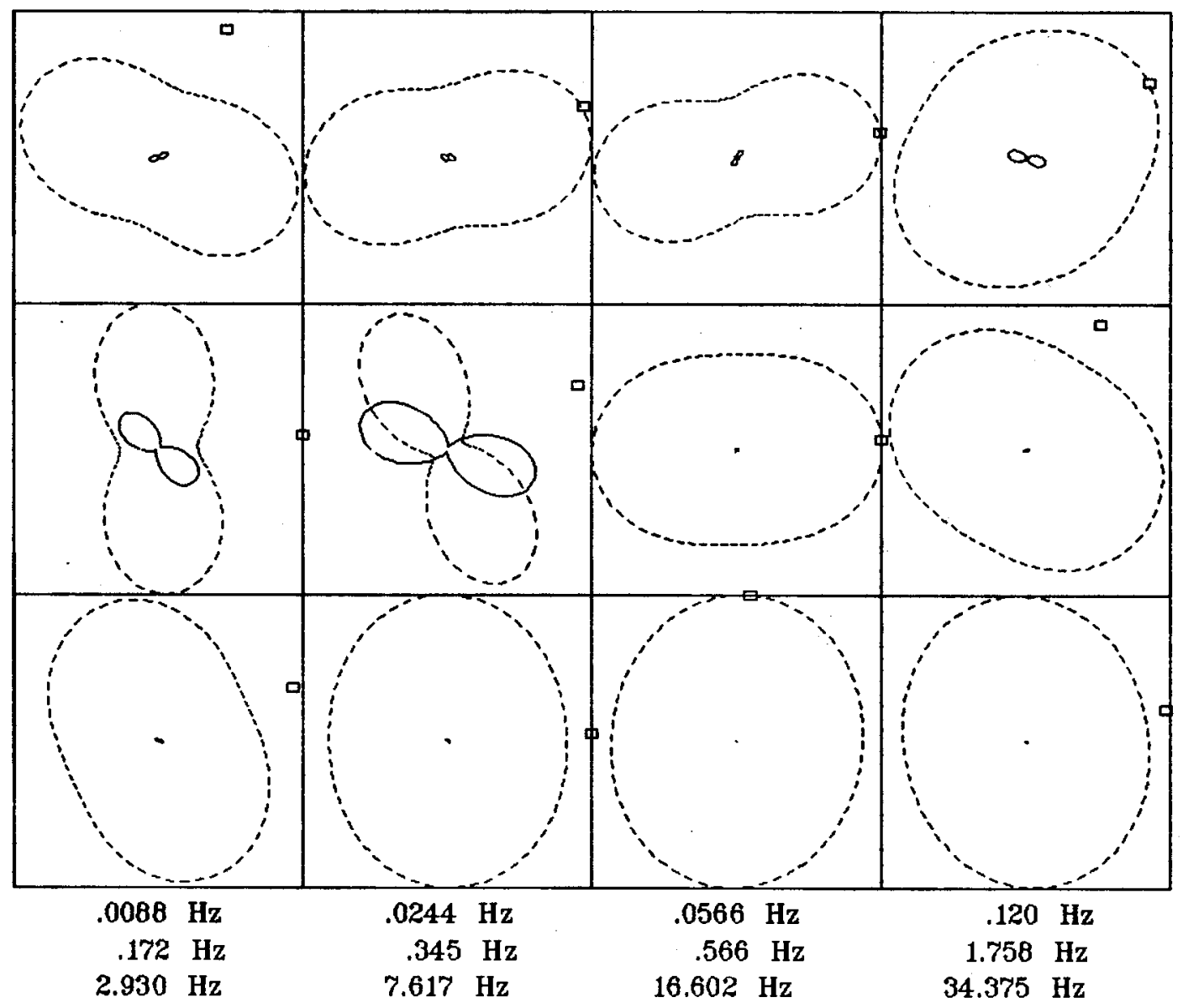

Client:

Remote: none

Acquired: 14:4 Jul 22, 2000 Survey Co:USGS
Rotation:

Filename: hr49a.avg

Channels: Ch1 Ch2 Ch3 Ch4 Ch5 Ch3 Ch4 Plotted: 11:06 Feb 06, 2001

$<$ EMI - ElectroMagnetic Instruments > 
Station 49

TIPPER MAGNITUDE

Osgood Mtns, NV 100K

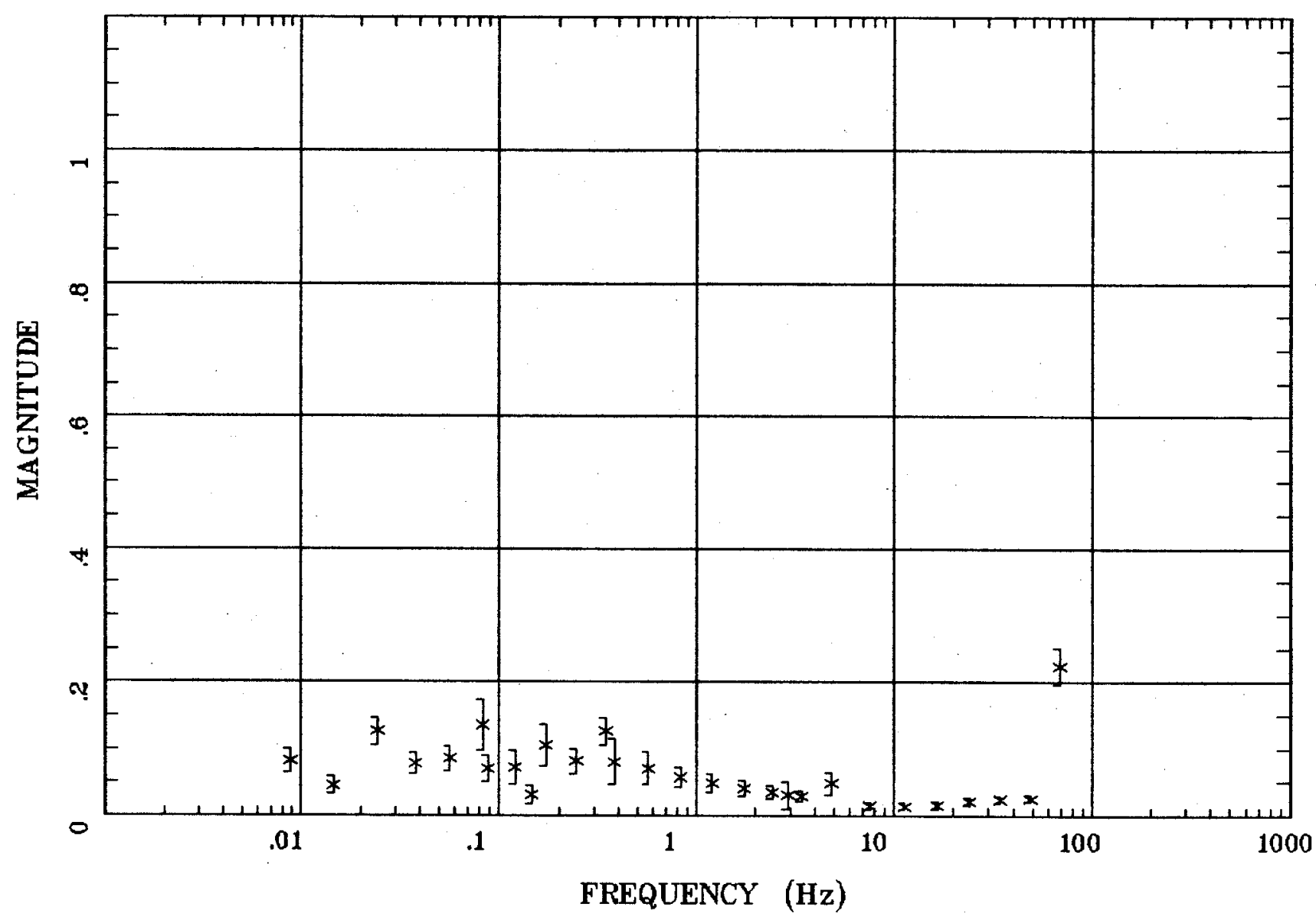

Client:

Remote: none

Acquired: 14:4 Jul 22, 2000

Survey Co:USGS
Rotation:

Filename: hr49a.avg

Channels: Ch1 Ch2 Ch3 Ch4 Ch5 Ch3 Ch4

Plotted: 11:06 Feb 06, 2001

< EMI - ElectroMagnetic Instruments > 
TIPPER STRIKE

Osgood Mtns, NV 100K

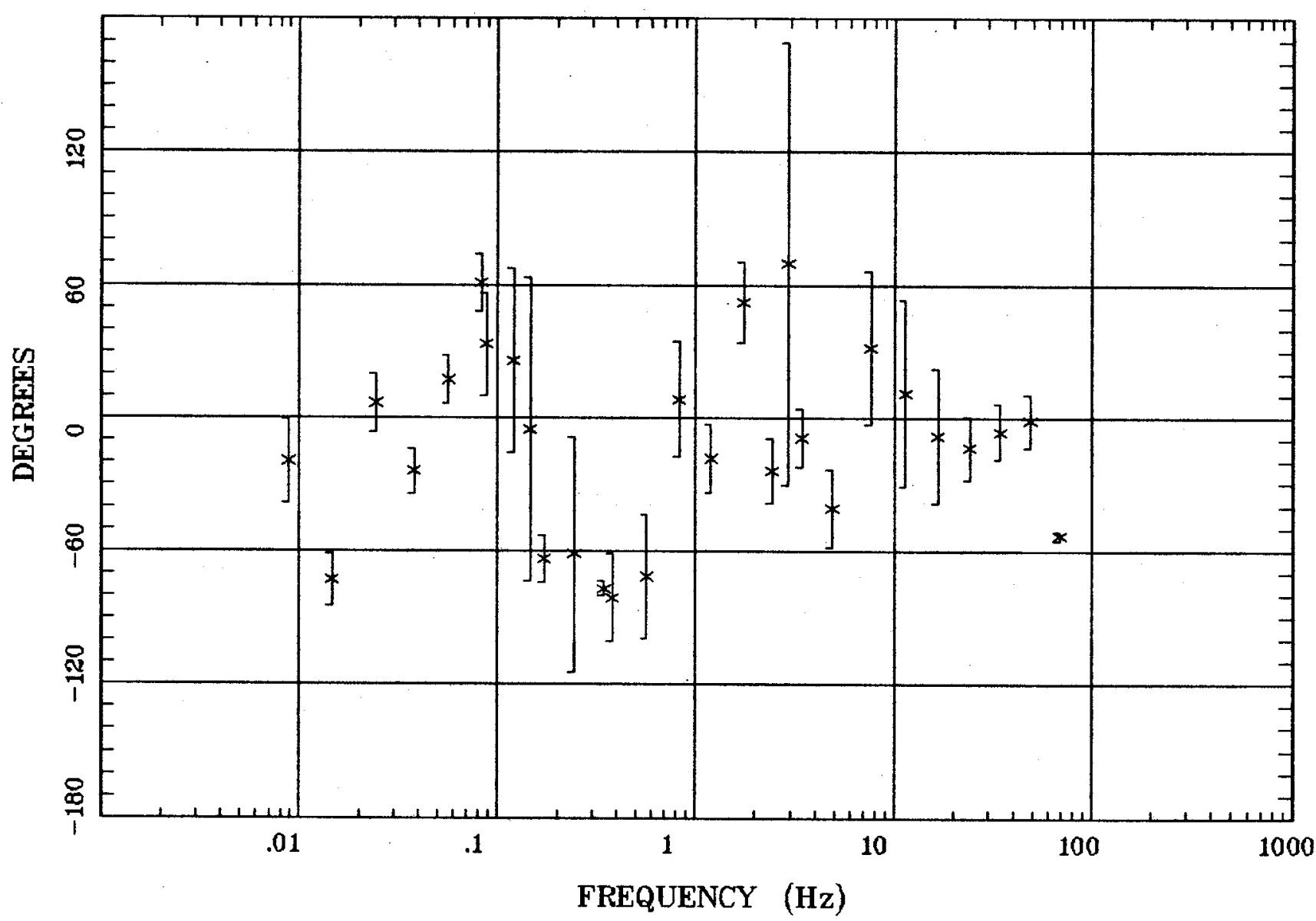

Client:

Remote: none

Acquired: 14:4 Jul 22, 2000

Survey Ca:USGS
Rotation:

Filename: hr49a.avg

Channels: Ch1 Ch2 Ch3 Ch4 Ch5 Ch3 Ch4 Plotted: 11:06 Feb 06, 2001

$<$ EMI - ElectroMagnetic Instruments 
HzHx.x Coh HzHy.o

Osgood Mtns, NV 100K

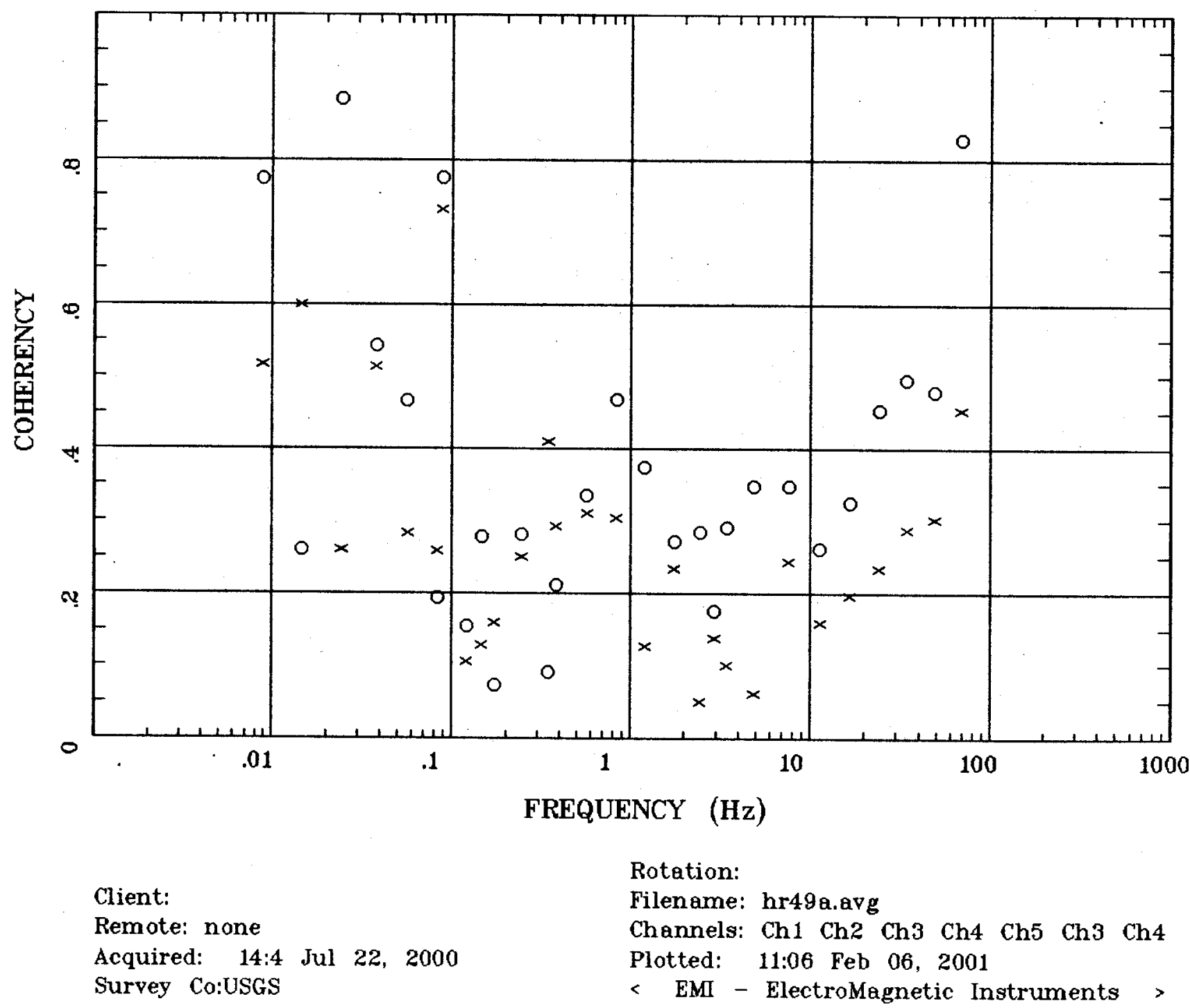




\section{APPARENT RESISTIVITY}

Osgood Mtns, NV 100K

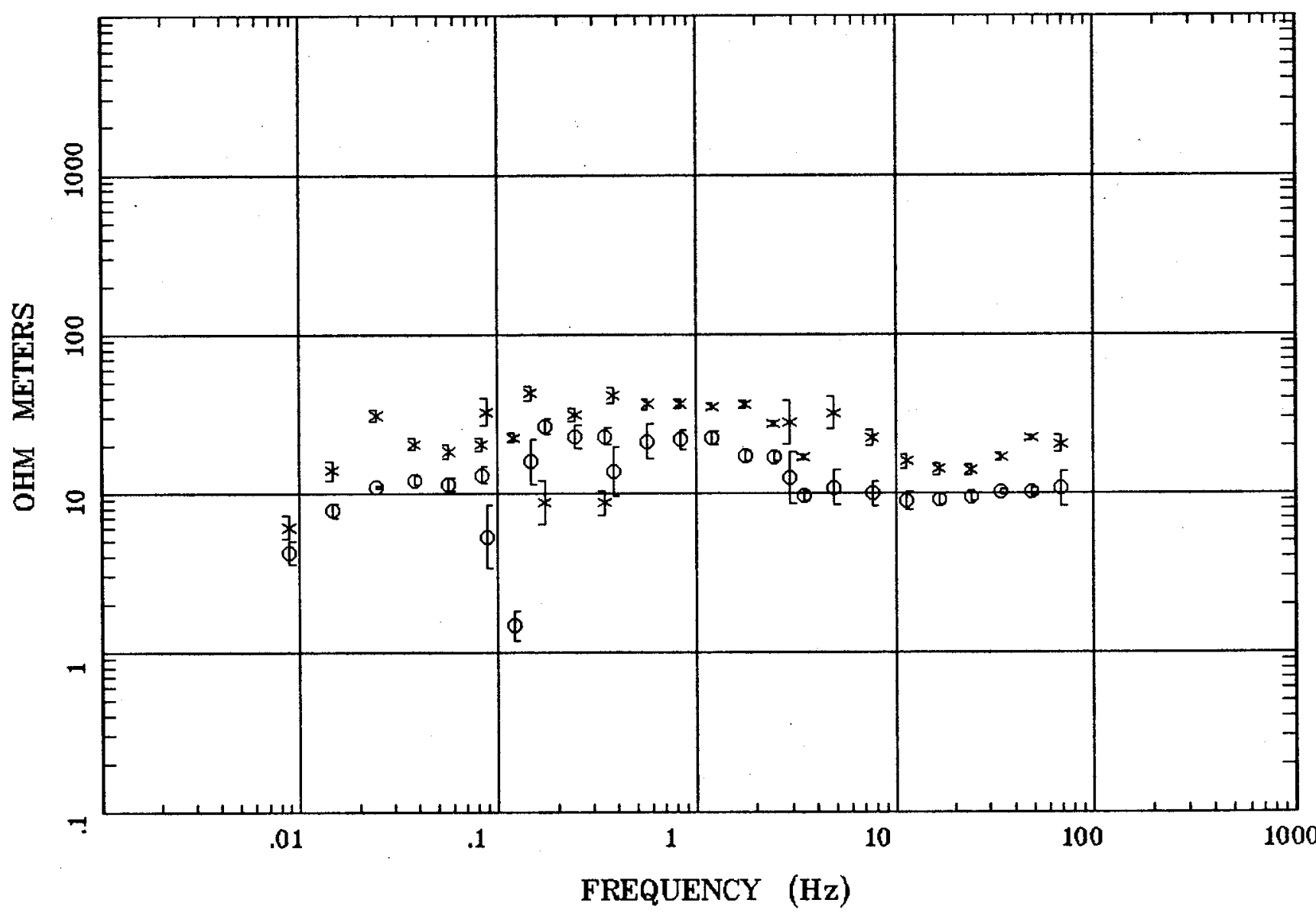

Client:

Remote: none

Acquired: 10:1 Jul 29, 2000

Survey Co:USGS
Rotation:

Filename: hr95b.avg

Channels: Ch1 Ch2 Ch3 Ch4 Ch5 Ch3 Ch4 Plotted: 11:09 Feb 06, 2001

< EMI - ElectroMagnetic Instruments $>$ 


\section{Station 95}

IMPEDANCE PHASE

Osgood Mtns, NV 100K

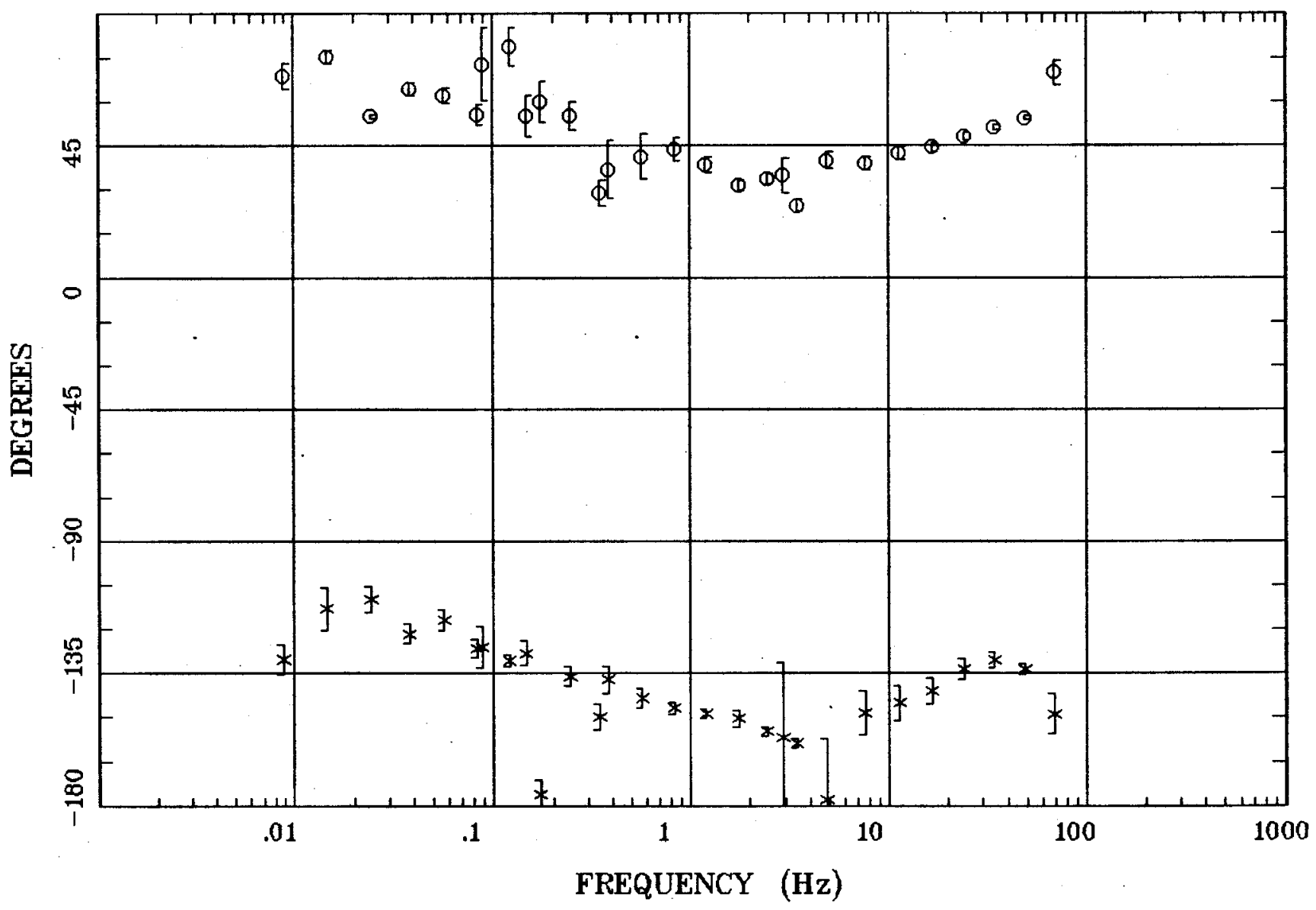

Client:

Remote: none

Acquired: 10:1 Jul 29, 2000

Survey Co:USGS

Rotation:

Filename: hr95b.avg

Channels: Ch1 Ch2 Ch3 Ch4 Ch5 Ch3 Ch4

Plotted: 11:09 Feb 06, 2001

< EMI - ElectroMagnetic Instruments > 
ROTATION ANGLE

Osgood Mtns, NV 100K

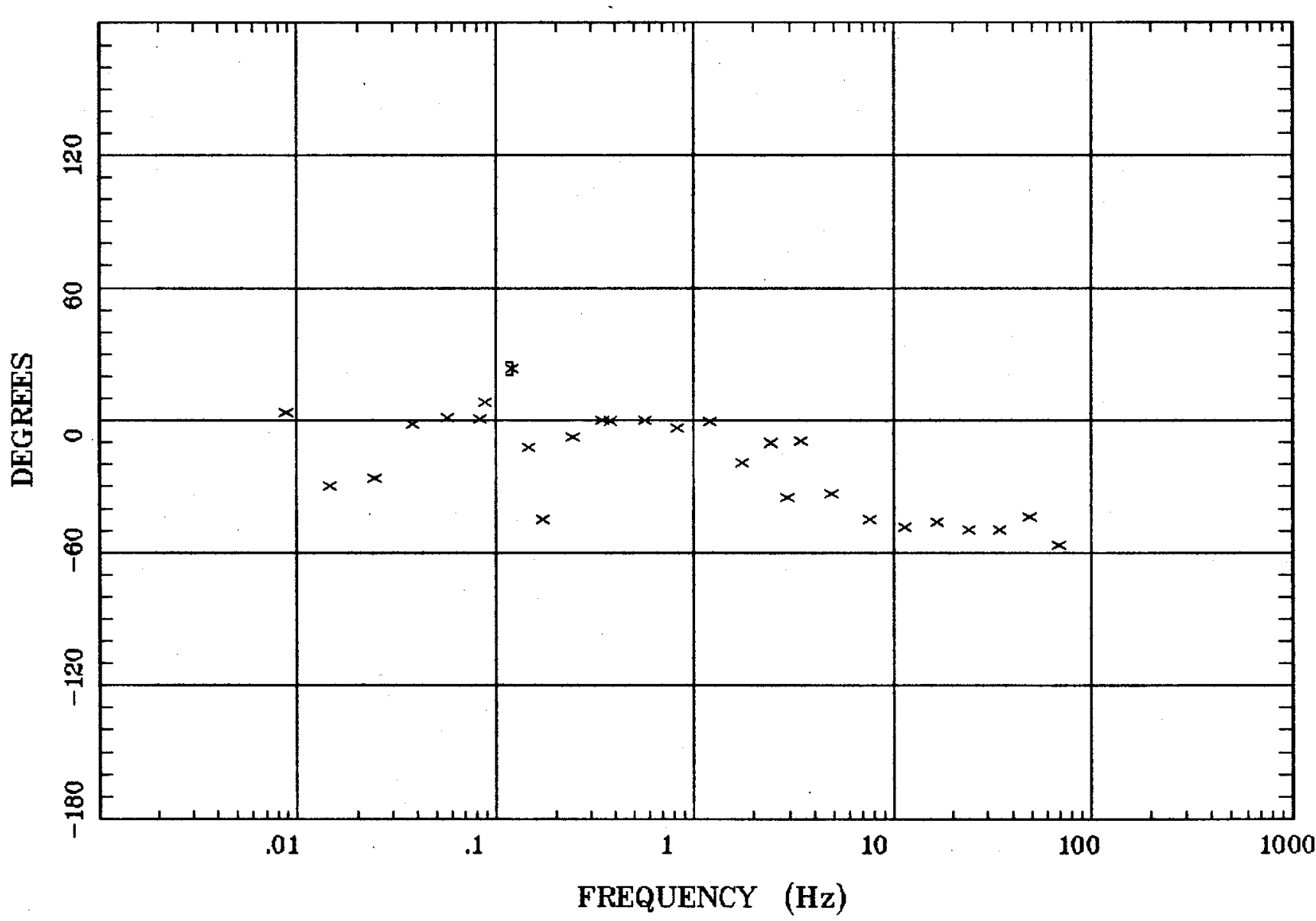

Client:

Remote: none

Acquired: 10:1 Jul 29, 2000

Survey Co:USGS
Rotation:

Filename: hr95b.avg

Channels: Ch1 Ch2 Ch3 Ch4 Ch5 Ch3 Ch4

Plotted: 11:09 Feb 06, 2001

$<$ EMI - ElectroMagnetic Instruments > 


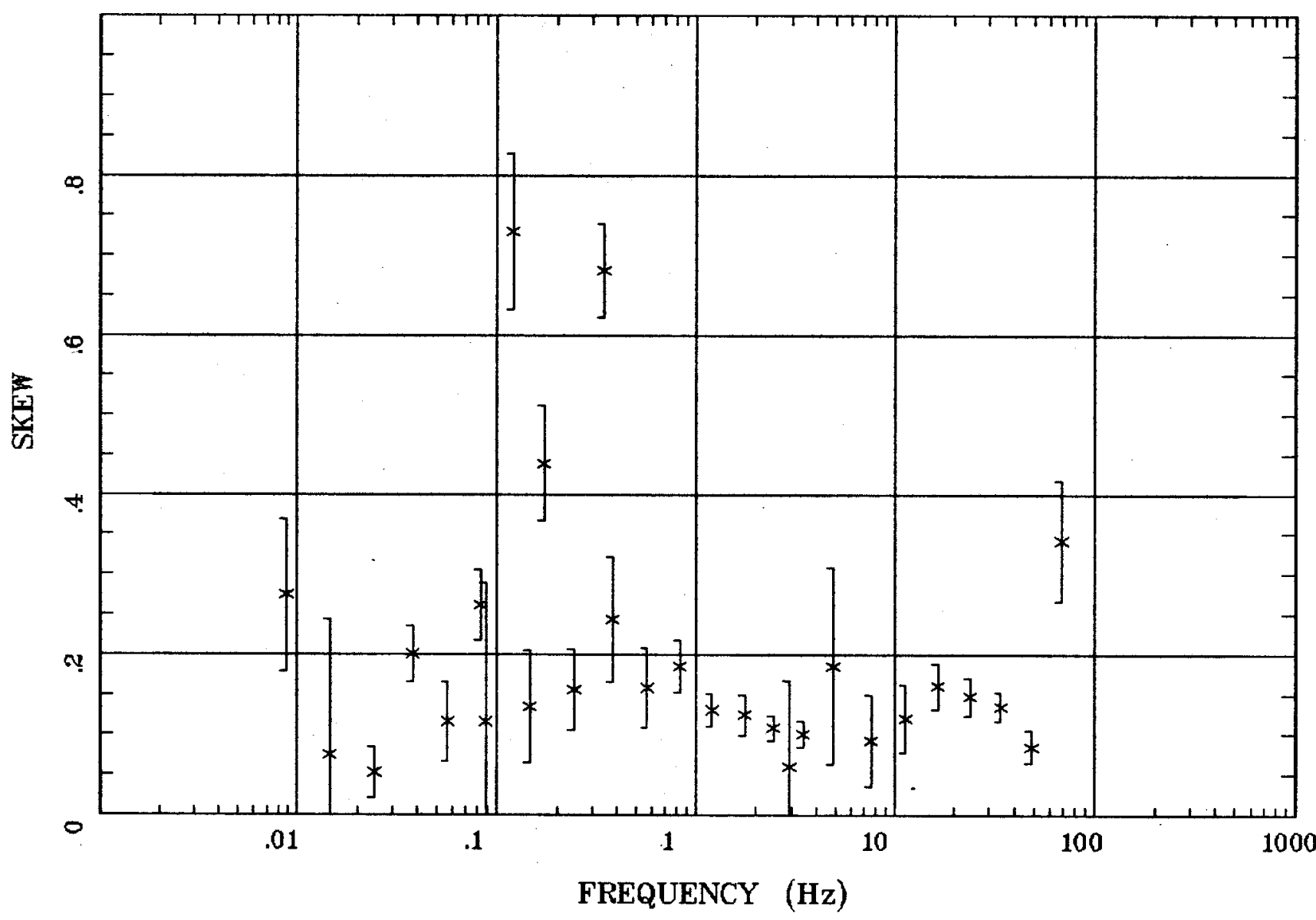

Client:

Remote: none

Acquired: 10:1 Jul 29, 2000

Survey Co:USGS
Rotation:

Filename: hr95b.avg

Channels: Ch1 Ch2 Ch3 Ch4 Ch5 Ch3 Ch4

Plotted: 11:09 Feb 06, 2001

< EMI - ElectroMagnetic Instruments 
Station 95

E MULT Coh.

Osgood Mtns, NV 100K

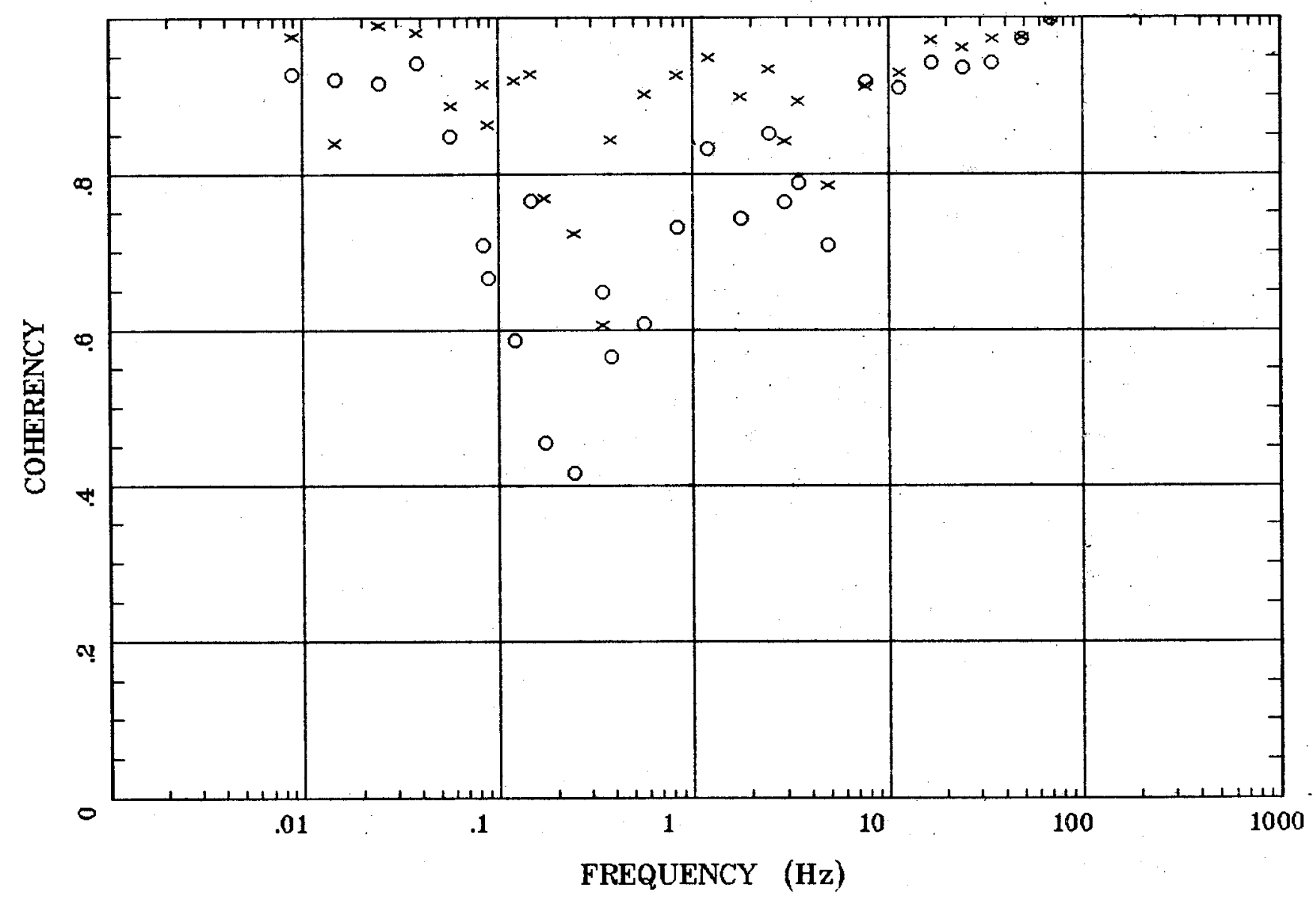

Client:

Remote: none

Acquired: 10:1 Jul 29, 2000

Survey Co:USGS

Rotation:

Filename: hr95b.avg

Channels: Ch1 Ch2 Ch3 Ch4 Ch5 Ch3 Ch4

Plotted: 11:09 Feb 06, 2001

< EM - ElectroMagnetic Instruments > 
Station 95

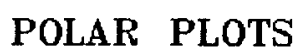

Osgood Mtns, NV 100K

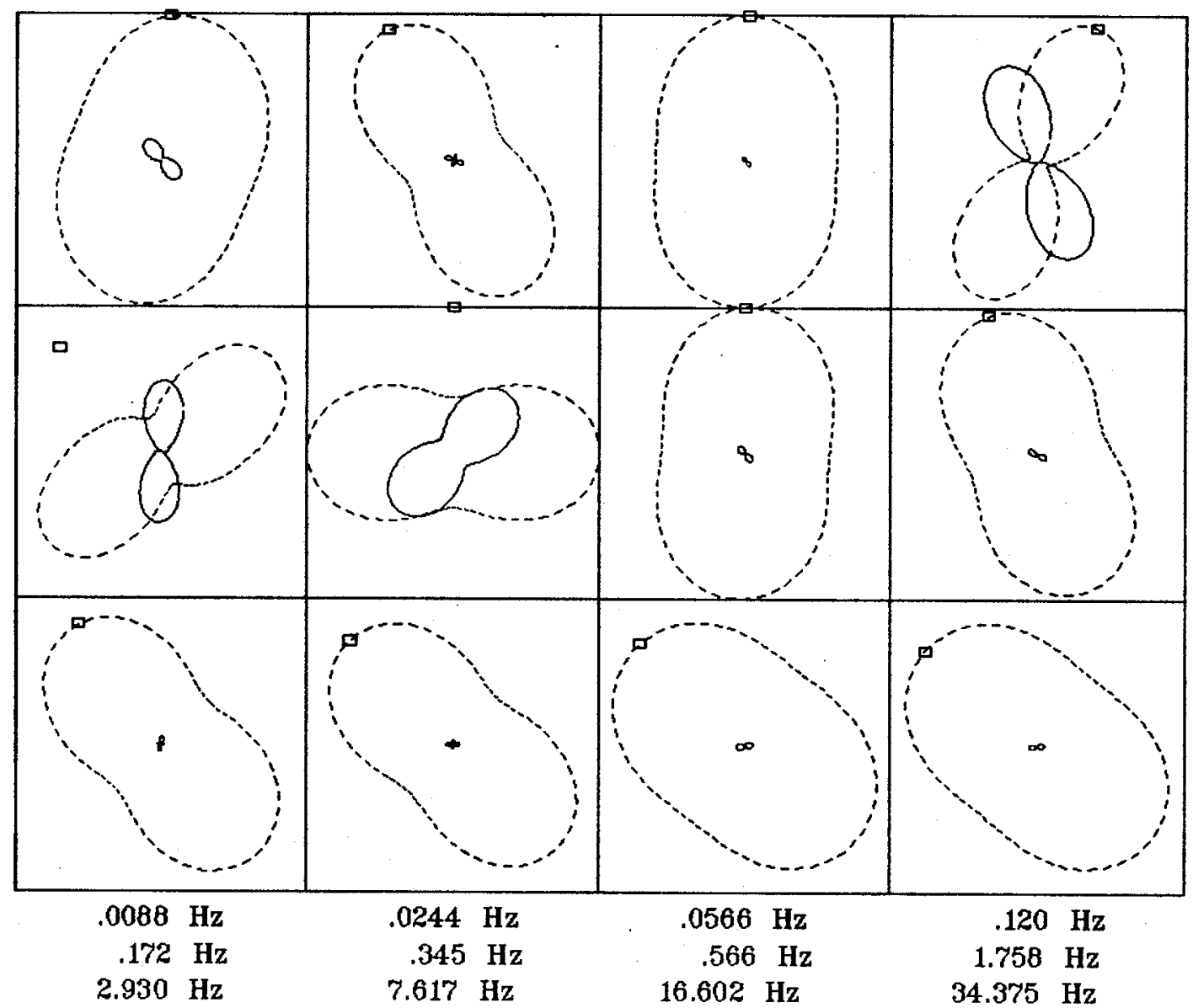

Client:

Remote: none

Acquired: 10:1 Jul 29, 2000

Survey Co:USGS
Rotation:

Filename: hr95b.avg

Channels: Ch1 Ch2 Ch3 Ch4 Ch5 Ch3 Ch4

Plotted: 11:09 Feb 06, 2001

< EMI - ElectroMagnetic Instruments > 
Station 95

TIPPER MAGNITUDE

Osgood Mtns, NV 100K

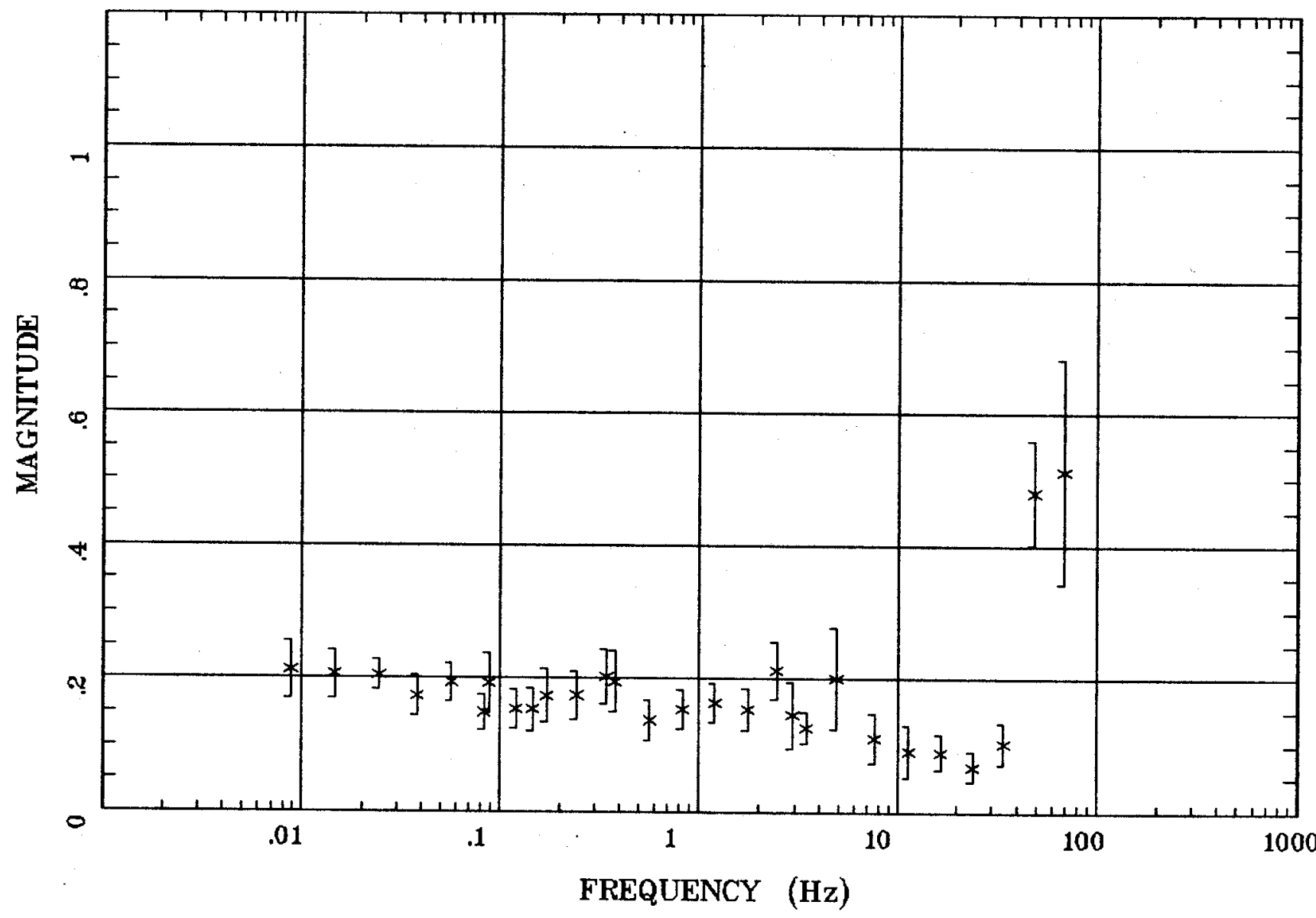

Client:

Remote: none

Acquired: 10:1 Jul 29, 2000

Survey Co:USGS
Rotation:

Filename: hr95b.avg

Channels: Ch1 Ch2 Ch3 Ch4 Ch5 Ch3 Ch4 Plotted: 11:09 Feb 06, 2001

$<$ EMI - ElectroMagnetic Instruments 


\section{Station 95}

TIPPER STRIKE

Osgood Mtns, NV 100K

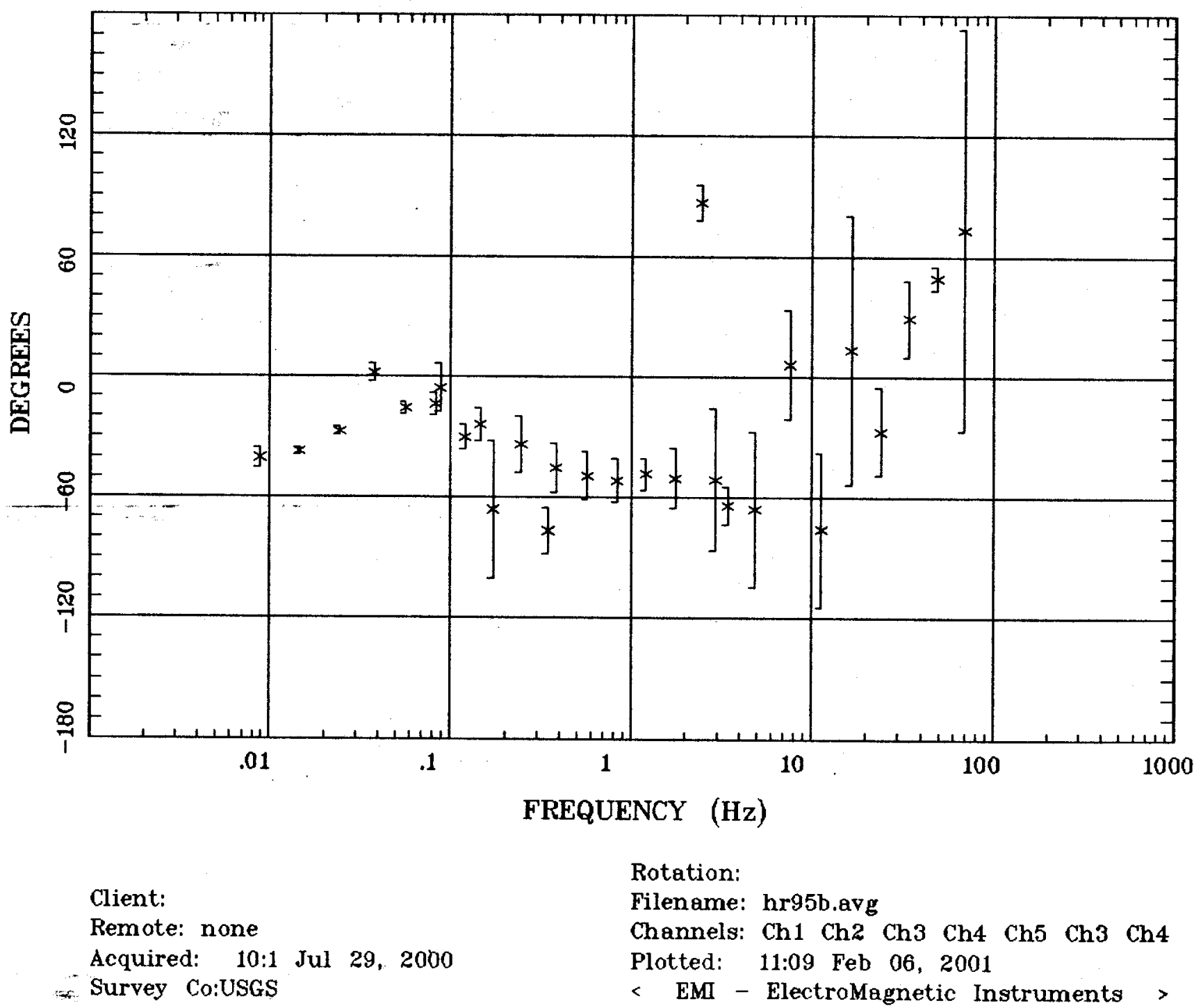


HzHx.x Coh HzHy.o

Osgood Mtns, NV 100K

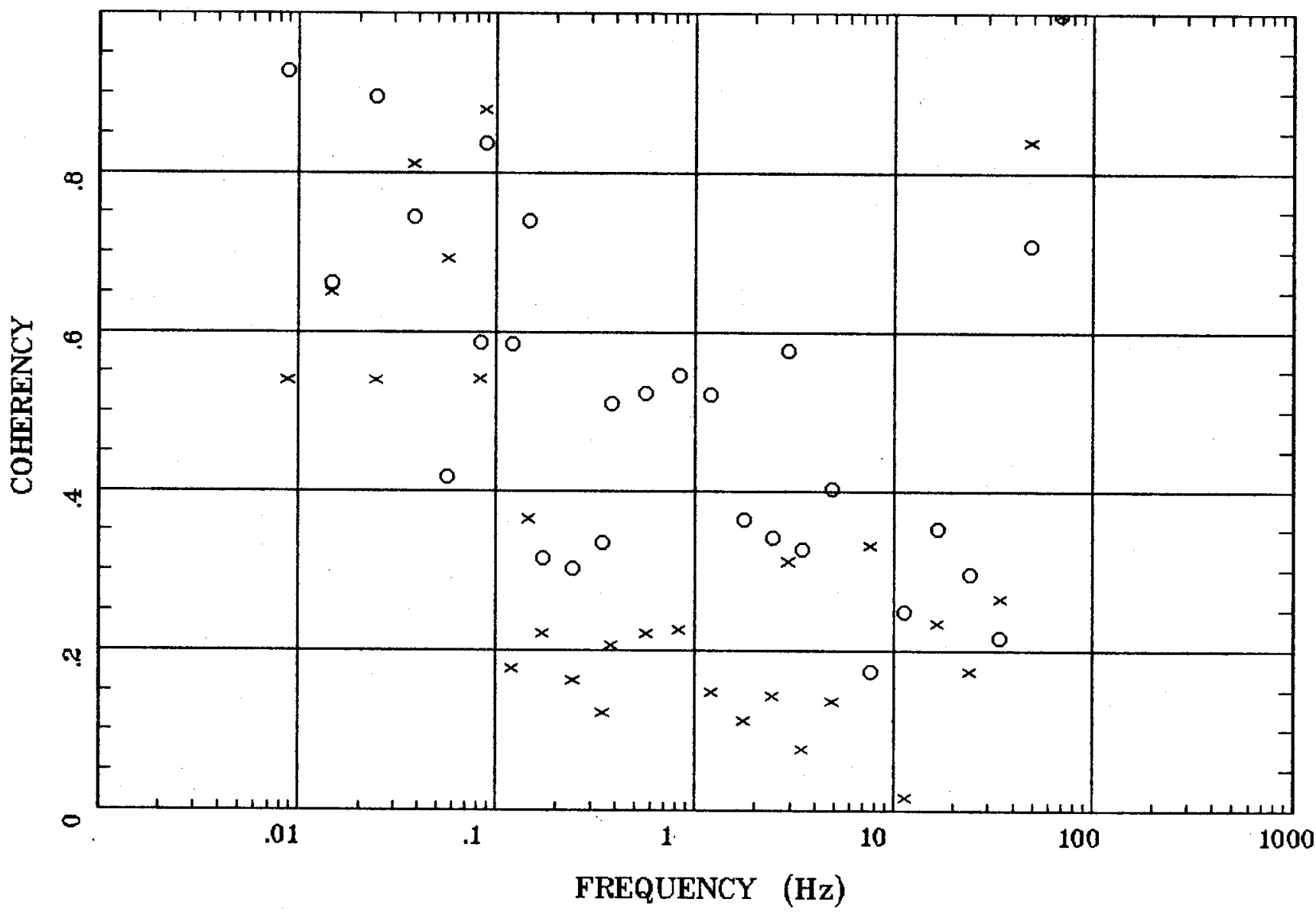

Client:

Remote: none

Acquired: 10:1 Jul 29, 2000

Survey Co:USGS
Rotation:

Filename: hr95b.avg

Channels: Ch1 Ch2 Ch3 Ch4 Ch5 Ch3 Ch4

Plotted: 11:09 Feb 06, 2001

$<$ EMI - ElectroMagnetic Instruments 


\section{APPARENT RESISTIVITY}

Tuscarora, NV 100K

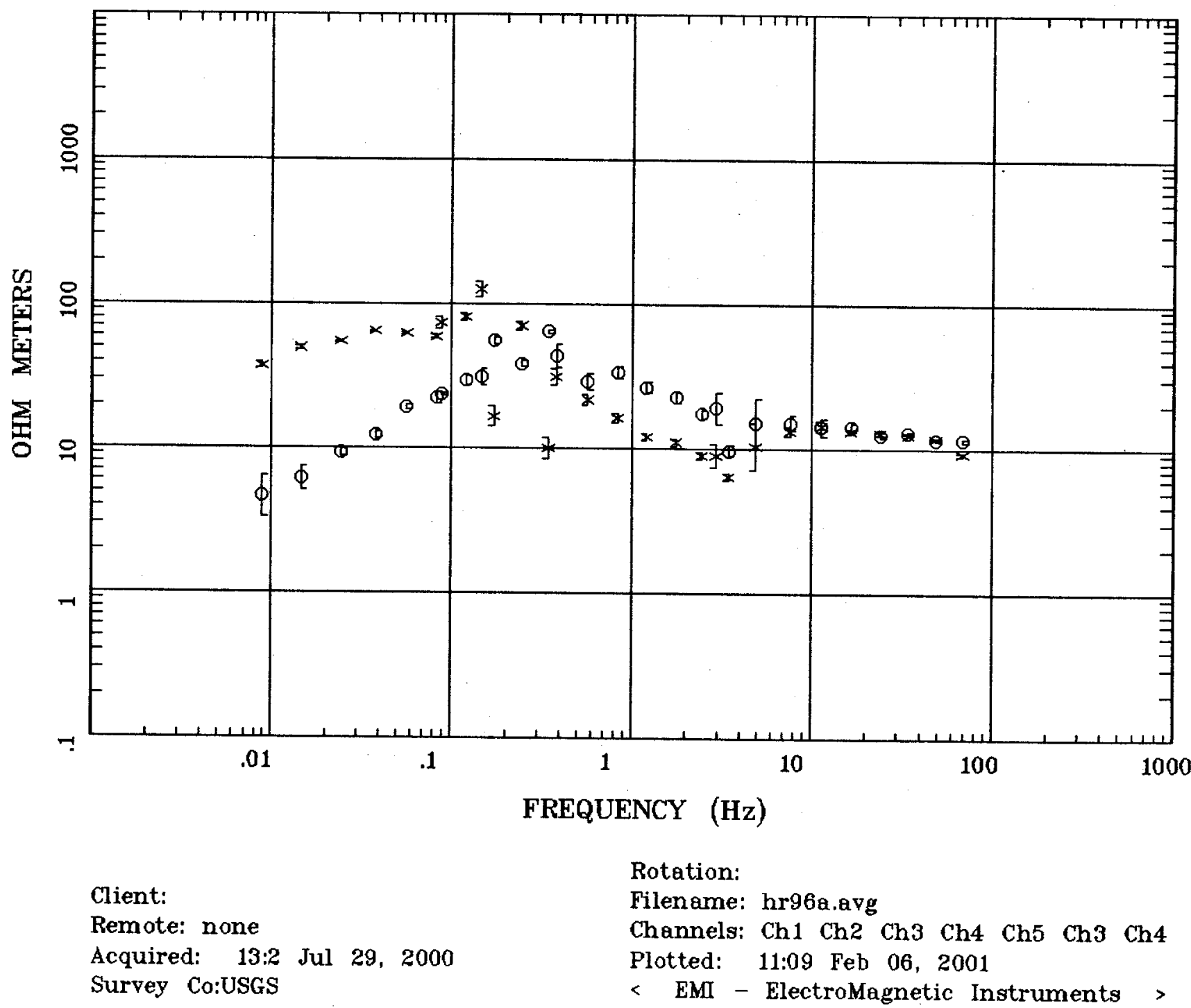




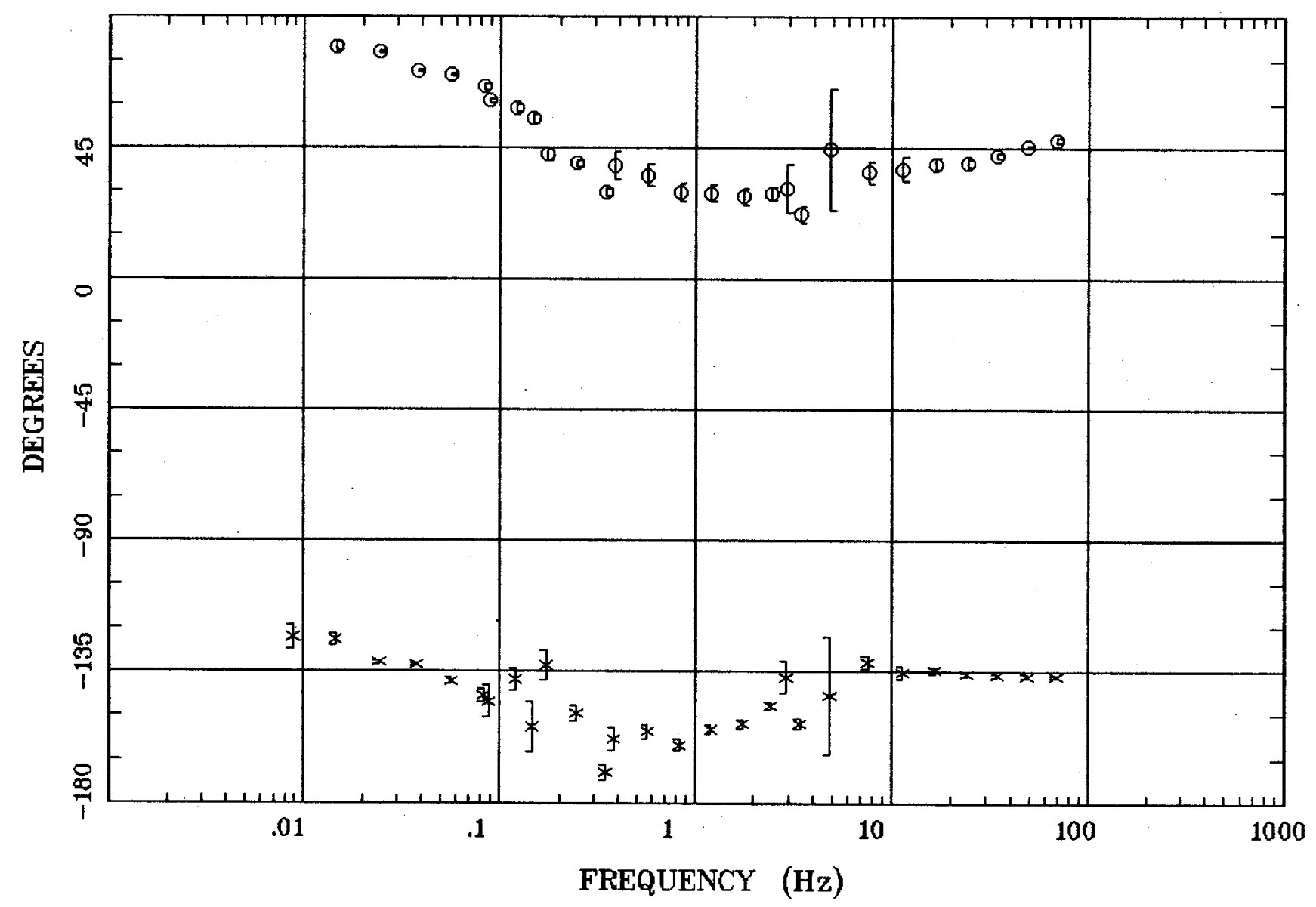

Client:

Remote: none

Acquired: 13:2 Jul 29, 2000 Survey Co:USGS
Rotation:

Filename: hr96a.avg

Channels: Ch1 Ch2 Ch3 Ch4 Ch5 Ch3 Ch4

Plotted: 11:09 Feb 06, 2001

$<$ EMI - ElectroMagnetic Instruments > 
ROTATION ANGLE

Tuscarora, NV 100K

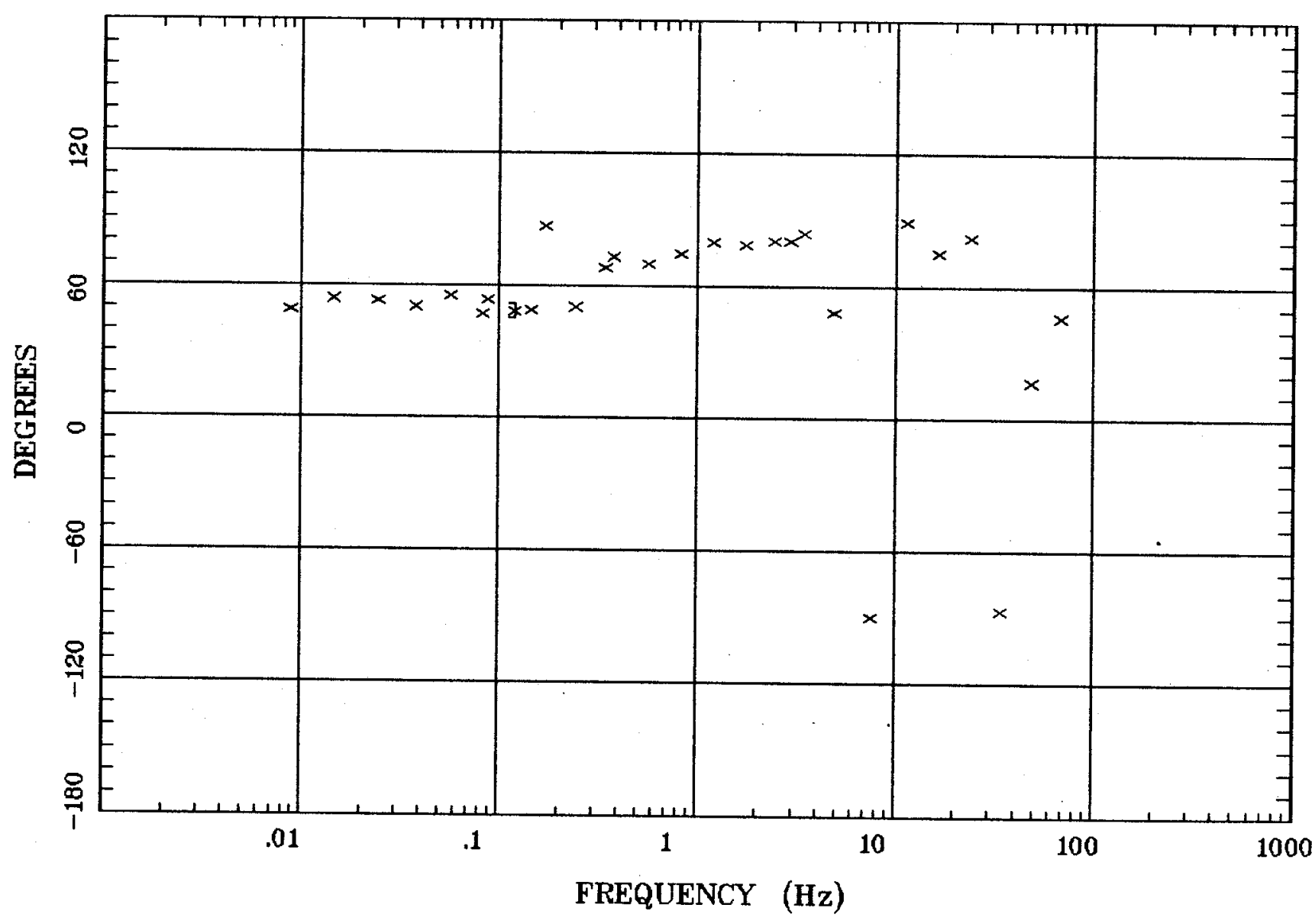

Client:

Remote: none

Acquired: 13:2 Jul 29, 2000

Survey Co:USGS
Rotation:

Filename: hr96a.avg

Channels: Ch1 Ch2 Ch3 Ch4 Ch5 Ch3 Ch4

Plotted: 11:09 Feb 06, 2001

< EMI - ElectroMagnetic Instruments 
IMPEDANCE SKEW

Tuscarora, NV 100K

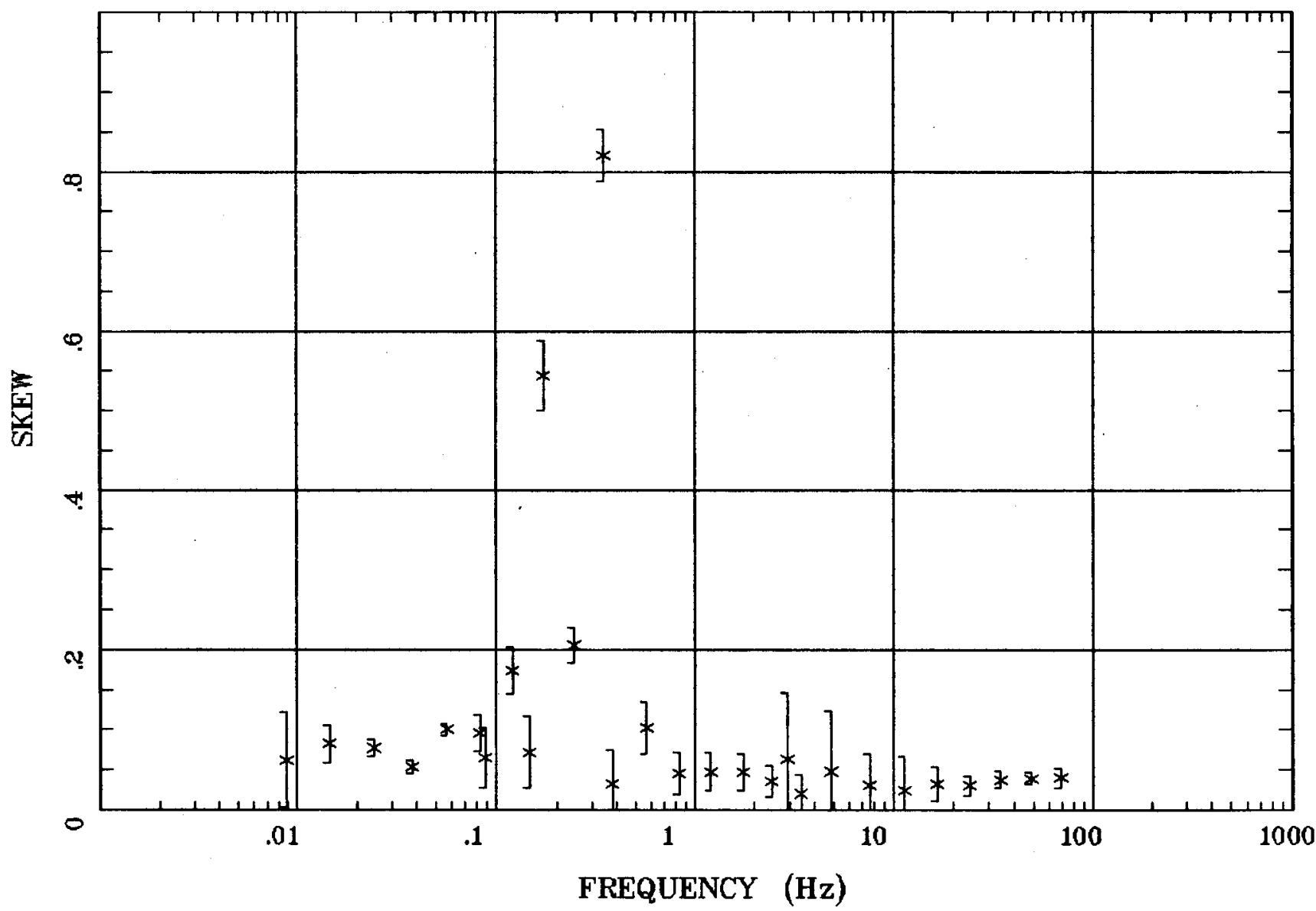

Client:

Remote: none

Acquired: 13:2 Jul 29, 2000

Survey Co:USGS
Rotation:

Filename: hr96a.avg

Channels: Ch1 Ch2 Ch3 Ch4 Ch5 Ch3 Ch4 Plotted: 11:09 Feb 06, 2001

$<$ EMI - ElectroMagnetic Instruments > 
E MULT Coh.

Tuscarora, NV 100K

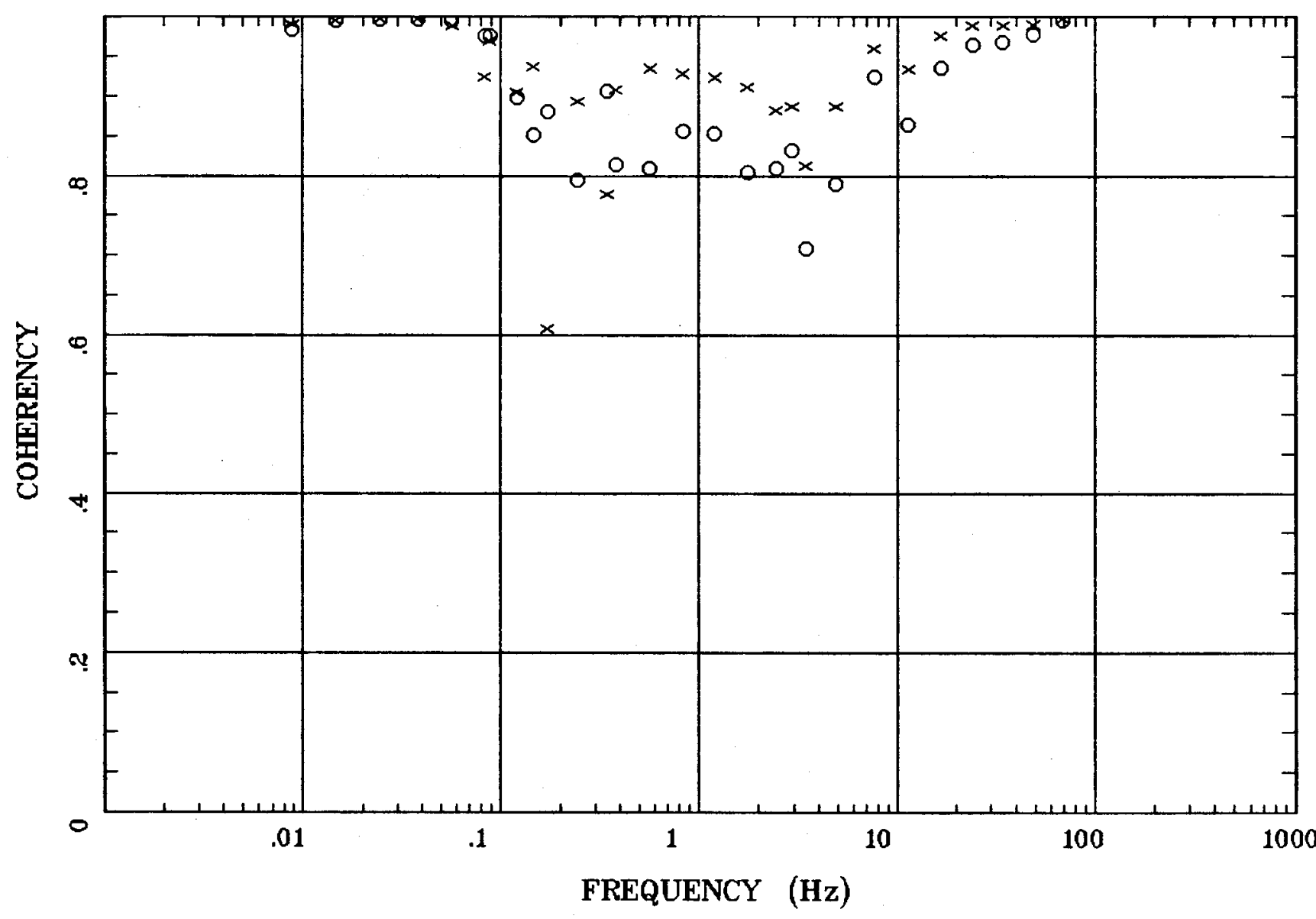

Client:

Remote: none

Acquired: 13:2 Jul 29, 2000

Survey Co:USGS
Rotation:

Filename: hr96a.avg

Channels: Ch1 Ch2 Ch3 Ch4 Ch5 Ch3 Ch4

Plotted: 11:09 Feb 06, 2001

$<$ EMI - ElectroMagnetic Instruments 


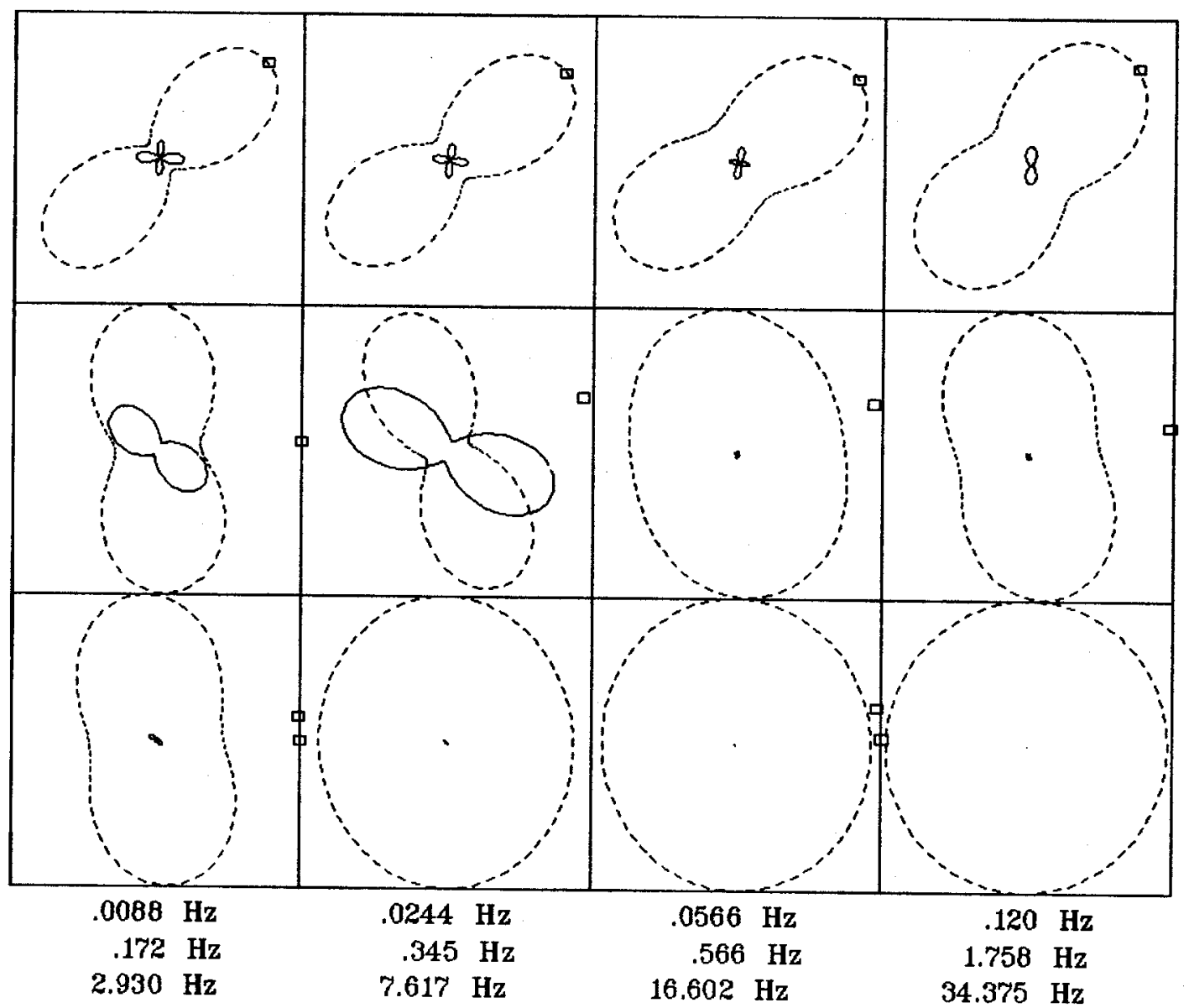

Client:

Remote: none

Acquired: 13:2 Jul 29, 2000

Survey Co:USGS
Rotation:

Filename: hr96a.avg

Channels: Ch1 Ch2 Ch3 Ch4 Ch5 Ch3 Ch4 Plotted: 11:09 Feb 06, 2001

<EMI - ElectroMagnetic Instruments > 
Tuscarora, NV 100K

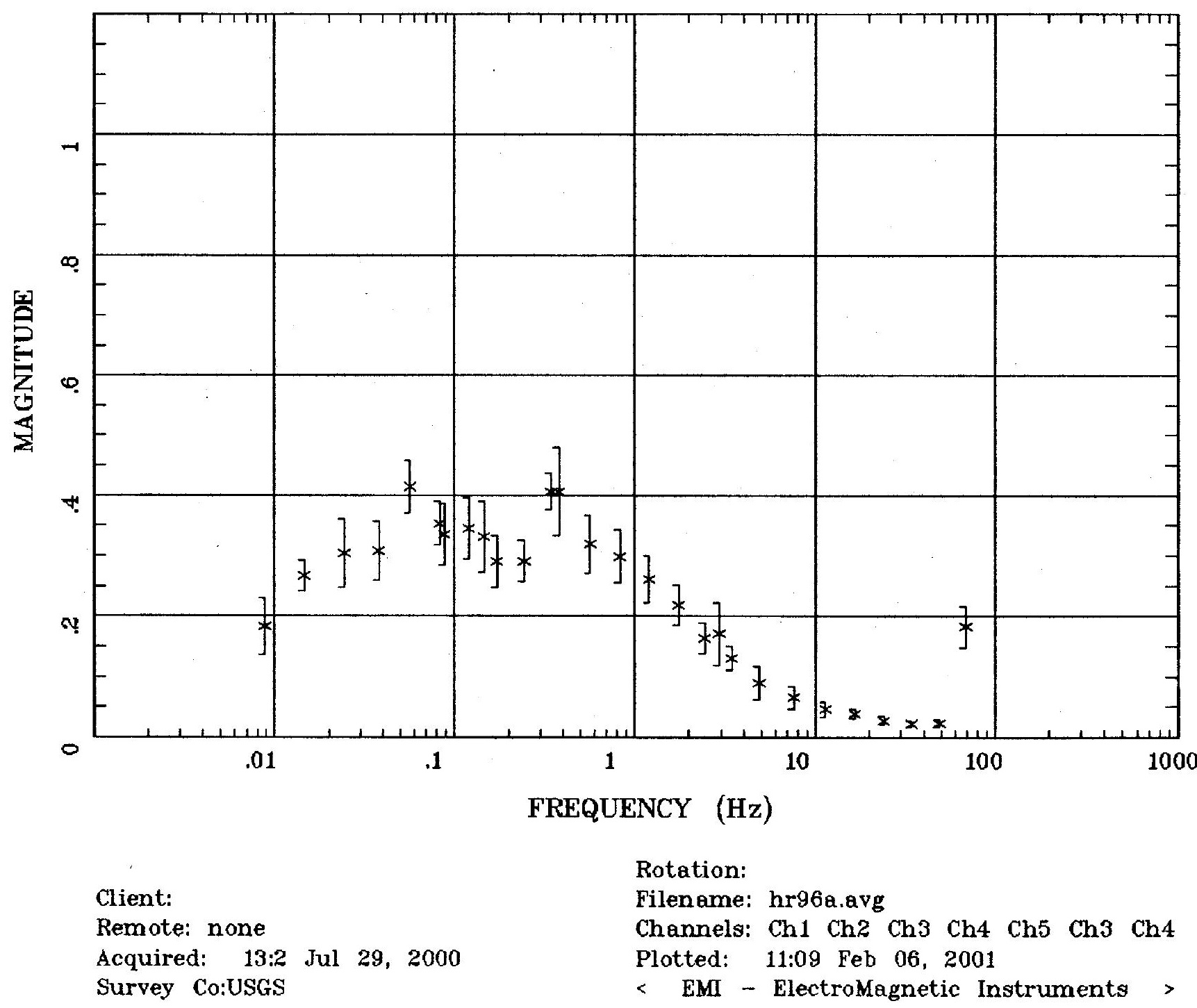




\section{Station 96}

Tuscarora, NV 100K

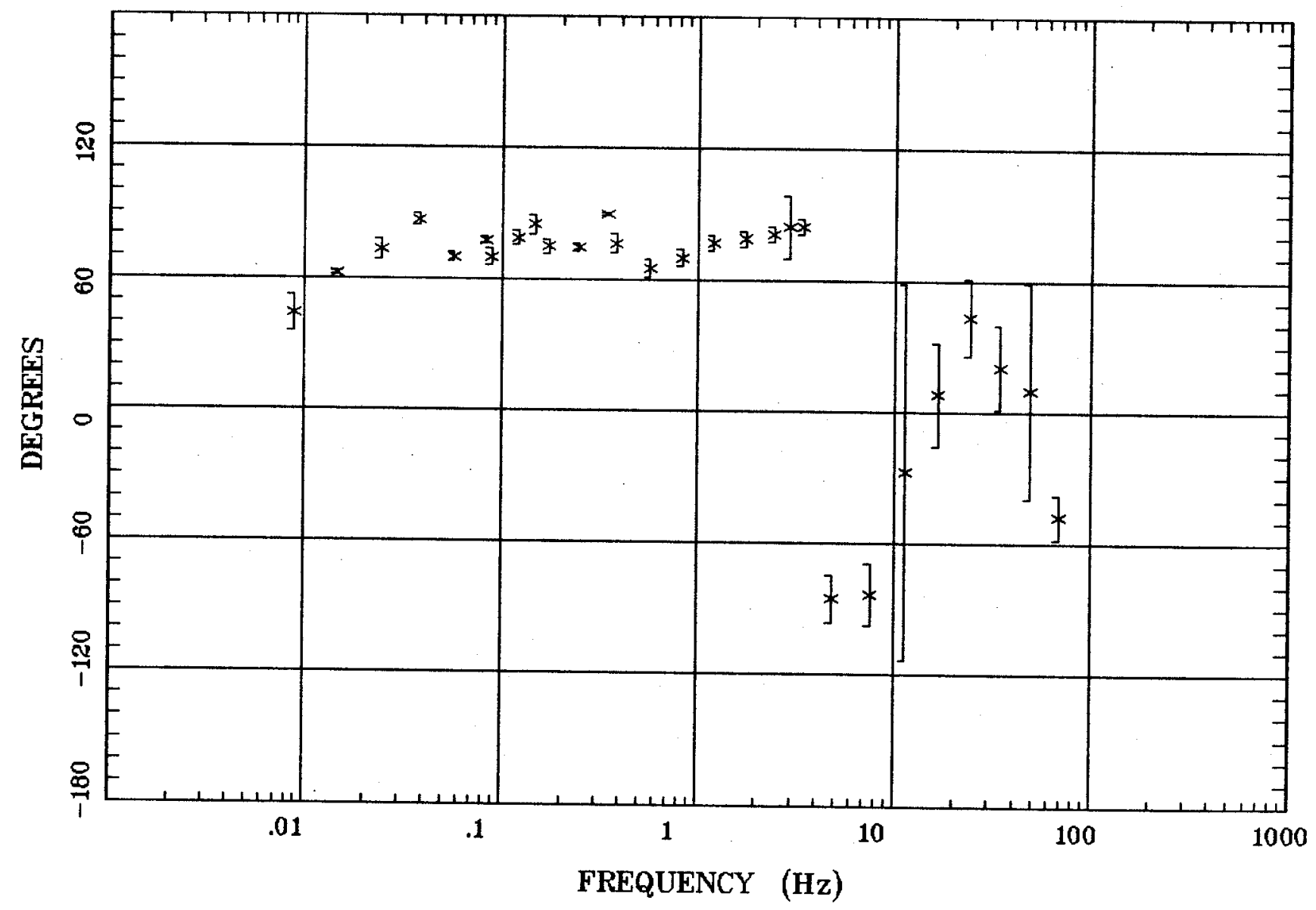

Client:

Remote: none

Acquired: 13:2 Jul 29, 2000

Survey Co:USGS
Rotation:

Filename: hr96a.avg

Channels: Ch1 Ch2 Ch3 Ch4 Ch5 Ch3 Ch4

Plotted: 11:09 Feb 06, 2001

< EMI - ElectroMagnetic Instruments > 


\section{Station 96}

HzHx.x Coh HzHy.o

Tuscarora, NV 100K

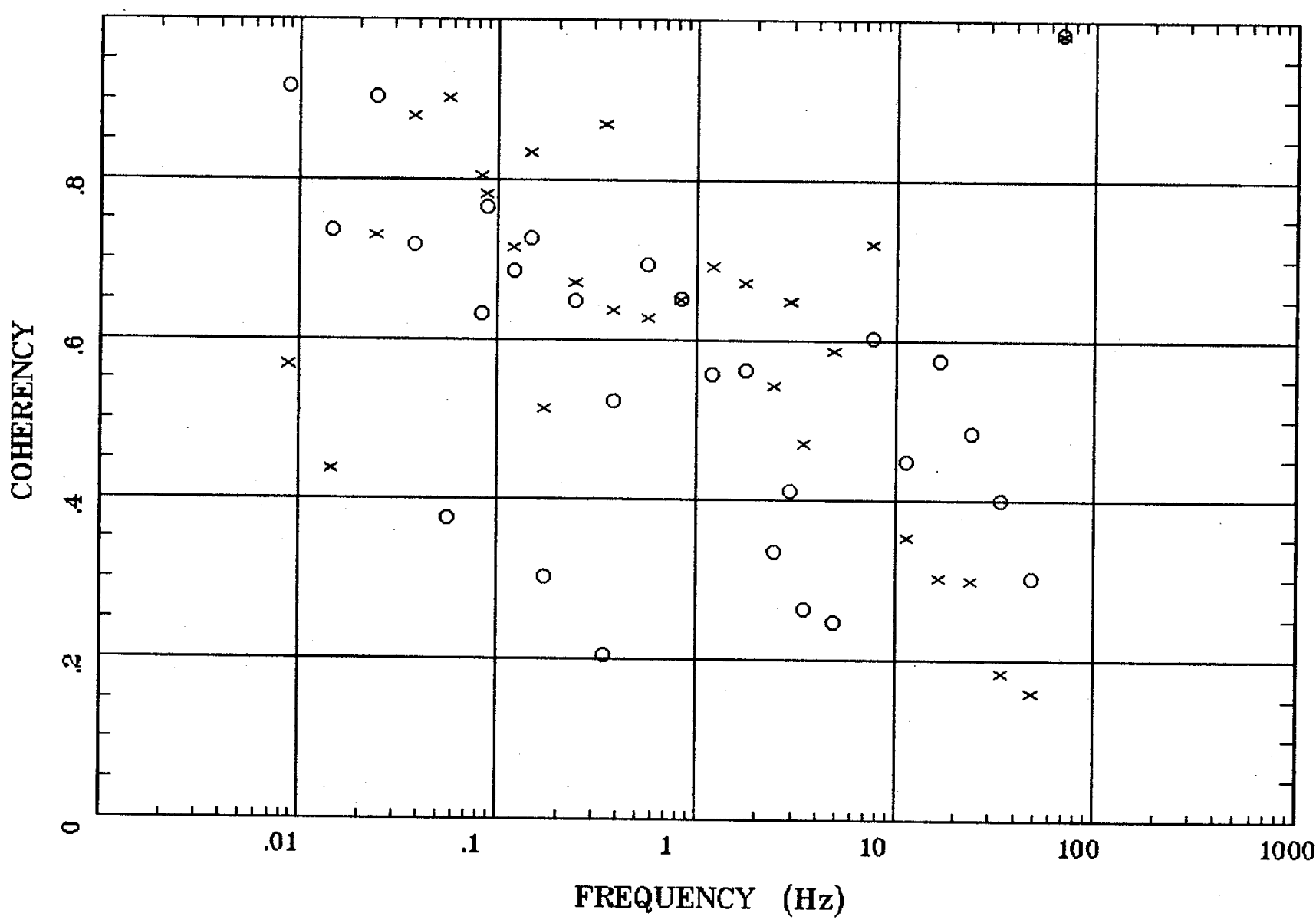

Client:

Remote: none

Acquired: 13:2 Jul 29, 2000

Survey Co:USGS
Rotation:

Filename: hr96a.avg

Channels: Ch1 Ch2 Ch3 Ch4 Ch5 Ch3 Ch4

Plotted: 11:09 Feb 06, 2001

$<$ EMI - ElectroMagnetic Instruments 


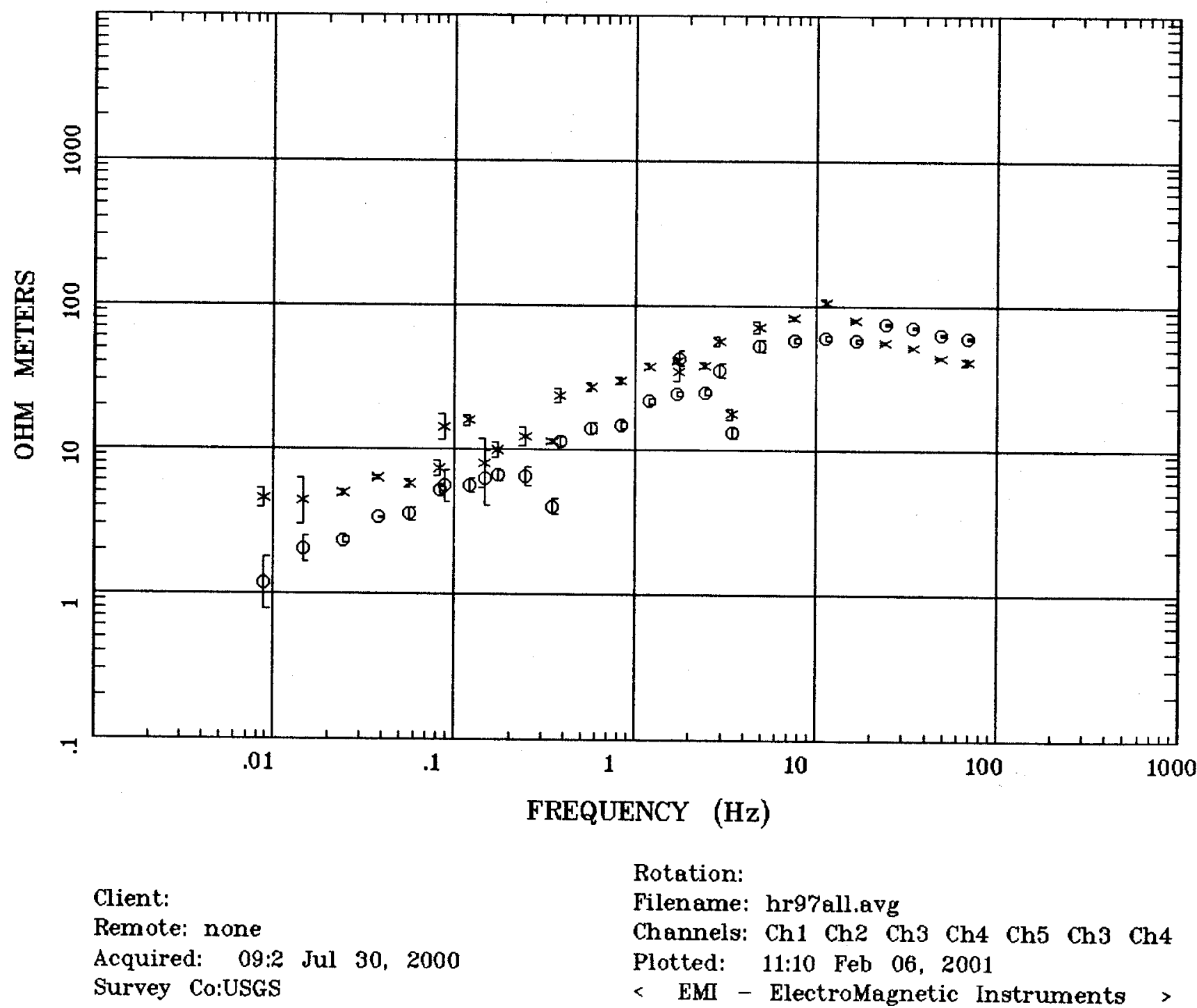




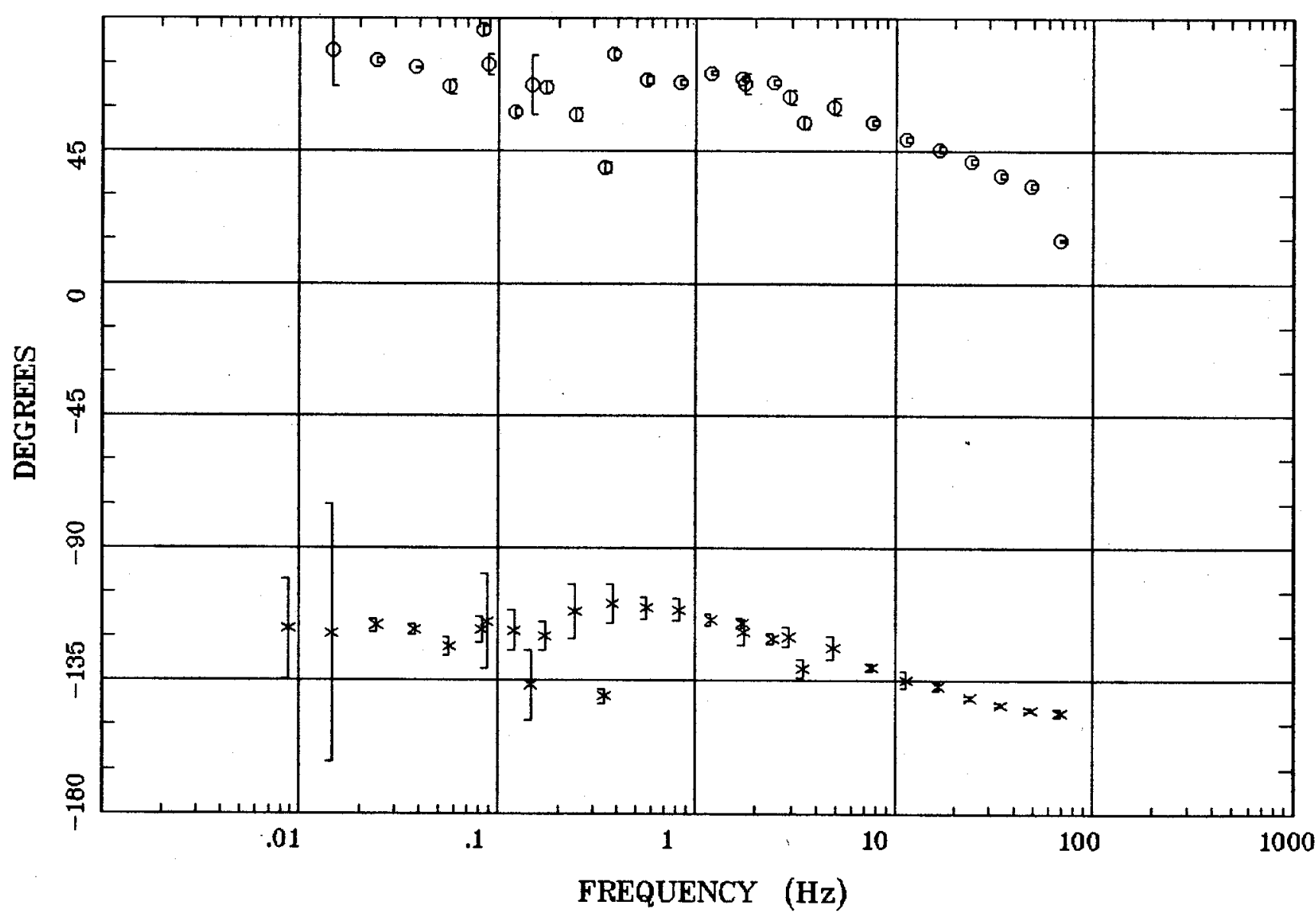

Client:

Remote: none

Acquired: 09:2 Jul 30, 2000

Survey Co:USGS
Rotation:

Filename: hr97all.avg

Channels: Ch1 Ch2 Ch3 Ch4 Ch5 Ch3 Ch4

Plotted: 11:10 Feb 06, 2001

$<$ EMI - ElectroMagnetic Instruments > 


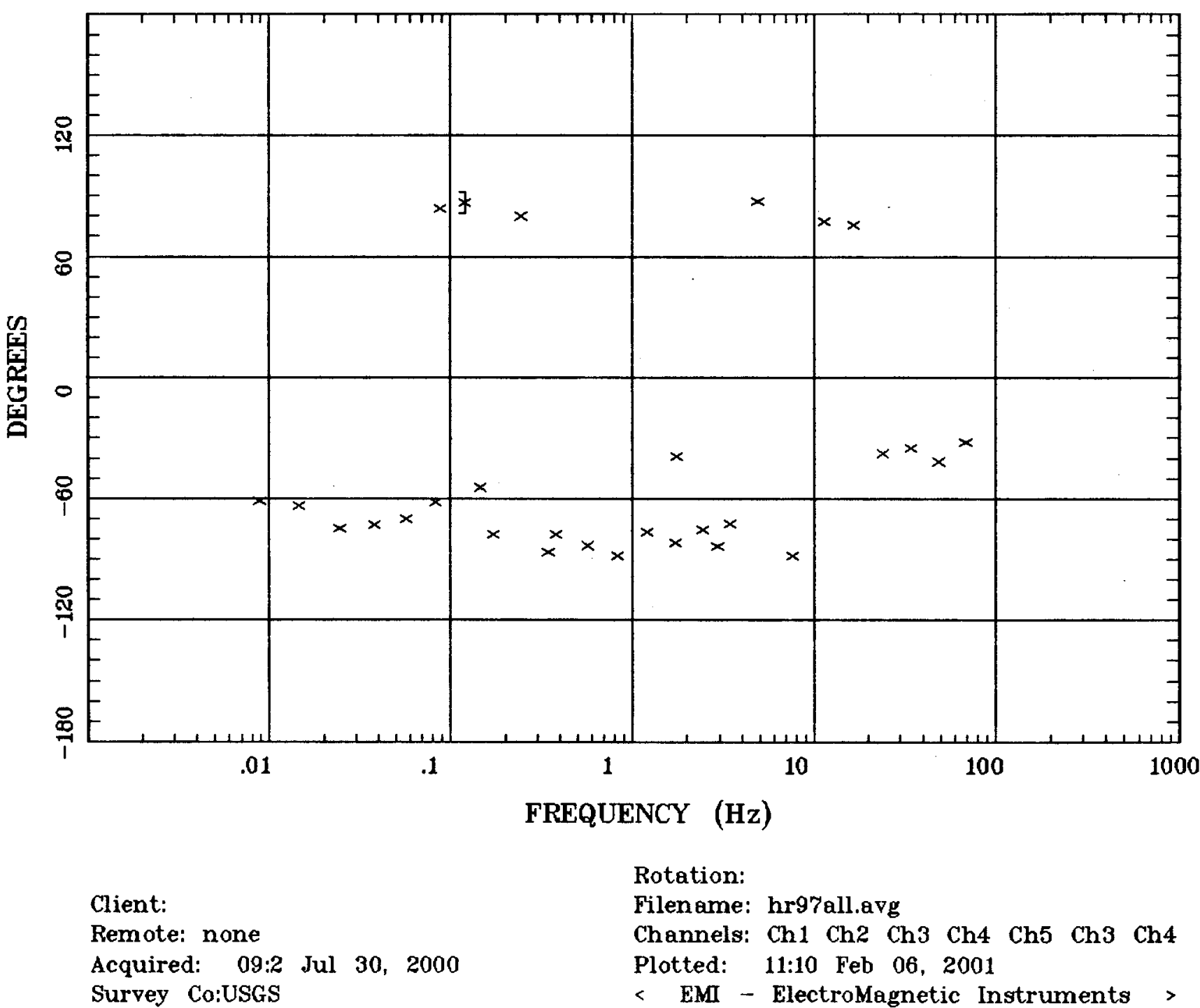




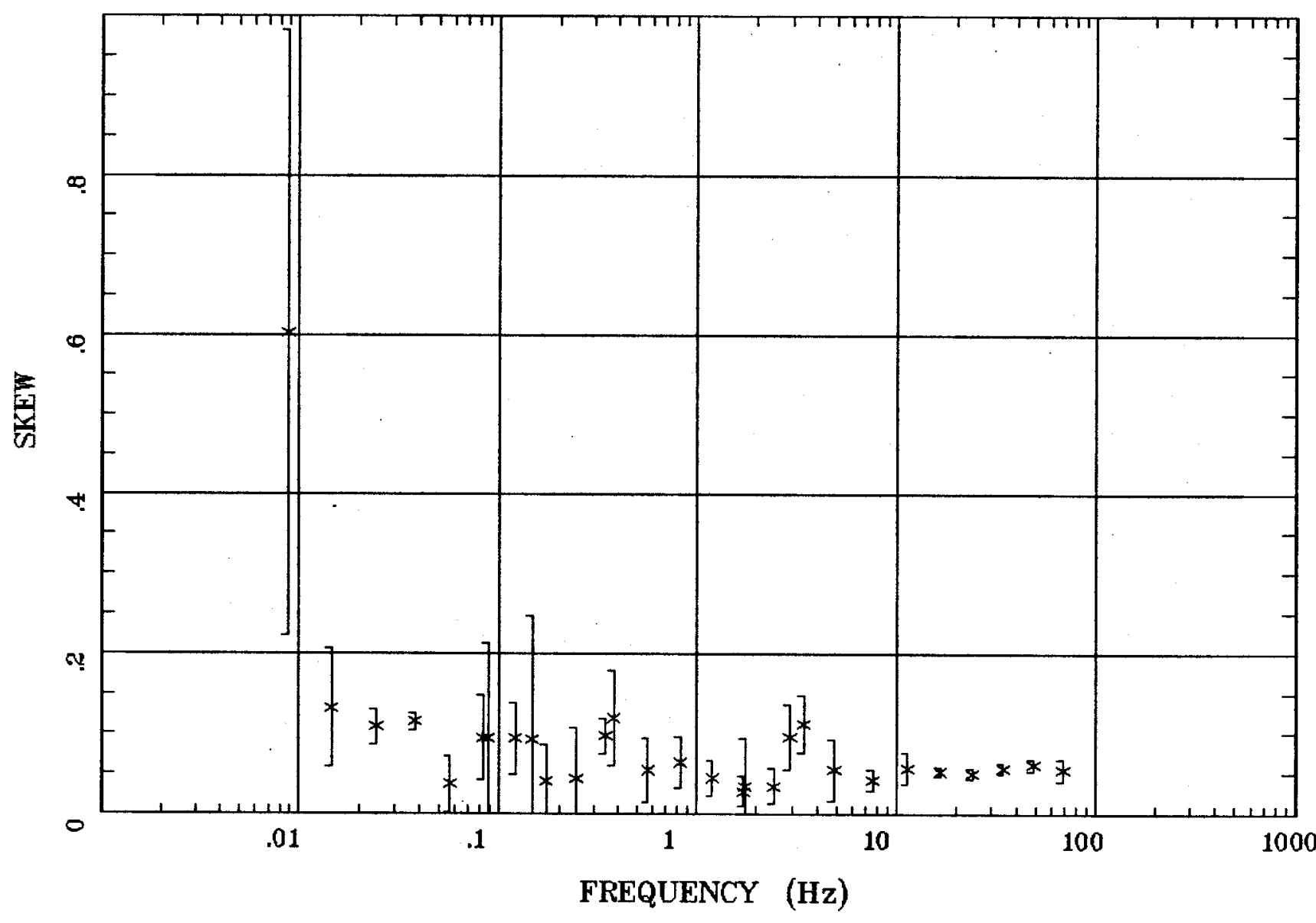

Client:

Remote: none

Acquired: 09:2 Jul 30, 2000

Survey Co:USGS
Rotation:

Filename: hr97all.avg

Channels: Ch1 Ch2 Ch3 Ch4 Ch5 Ch3 Ch4

Plotted: 11:10 Feb 06, 2001

< EMI - ElectroMagnetic Instruments > 


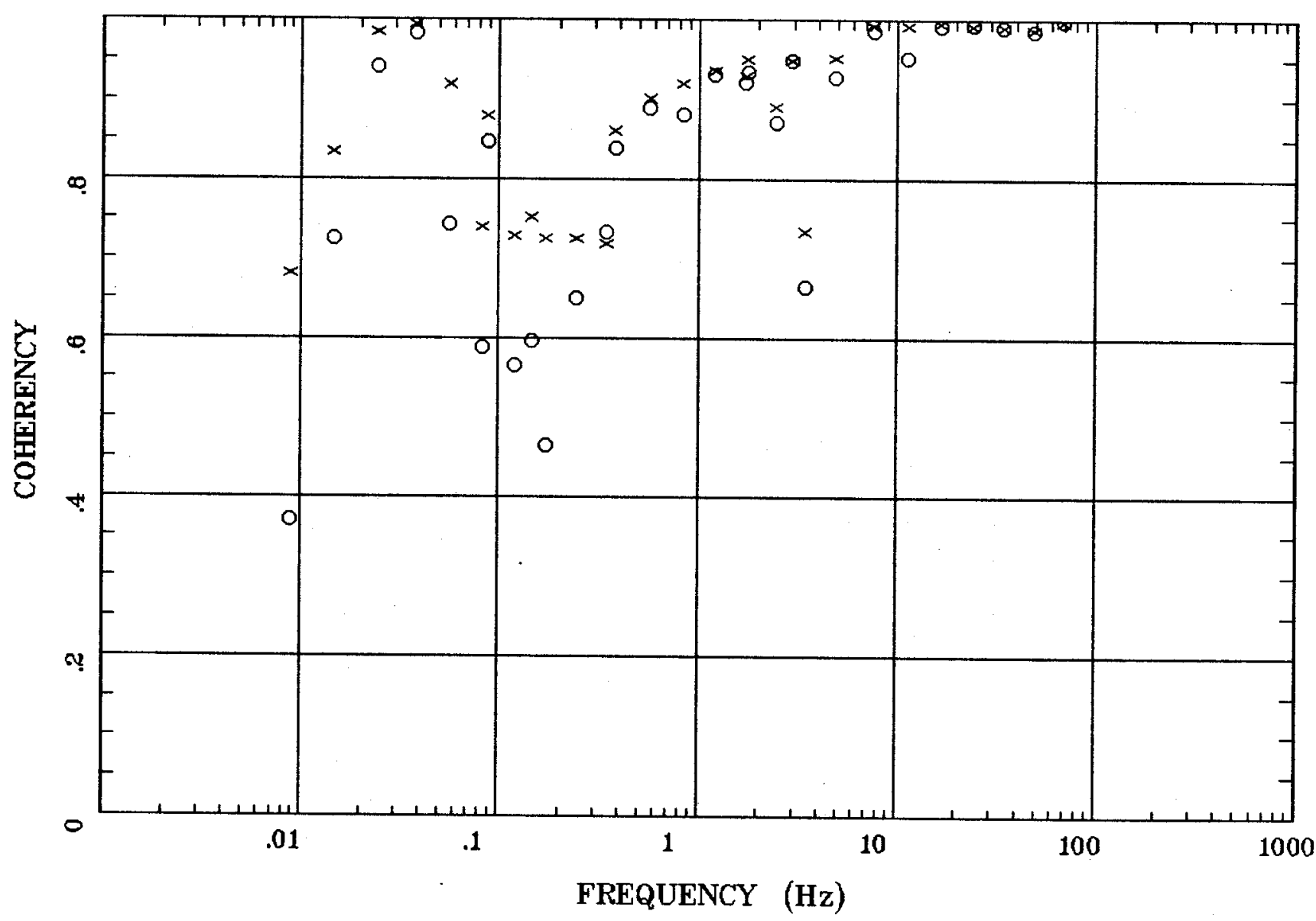

Client:

Remote: none

Acquired: 09:2 Jul 30, 2000

Survey Co:USGS
Rotation:

Filename: hr97all.avg

Channels: Ch1 Ch2 Ch3 Ch4 Ch5 Ch3 Ch4

Plotted: 11:10 Feb 06, 2001

$<$ EMI - ElectroMagnetic Instruments 


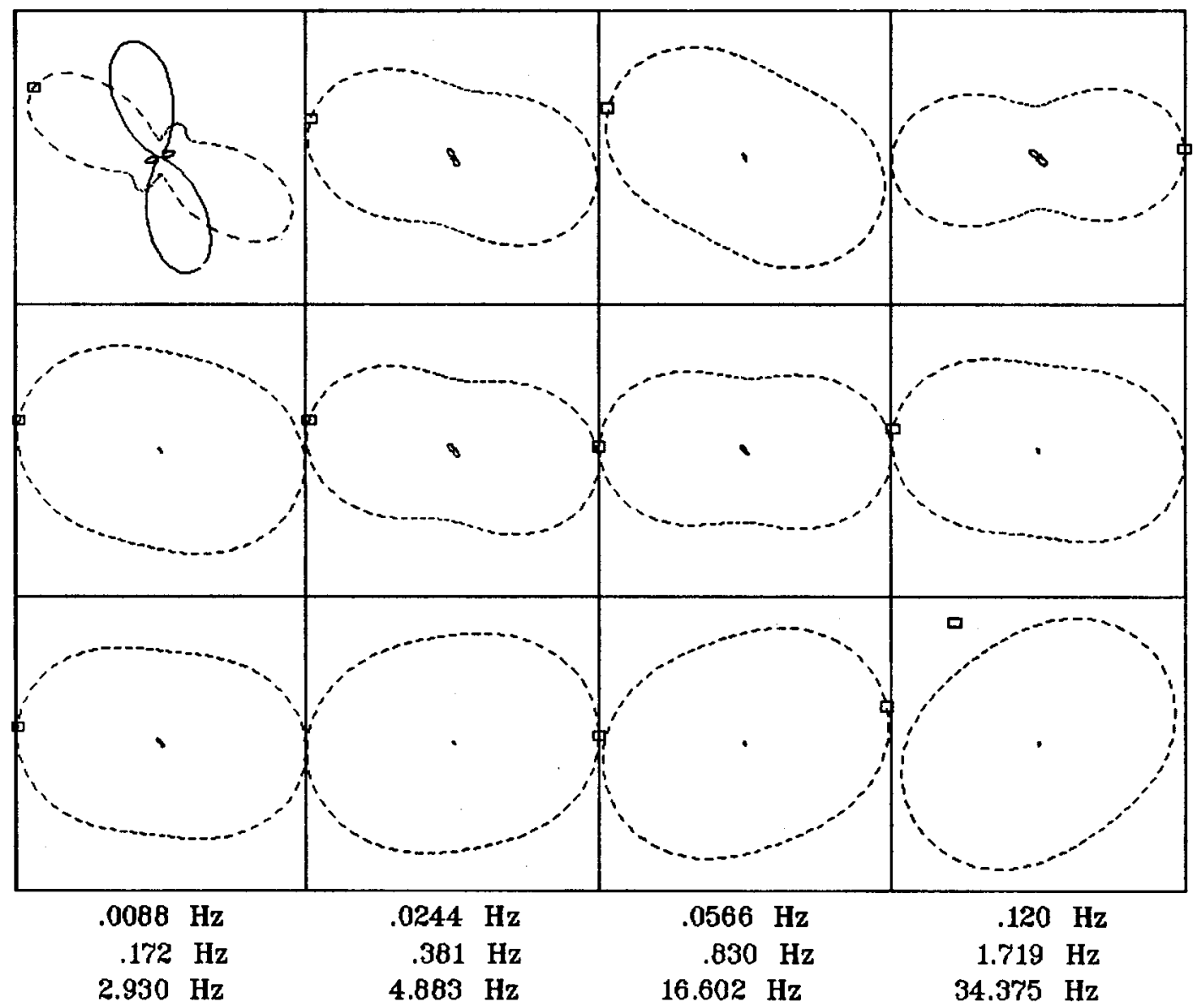

Client:

Remote: none

Acquired: 09:2 Jul 30, 2000

Survey Co:USGS
Rotation:

Filename: hr97all.avg

Channels: Ch1 Ch2 Ch3 Ch4 Ch5 Ch3 Ch4

Plotted: 11:10 Feb 06, 2001

< EMI - ElectroMagnetic Instruments > 


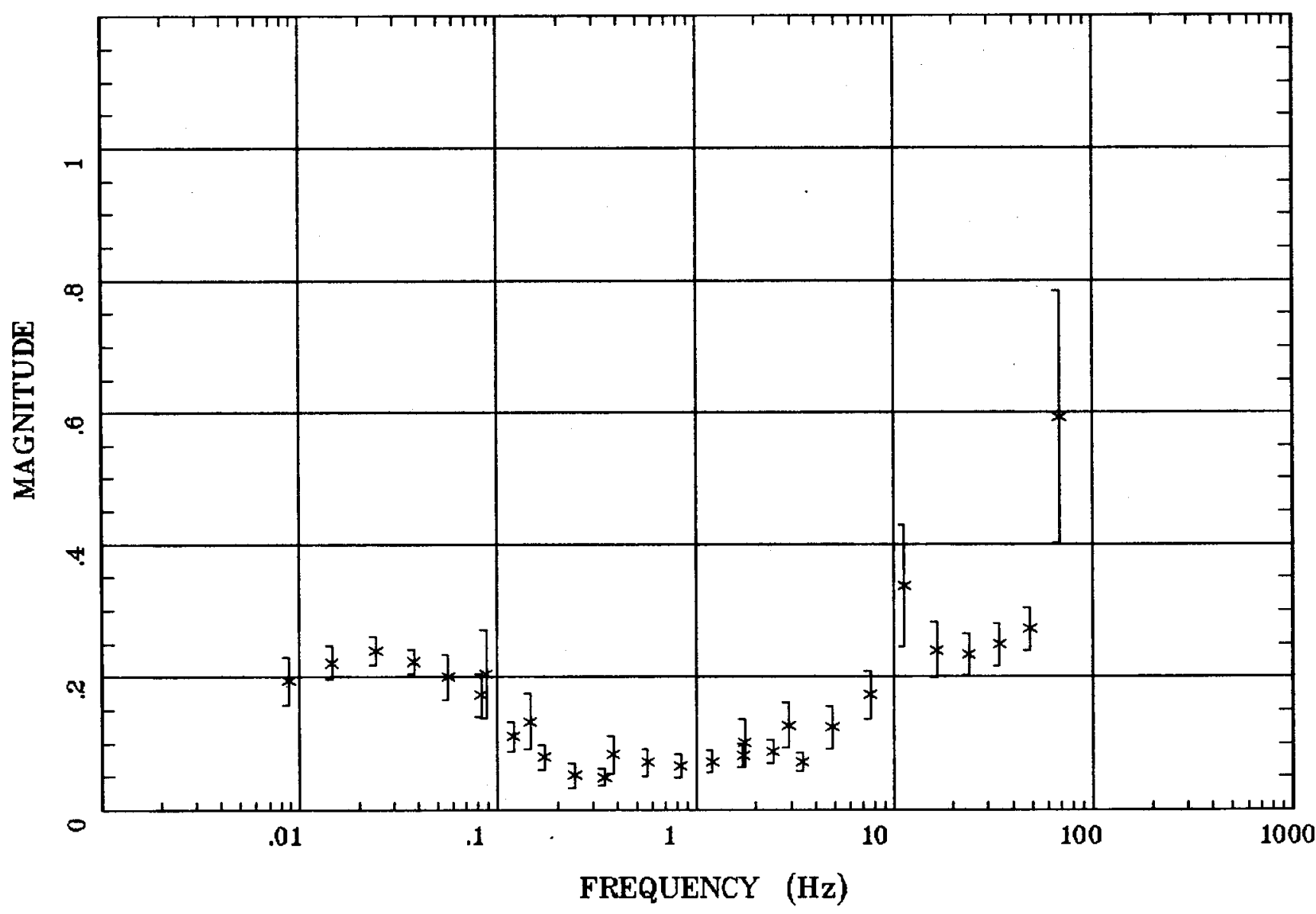

Client:

Remate: none

Acquired: 09:2 Jul 30, 2000 Survey Co:USGS

\section{Rotation:}

Filename: hr97all.avg

Channels: Ch1 Ch2 Ch3 Ch4 Ch5 Ch3 Ch4 Plotted: 11:10 Feb 06, 2001

< EMI - ElectroMagnetic Instruments > 


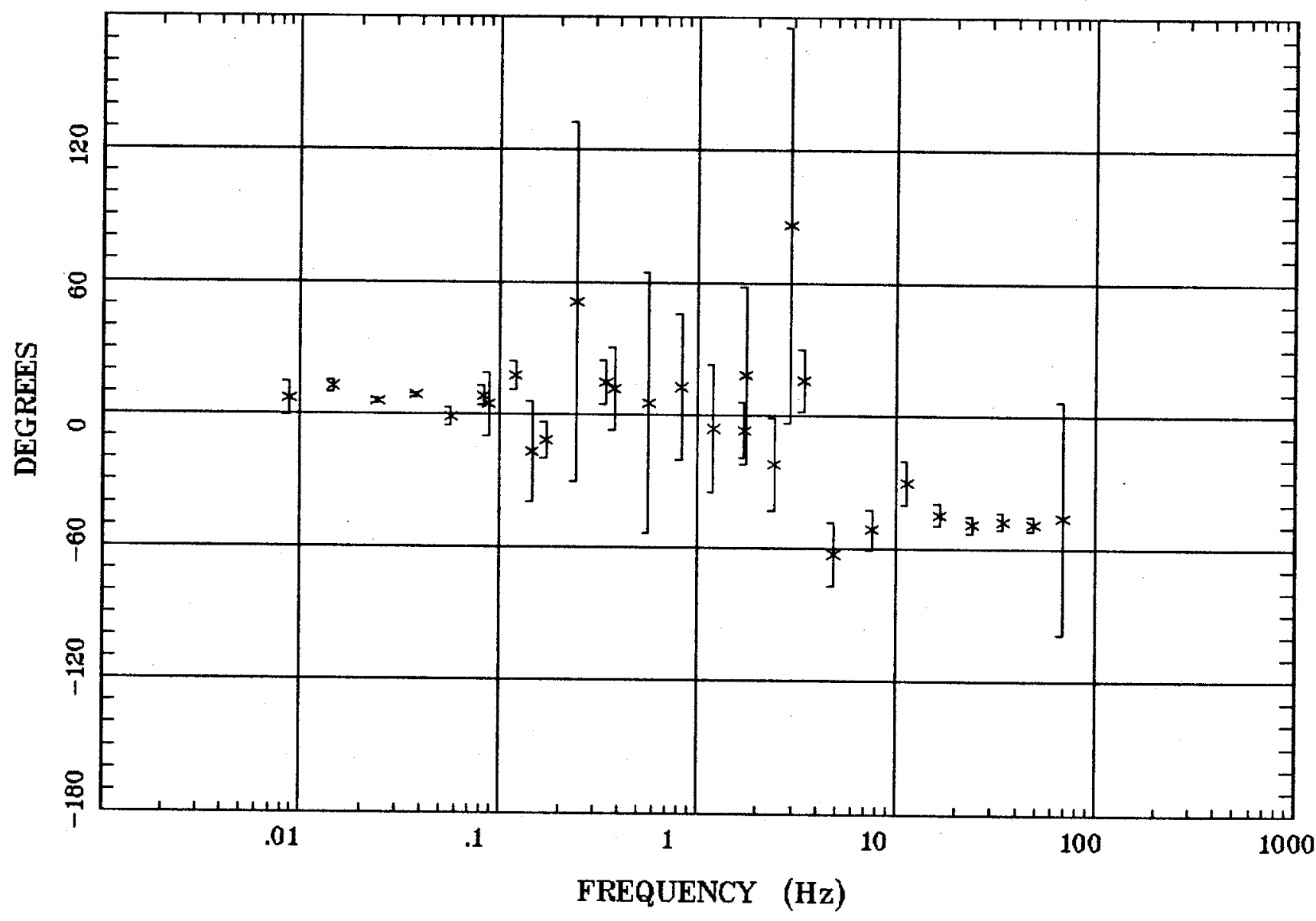

Client:

Remote: none

Acquired: 09:2 Jul 30, 2000 Survey Co:USGS
Rotation:

Filename: hrgryall.avg

Channels: Ch1 Ch2 Ch3 Ch4 Ch5 Ch3 Ch4

Plotted: 11:10 Feb 06, 2001

$<$ EMI - ElectroMagnetic Instruments 
HzHx.x Coh HzHy.o

Station 97

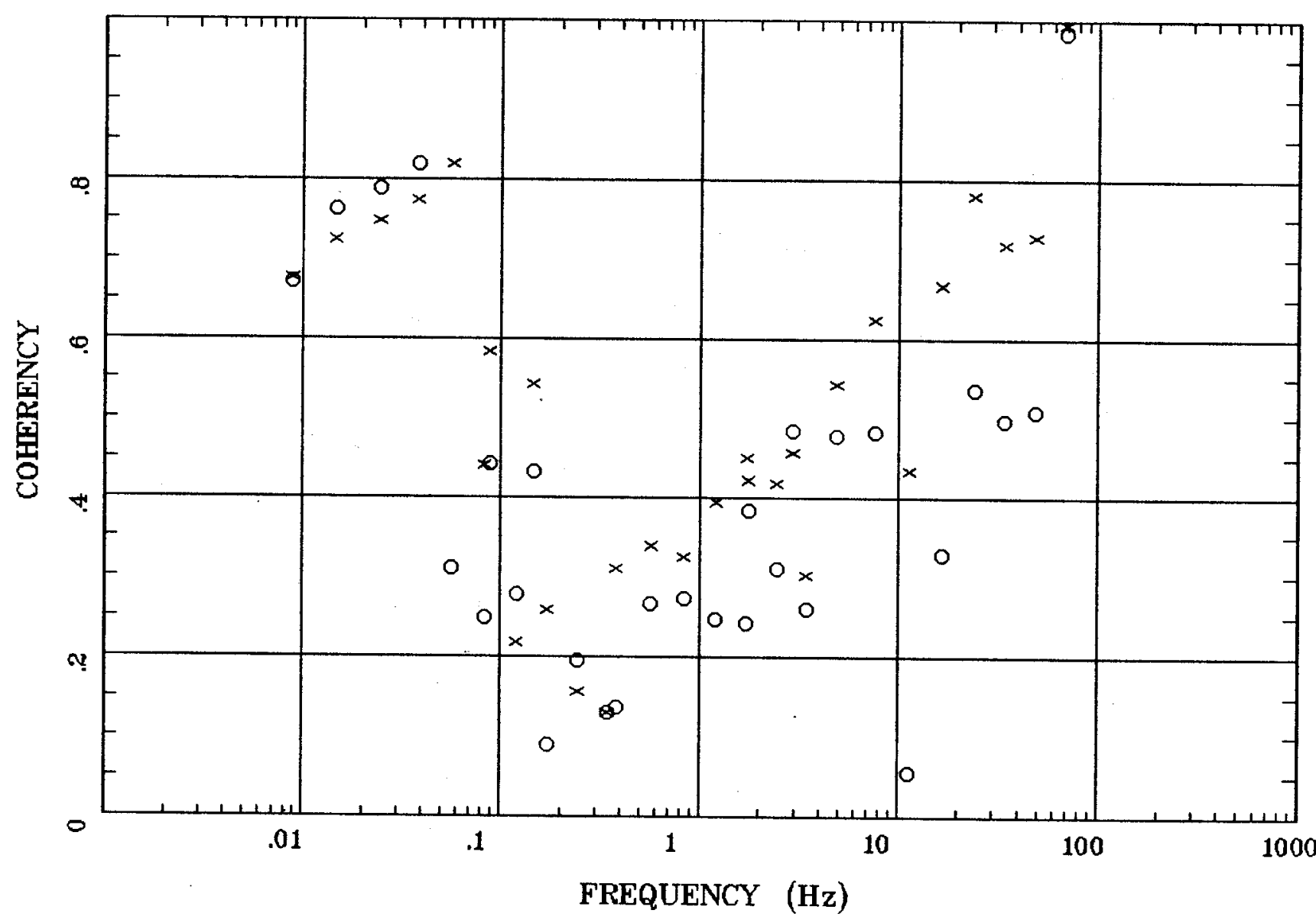

Client:

Remote: none

Acquired: 09:2 Jul 30, 2000

Survey Co:USGS
Rotation:

Filename: hr97all.avg

Channels: Ch1 Ch2 Ch3 Ch4 Ch5 Ch3 Ch4

Plotted: 11:10 Feb 06, 2001

< EMI - ElectroMagnetic Instruments 